(1)

(1)

5

Pau Clavero, ${ }^{a}$ Arnald Grabulosa ${ }^{* a}$ Mercè Rocamora, ${ }^{a}$ Guillermo Muller ${ }^{a}$ and Mercè Font-Bardia ${ }^{b}$

aDepartament de Química Inorgànica i Orgànica, Secció de Química Inorgànica, Universitat de Barcelona, Martí i Franquès, 1-11, E-08028 Barcelona, Spain.

E-mail: arnald.grabulosa@qi.ub.es

bDepartament de Cristal·lografia, Mineralogia i Dipòsits Minerals, Universitat de Barcelona, Martí i Franquès, s/n, E-08028 Barcelona, Spain 
40 ABSTRACT:

42 The synthesis via phosphine-boranes of 13 new optically pure P-stereogenic diarylphosphines

$43 \mathrm{P}(\mathrm{Het}) \mathrm{PhR}(\mathrm{Het}=$ 4-dibenzofuranyl (DBF), 4-dibenzothiophenyl (DBT), 4-dibenzothiophenyl-S,S-

44 dioxide (DBTO2) and 1-thianthrenyl (TA); R = OMe, Me, i-Pr, Fc (ferrocenyl)) following the Jugé-

45 Stephan method is described. The ligands were designed with the aim of having a heteroatom in a

46 position capable of interacting with a metal upon coordination. The ligands and their precursors have

47 been fully characterised, including the determination of two crystal structures of phosphine-boranes. Ru

48 neutral complexes of the type $[\mathrm{RuCl} 2(\eta 6$-arene) $(\kappa \mathrm{P}-\mathrm{P})]($ arene $=\mathrm{p}$-cymene and methyl benzoate) have

49 been prepared and characterised, including three crystal structure determinations. Treatment of solutions

50 of the complexes with TIPF6 allowed the preparation of well-defined cationic complexes [RuCl( $\eta 6-$

51 arene)(ผ2P,S-P)]PF6 for DBTand TA-based phosphines. The complexes possess a stereogenic Ru atom

52 and in most of the cases they are present as a single isomer in solution. All the Ru complexes have been

53 used in the asymmetric transfer hydrogenation of acetophenone in refluxing 2-propanol, with good

54 activities and up to $70 \%$ ee.

55

56

57 
60 The preparation of optically pure P-stereogenic compounds is still a considerable challenge despite their 61 long history, stretching for more than a century,1,2 and their importance as ligands for transition metal62 based homogeneous catalysis.3-5 The lack of generality of most of the known synthetic methods and 63 the long and tedious steps required to prepare such compounds can be blamed for the sluggish

64 development of this area. This makes that even today the preparation of new ligands of this kind can be considered a valuable achievement. During the last twenty years, however, several very promising advances have been made, 4 which have allowed the synthesis of new families of ligands with superior performance in Rhcatalysed hydrogenation and other reactions, and the pace of these advances has been increasing lately.6-17 At present, most of the ligands of this kind are prepared using phosphineboranes 18-20 as intermediates and by asymmetric synthesis methods relying on chiral auxiliaries. Two of the most important routes are that developed by Jugé, Stephan and coworkers21,22 furnishing diarylphosphines and that firstly devised by Evans and coworkers 23 and much expanded by Imamoto and coworkers24,25 to give trialkylphosphines. Both methods are based on phosphine-boranes and employ organolithium reagents as nucleophiles or bases in at least one step. Joining these efforts, we have described several kinds of P-stereogenic monophosphines, initially prepared by resolution of the racemic ligands 26-28 and more recently by the Jugé-Stephan29-35 or Evans32,36,37 method. They were initially employed in Pd-catalysed hydrovinylation29,32,34 and later in allylic substitution reactions31,34 and Ru-catalysed cyclopropanation33 and transfer hydrogenation33-35,37 reactions.

We reasoned that it would be interesting to design families of new P-stereogenic monophosphines containing heteroatoms adequately located in the ligand in order to interact with the metal with a coordination bond or by a weaker secondary (hemilabile) interaction and study their performance in catalysis. With these ideas in mind, a recent paper by Hayes and coworkers 38 describing the synthesis of P-stereogenic monophosphinimine ligands for Zn-catalysed ring-opening polymerisation of lactide caught our attention. In this paper the synthesis of $\mathrm{P}$ (4-dibenzofuranyl) $\mathrm{MePh}$ was described, albeit in the racemic form. This phosphine was prepared using 4-lithiodibenzofuran,39 easily prepared by direct o-lithiation of dibenzofuran (Scheme 1).

This ligand has the heteroatom at the $\gamma$ position with respect to the $\mathrm{P}$ atom, a feature that would create a favoured 5-membered ring upon interaction with a transition metal. Therefore, we started a study aiming to prepare P-stereogenic phosphines bearing a heterocyclic substituent with the following requirements: (i) the ligands should have the heteroatom of the heterocycle at the $\gamma$ or $\delta$ position relative to the phosphorus atom, (ii) the heterocycle should be selectively lithiated at the $\beta$ position, so it can be installed at the $\mathrm{P}$ atom by the Jugé-Stephan method and (iii) the heterocycle should be commercially available. After analysis of the literature, we concluded that dibenzofuran (DBF), dibenzothiophene (DBT) and thianthrene (TA) met these requirements (Scheme 2). 
95 The number of monophosphorus ligands or precursors bearing any of these substituents is very limited.

96 With DBF, Haenel and coworkers39 first reported the preparation of 4-diphenylphosphinodibenzofuran

97 in the course of their studies on lithiation of DBF and DBT. Much more recently several 4-

98 diphenylphosphinodibenzofuran oxides, substituted with different moieties at the dibenzofuran

99 fragment, have been reported because they have interesting photochemical applications.40-43 Wills and

100 coworkers44,45 prepared 4-bis(dimethylamino) phosphinodibenzofuran and condensed it at high

101 temperature with a chiral diamine to obtain an optically pure diazaphospholidine, a ligand that was used

102 in Pd-catalysed allylic substitution reactions. This is the only reported example of an optically pure

103 monophosphorus ligand based on the DBF skeleton. Finally, Hayes and coworkers38 recently reported

104 the synthesis of racemic (4-dibenzofuranyl)methylphenylphosphine as mentioned before, by

105 deprotection of its phosphine-borane, previously obtained by reaction of methyllithium with (4-

106 dibenzofuranyl)methylphenylphosphineborane. With DBT, Rauchfuss, Rheingold and coworkers46

107 reported the synthesis of 4-diphenylphosphino- and 4-di(p-tolyl)phosphinodibenzothiophene and some

108 derived Ru complexes. The crystal structures of the former phosphine and a derived Fe complex were

109 also described a few years later.47 4-Diphenylphosphinodibenzothiophene was also reported by Haenel

110 and coworkers soon afterwards.39 The only optically pure monophosphorus ligand precursor with the

111 DBT moiety was reported by Fiaud and coworkers, 48 who attached an enantiomerically pure 2,5-

112 diphenylphospholane oxide moiety to the 4 position of DBT by Pd-catalysed C-P bond formation.

113 Finally, no phosphines with the TA substituents have been described to the best of our knowledge. In

114 addition, there are no examples of optically pure P-stereogenic phosphines bearing any of those

115 heterocyclic substituents.

116 In this paper we describe the synthesis of a series of new P-stereogenic phosphine-boranes containing a

117 DBF, DBT or TA substituent employing the Jugé-Stephan method, the preparation of several types of complexes containing $[\mathrm{Ru}(\eta 6$-arene $)]$ moieties and their application as precatalysts in the asymmetric transfer hydrogenation of acetophenone. 


\section{Ligand synthesis}

129 The desired ligands were designed to be obtainable by the Jugé-Stephan method,21,22 in which the groups are sequentially introduced at the phosphorus atom via organolithium reagents. Therefore, following slightly modified literature procedures, the selective monometallation of DBF,38 DBT49 and TA50 was successfully accomplished by ortholithiation with n-butyllithium under different conditions (Scheme 3).

134 The solutions of the organolithiums were reacted with Jugé-Stephan's oxazaphospholidine-borane 1 at low temperature giving aminophosphine-boranes 2-Het in good yields as white solids (Scheme 4). The acidic methanolysis of 2-Het proceeded smoothly, affording phosphinite-boranes 3-Het as pure pasty solids or oils after column chromatography purification. Treatment of these compounds with an excess of $\mathrm{RLi}(\mathrm{R}=\mathrm{Me}$, i-Pr, t-Bu and Fc) at low temperatures was carried out to obtain a series of phosphine-boranes as resins or oils. It is known that this step is very sensitive to the bulkiness of the incoming organolithium reagent.29,51 Therefore, it is not surprising that in the case of methyllithium the reactions were successful for all the substrates, giving the methylphosphine-boranes 4-Het-Me in good yields. Isopropyllithium reacted well with 3-DBF and 3-DBT giving the desired 4-Het-iPr phosphine-boranes but reaction with $3-\mathrm{TA}$ at $-30{ }^{\circ} \mathrm{C}$ produced a compound containing two isopropyl groups. According to $1 \mathrm{H}$ and $13 \mathrm{C}$ NMR spectroscopy, one of them was bound to the $\mathrm{P}$ atom whereas the other was not. No further aliphatic hydrogen or carbon atoms could be detected. Addition of less than one equivalent of isopropyllithium led to the same product with two isopropyl groups along with incomplete conversion of the starting phosphinite-borane 3-TA. This fact indicates that isopropyllithium is not able to directly attack the phosphorus atom, so it probably reacts first with the thianthrene ring and opens it, releasing steric encumbrance at the $\mathrm{P}$ atom and allowing a rapid attack of a second equivalent of isopropyllithium. Although NMR suggested that only a single diastereomerically pure product was formed, we have been unable to clarify either its identity or its optical purity. Interestingly, the addition of isopropyllithium to a diethyl ether solution of thianthrene at $-30^{\circ} \mathrm{C}$ did not lead to any opened product but to the full recovery of unchanged thianthrene. Reaction of 3-Het with monolithiated ferrocene worked well for Het $=\mathrm{DBF}$ and DBT but not for TA, since unchanged 3-TA was isolated after workup.

The introduction of the t-Bu group is (usually)51,52 impossible using the Jugé-Stephan method due to steric reasons.29 In line with this finding, reaction of 3-DBT and 3-TA with t-BuLi was unsuccessful since complex mixtures of products were obtained according to 31P NMR spectroscopy. In contrast, under carefully controlled conditions, 3-DBF reacted with t-BuLi to afford the phosphine 4-DBF-tBu, which could be isolated as an oil in $60 \%$ yield. It is possible that the hard oxygen atom of DBF assists the nucleophilic attack of t-BuLi by coordination of the Li cation.52 To take advantage of this reactivity, 
A peculiarity of this phosphine is that it suffers partial spontaneous deboronation and therefore the work-up had to be carried out under a nitrogen atmosphere to minimise the oxidation of the free phosphine. Due to this fact, the phosphine-borane was not isolated but fully deprotected with morpholine (see later) to yield the completely free phosphine, which was subsequently coordinated to ruthenium.

All the intermediates have been fully characterised by the usual techniques and the details can be found in the Experimental section. Phosphine-boranes 4-DBF-Fc and 4-DBT-Fc were also characterised in the solid state by determination of their X-ray crystal structures (Fig. 1).

The crystals contain discrete molecules having the expected $\mathrm{S}$ absolute configuration at the $\mathrm{P}$ atom. The distances and angles are in the range expected for similar compounds29,35,53 and are very similar for both structures. The only noticeable differences between the two structures are in the parameters around the heteroatom: for $\mathrm{DBF}$, the two $\mathrm{O}-\mathrm{C}$ distances are much shorter compared to the two $\mathrm{S}-\mathrm{C}$ distances in DBT and the angle $\mathrm{C}-\mathrm{O}-\mathrm{C}$ is much wider than the angle $\mathrm{C}-\mathrm{S}-\mathrm{C}$ in DBT. In both structures, the heterocyclic substituent is essentially planar and the two Cp rings of the ferrocene are almost eclipsed, as observed in other ferrocenylphosphineboranes. $32,54,55$ It is well known that the sulfur atoms of DBT and TA can be oxidised to sulfoxides (SO)50,56-60 or sulfones (SO2).56,57,60-68 For this reason it was considered worth exploring the oxidation of the ligands containing these heterocycles because the sulfoxy group of the new ligands could interact with the metal during catalysis. Phosphine-borane 4-DBT-Me was therefore treated with a variety of oxidants such as MCPBA,58 H2O2/ HAcO,60,64-67 and CrO3/H5IO6 (Scheme 5).63

With the treatment with MCPBA and $\mathrm{H} 2 \mathrm{O} 2 / \mathrm{HAcO}$ it was found that partial deprotection and oxidation of the $\mathrm{P}$ atom of the phosphine as well as formation of byproducts had taken place according to $31 \mathrm{P}$ NMR spectroscopy. In contrast, with $\mathrm{CrO} 3 / \mathrm{H} 5 \mathrm{IO} 6$ in acetonitrile63 a single product corresponding to the complete deprotection and oxidation, namely the trioxide 4-DBTO3-Me, could be isolated. It seems therefore that the borane protecting group cannot withstand the strongly oxidant conditions of the reaction. It was then reasoned that if oxidation of $\mathrm{DBT}$ was not possible once installed at the $\mathrm{P}$ atom, maybe the DBTO2 fragment could be introduced in the first step of the Jugé-Stephan method. To this end, DBT was oxidised with hydrogen peroxide66,67 and lithiated with n-BuLi (Scheme 6).

The lithiation of DBTO2 has not been reported. After a series of experiments it was found that the best conditions consisted of adding $\mathrm{n}-\mathrm{BuLi}$ to a solution of DBTO2 precooled at $-78^{\circ} \mathrm{C}$, removing the cold bath immediately and stirring the mixture for $3 \mathrm{~h}$ at room temperature. Even under these conditions, however, the lithiation was incomplete and not always reproducible. Despite the rather unsatisfactory lithiation, it allowed the introduction of the oxidised heterocycle at the $\mathrm{P}$ atom and following the standard method compounds 2-DBTO2 and 3-DBTO2 could be prepared. The latter compound was treated with an excess of MeLi under usual conditions but did not give the expected 4-DBTO2-Me but dimethylphenylphosphine- borane.69,70 It is possible that the strongly electron-withdrawing sulfone group weakens the $\mathrm{P}-\mathrm{C}$ bond to such an extent that it can be cleaved by methyllithium even at low 
temperature.71 Therefore no other phosphines with DBTO2 were prepared. Finally, the obtained phosphine-boranes were deprotected with morpholine under standard conditions29,53 to give the free phosphinites and phosphines L1-13 (Scheme 7).

The free phosphines were all air-sensitive, especially the t-Bu-containing ligand L7 and hence after deprotection the 13 ligands were immediately coordinated to Ru moieties.

\section{Ru complexes}

Neutral complexes. The ligands were used to obtain the ruthenium neutral complexes of the type $[\mathrm{RuCl} 2(\eta 6$-arene)(P)], with the arene being p-cymene or methyl benzoate (Scheme 8).34,35 The complexes were easily prepared by splitting the usually employed ruthenium p-cymene dimer (D1) and for some of the ligands the much lesser used35 ruthenium methyl benzoate dimer (D2), in dichloromethane at room temperature as previously reported for analogous compounds. 35 The products were obtained as red or brown solids that were characterised by IR, chemical microanalysis or MS and by multinuclear NMR in solution. The data confirmed the identity of the proposed structures and the purity of the products. Hence, single $31 \mathrm{P}$ resonances were found for all the complexes and due to the chirality of the phosphorus ligand, all the $\mathrm{H}$ and $\mathrm{C}$ atoms were potentially different. Accordingly, apart from the peaks corresponding to the phosphorus ligand, 4 distinct $\mathrm{H}$ (4.0-6.5 ppm region) and $6 \mathrm{C}(80-$ $110 \mathrm{ppm})$ peaks appeared, respectively, in the $1 \mathrm{H}$ and $13 \mathrm{C}\{1 \mathrm{H}\}$ NMR spectra of the p-cymene complexes whereas $5 \mathrm{H}$ resonances could be found for the methyl benzoate complexes. As expected, the latter complexes also featured a singlet at approximately $3.9 \mathrm{ppm}$ in the $1 \mathrm{H}$ NMR spectra, corresponding to the COOMe group. Unexpectedly, for most of the methyl benzoate complexes a pair of peaks around $53 \mathrm{ppm}$ and another pair around $167 \mathrm{ppm}$ can be seen in the $13 \mathrm{C}\{1 \mathrm{H}\}$ NMR spectra, corresponding to the methylic and carbonylic carbon atoms of the COOMe group. The observation of the two peaks is probably due to the presence of the two rotamers represented in Scheme 9 in the solution.

Finally, a sharp band in the IR spectra of methyl benzoate complexes close to $1728 \mathrm{~cm}-1$ confirms the presence of the carbonyl of the ester group. The complex Ru7 could not be obtained satisfactorily since an extremely broad $31 \mathrm{P}\{1 \mathrm{H}\}$ NMR spectrum resulted and multiple peaks in the $1 \mathrm{H}$ NMR spectrum could be observed. This can be due to the bulkiness of L7 precluding efficient coordination to the Ru unit.

Single crystals, suitable for X-ray crystallography, could be obtained for complexes Ru5, Ru6 and Ru10 by slow diffusion of hexane into saturated solutions of the complexes in dichloromethane. The representation of their molecular structures is given in Fig. 2.

All the complexes adopt the typical pseudotetrahedral, "three-legged piano stool" geometry, with the Ru atom located in the centre of a distorted octahedron. The structures allow the confirmation of the expected absolute configurations of the $\mathrm{P}$ atoms ( $\mathrm{S}$ for the free ligands). The crystals of complex Ru5 contain two molecules in the unit cell, whose main difference is that the p-cymene is rotated $180^{\circ}$ 
around the $\mathrm{Ru}$-arene central axis. The most relevant metric parameters of the structures are given in Table 1.

238 As commonly found for this type of compound, the $\eta 6$-coordinated p-cymene ring is located in such a way that the imaginary line defined by the two $\mathrm{Cl}$ atoms is approximately parallel to the line passing through the substituted $\mathrm{C}$ atoms of the p-cymene group. It can also be seen that the heterocyclic substituent is almost completely flat. In general, the distances and angles are in the range expected for previously reported similar compounds.33,34,37,72,73

\section{Cationic complexes}

245 Neutral p-cymene Ru complexes were treated with thallium hexafluorophosphate (or tetrafluoroborate in

246 the case of Ru10) in order to abstract the chloride ligand and force the coordination of the heteroatom of

247 the heterocycle to the metal (Scheme 10).74-76

248 Treatment of dichloromethane solutions of complexes Ru1 $(\delta \mathrm{P}, \mathrm{Ru} 1=+112.7 \mathrm{ppm})$ and Ru6 $(\delta \mathrm{P}, \mathrm{Ru} 6=$ $249+21.5 \mathrm{ppm}$ ), bearing a phosphine with the DBF group, with TIPF6 caused a rapid precipitation of TlCl that was filtered, the solvent removed and the crude product analysed by NMR. In both experiments, a singlet at +113.8 and +24.0 ppm respectively in the $31 \mathrm{P}\{1 \mathrm{H}\}$ spectra of the isolated product was observed. Since the values are almost unchanged from Ru1 and Ru6, it can be concluded that the desired complex with a five-membered chelate ring with the $\kappa 2 \mathrm{P}, \mathrm{O}-$ coordinated phosphine did not form because a large downfield shift would be expected.77 1H NMR spectra, however, revealed that the products were not the starting complexes and that they contained the p-cymene and the phosphine moieties in a 1 : 1 ratio. They could correspond to dimeric species although their constitution was not further investigated. In the case of $\mathrm{Ru} 4(\delta \mathrm{P}, \mathrm{Ru} 4=117.0 \mathrm{ppm})$, after treatment with TIPF6, 31P $\{1 \mathrm{H}\} \mathrm{NMR}$ showed that $30 \%$ of the starting material was still present but another species slightly shifted upfield ( $\delta \mathrm{P}$ $=112.0 \mathrm{ppm}$ ) had also formed. This species could indeed correspond to the desired $\mathrm{\kappa} 2 \mathrm{P}, \mathrm{O}$-chelate since it is known that the ring contribution to the $31 \mathrm{P}$ shift is small and negative in six-membered rings.77 Despite this, given that only partial conversion could be achieved, its synthesis was not pursued further. In contrast to the unsuccessful coordination of the $\mathrm{O}$ atom, the coordination of the $\mathrm{S}$ atom of the dibenzothiophenyl and thianthryl groups could be achieved, yielding cationic complexes Ru2', Ru3' and $\mathrm{Ru} 9^{\prime}-13^{\prime}$. A strong deshielding of the 31P signals $\left(\Delta \delta\left(R u^{\prime}-\mathrm{Ru}\right)=20-43 \mathrm{ppm}\right)$ occurred upon formation of the 5-membered ring via coordination of the $\mathrm{S}$ atom, as expected.77 Similarly, in the 1H NMR the peaks of the $\mathrm{H}$ atoms of the coordinated arene ring shifted downfield approximately $1 \mathrm{ppm}$ and in the $13 \mathrm{C}\{1 \mathrm{H}\}$ the six $\mathrm{C}$ resonances also shifted roughly $5 \mathrm{ppm}$ downfield. These downfield shifts possibly reflect the decreased electron density of the $\eta 6$-coordinated arene ring due to the presence of a positive charge compared to the neutral $\mathrm{Ru}$ complexes. The identity of the complexes was also verified by elemental analyses or high resolution mass spectrometry as detailed in the Experimental section. The complex Ru11*', bearing the methyl benzoate as coordinated arene, was also obtained by treating Ru11* with thallium hexafluorophosphate. 
273 An interesting aspect of the cationic Ru complexes described here is the possible formation of two

274 diastereomeric complexes due to the presence of a stereogenic Ru atom (Scheme 10). NMR analysis

275 showed a single 31P signal and a unique set of $\mathrm{C}$ and $\mathrm{H}$ signals for complexes Ru2', Ru3', Ru11' and

276 Ru11*', suggesting that they are present as an optically pure species. In contrast, the two isomers could

277 be detected for the rest of the complexes, since two 31P peaks and two sets of $\mathrm{C}$ and $\mathrm{H}$ signals were

278 found as detailed in the Experimental section. The ratio between isomers was approximately $1: 4$ for

279 complexes Ru9' and Ru10' and $1: 2$ for Ru12' and Ru13'. It seems that there is no simple correlation

280 between the structure of the ligand and the isomeric ratio. Despite many attempts we were unable to

281 obtain crystals suitable to perform X-ray diffraction studies of any of the complexes in order to ascertain

282 the absolute configuration of the main isomer.

\section{Ru-catalysed transfer hydrogenation}

285 The reduction of ketones to alcohols is an extremely important transformation in organic chemistry that can be catalytically performed by hydrogenation using hydrogen gas, or in a safer way, by transfer hydrogenation, using a hydrogen donor.78,79 The latter reaction has been studied with a large number of soluble $\mathrm{Ru}$ (II) systems, very often chiral, to obtain enantioenriched alcohols.80-82 The model substrate for the asymmetric transfer hydrogenation is acetophenone and the typical conditions involve carrying out the reaction in refluxing 2-propanol in the presence of a base (Scheme 11). Although not the most typical precursors, $\mathrm{Ru}$ complexes of the type $[\mathrm{RuCl} 2(\eta 6$-arene)(P)] are easy to prepare and they are active in the reaction, as shown by us33-35,37 and other groups.74,83-86 The enantioselectivities of our systems with P-stereogenic phosphines are, however, rather low (up to 50\% ee),33,35,37 so the performance of neutral and cationic Ru complexes with the new heterocyclic phosphines was studied (Table 2).

The precursors were activated for $15 \mathrm{~min}$ in the presence of $\mathrm{t}$-BuOK before the addition of acetophenone to form the catalytically active ruthenium-hydride species.87 All were active in the reaction, resulting in full conversion at $24 \mathrm{~h}$. At shorter reaction times, however, notable differences in activity can be seen depending on the structure of the precursor. In most of the cases, neutral $\mathrm{kP}$-coordinated complexes lead to more active precursors compared to cationic $\kappa 2 \mathrm{P}, \mathrm{S}$-coordinated counterparts (cf. for example entries 15 and 17 or 21 and 23). The complexes with methyl benzoate give more active systems than those with p-cymene (cf. for example entries 8 and 9 or 15 and 16), in line with previously published results for similar systems. 35 These findings suggest that $\eta 6$-arene decoordination or slippage (hapticity reduction) probably occurs during the catalytic cycle. Such a process is easier for electron poor methyl benzoate complexes compared to p-cymene analogues and also for neutral complexes compared to cationic counterparts.

Finally, the enantioselection is very low for most of the precursors, as usually found with similar monophosphorus ligands.33,35 The precursors with L11 (entries 15-18) are moderately enantioselective, except Ru11' (entry 17). Interestingly, the same value of 70\% ee was obtained with 
310 complexes Ru11* and Ru11*' (entries 16 and 18 respectively), pointing to the formation of a common 311 intermediate under catalytic conditions. It is worth noting that Ru11 and Ru11* both form single 312 cationic species in solution, a fact that could be beneficial for the enantioselectivity. 


\section{CONCLUSIONS}

315

316 In this paper the Jugé-Stephan method has allowed the preparation of 13 optically pure P-stereogenic

317 diaryl monophosphinites and monophosphines of the type $\mathrm{PPh}(\mathrm{Het}) \mathrm{R}$ (Het = 4-DBF, 4-DBT, 1-TA and

318 4-DBTO2; $\mathrm{R}=\mathrm{OMe}, \mathrm{Me}, \mathrm{i}-\mathrm{Pr}, \mathrm{t}-\mathrm{Bu}, \mathrm{Fc}$ ) by direct lithiation of the heterocycle. The ligands are a

319 valuable addition to the small number of optically pure P-stereogenic ligands with a heterocyclic

320 substituent.

321 The ligands had been designed with the idea of introducing the heteroatom (A) at a position capable of

322 interacting with the ruthenium centre via the formation of a favoured five-membered $\kappa 2 \mathrm{P}, \mathrm{A}$-chelate.

323 This coordination has been achieved for DBT- and TA-containing phosphines but not for the DBFbased

324 ligands. This is possibly due to the hard character of the oxygen atom, showing less tendency to

325 coordinate to the Ru atom compared to sulfur. An important stereoselection in the formation of the

326 stereogenic Ru atom has been observed for most of the ligands.

327 The obtained complexes have been used in catalytic transfer hydrogenation of acetophenone with the

328 aim of comparing the performance of the new ligands with previously reported systems based in P-

329 stereogenic PArPhR ligands (Ar = polycyclic aromatic group).33-35,37,87 It has been found that the

330 activities are similar to some of the previous generation precursors but one of the ligands, L11, gives a

331 considerably higher enantioselectivity. 


\section{EXPERIMENTAL SECTION}

\section{General data}

336 All compounds were prepared under a purified nitrogen atmosphere using standard Schlenk and 337 vacuum-line techniques. The solvents were purified using a solvent purification system or by standard 338 procedures 88 and kept under nitrogen. $1 \mathrm{H}, 13 \mathrm{C}\{1 \mathrm{H}\}$, and $31 \mathrm{P}\{1 \mathrm{H}\}$ and HSQC $1 \mathrm{H}-13 \mathrm{C}$ NMR spectra 339 were recorded using 300 and $400 \mathrm{MHz}$ spectrometers using $\mathrm{CDCl} 3$ as a solvent unless otherwise 340 specified. Chemical shifts are reported downfield from standards. The protons of BH3 of the phosphine341 boranes group appeared in the aliphatic region of the spectra as very broad bands and have not been 342 assigned. IR spectra were recorded in $\mathrm{KBr}$ and the main absorption bands are expressed in $\mathrm{cm}-1$. High343 resolution mass analyses (HRMS) were carried out on a time-of-flight instrument using electrospray 344 ionisation. Optical rotations were measured at $\mathrm{rt}$ using a sodium lamp at the sodium D-line wavelength $345(589.592 \mathrm{~nm})$. For all the determinations, the solvent was $\mathrm{CH} 2 \mathrm{Cl} 2$ and the concentration was $1 \mathrm{~g}$ per 100 $346 \mathrm{~mL}$. Transfer hydrogenation reactions were analysed by GC with $\mathrm{He}$ as a carrier gas.

347 Oxazaphospholidine-borane 1 (prepared from (1R,2S)-(-)-ephedrine),21 dibenzothiophene 348 dioxide,66,67 and Ru dimer D289 were prepared using literature procedures whereas other reagents 349 were used as received from commercial suppliers. 
2-DBF, (1R,2S)-2-\{[(S)-(4-dibenzofuranyl)phenylphosphanyl] methylamino $\}$-1-phenylpropan-1-olborane. Dibenzofuran (1.85 g, $11.0 \mathrm{mmol})$ was dissolved in $30 \mathrm{~mL}$ of THF in a Schlenk flask. The solution was cooled to $-78^{\circ} \mathrm{C}$ and then $1.6 \mathrm{M} \mathrm{n}$-BuLi solution in hexanes $(6.9 \mathrm{~mL}, 11.0 \mathrm{mmol})$ was added using a syringe. The resulting brown solution was removed from the cold bath, left stirring for 30 min at room temperature and then recooled to $-78^{\circ} \mathrm{C}$. At the same time oxazaphospholidine-borane 1 $(2.85 \mathrm{~g}, 10.0 \mathrm{mmol})$ was dissolved in $40 \mathrm{~mL}$ of THF and the solution was cooled down to $-78{ }^{\circ} \mathrm{C}$. The content of the first flask was slowly transferred to the second Schlenk flask via cannula and the resulting mixture was stirred for $14 \mathrm{~h}$. Around $30 \mathrm{~mL}$ of water were added to the orange solution and THF was evaporated. The dark-brown residue was extracted with dichloromethane $(3 \times 30 \mathrm{~mL})$ and the combined organic phases were washed with water and dried with anhydrous sodium sulfate. The suspension was filtered and the solvents were evaporated to dryness, leaving a yellowish pasty solid that was purified by column chromatography (flash $\mathrm{SiO} 2$, from $95: 5$ to $80: 20$ of hexane/ethyl acetate). The title product was obtained as a whitish solid. Yield: $3.52 \mathrm{~g}(77 \%)$. 1H NMR (300 MHz): $8.11(\mathrm{dt}, \mathrm{J}=7.8,1.2,1 \mathrm{H}), 7.96(\mathrm{dm}, \mathrm{J}=6.6,1 \mathrm{H}), 7.78(\mathrm{ddd}, \mathrm{J}=12.3,7.5,1.2$, 1H), $7.58(\mathrm{dm}, \mathrm{J}=8.1,1 \mathrm{H}), 7.51-7.18(\mathrm{~m}, \mathrm{Ar}, 13 \mathrm{H}), 4.90(\mathrm{~d}, 3 \mathrm{JHH}=6.0,1 \mathrm{H}), 4.45(\mathrm{~m}, 1 \mathrm{H}), 2.63(\mathrm{~d}$, $3 \mathrm{JHP}=8.1,3 \mathrm{H}), 1.29(\mathrm{~d}, 3 \mathrm{JHH}=6.6,3 \mathrm{H}) .13 \mathrm{C}\{1 \mathrm{H}\} \mathrm{NMR}(101 \mathrm{MHz}): 156.3-111.6(\mathrm{C}, \mathrm{CH}, \mathrm{Ar}), 78.6$ $(\mathrm{d}, 3 \mathrm{JCP}=6.2, \mathrm{CH}), 58.2(\mathrm{~d}, 2 \mathrm{JCP}=11.0, \mathrm{CH}), 30.9(\mathrm{~d}, 2 \mathrm{JCP}=4.4, \mathrm{CH} 3), 13.0(\mathrm{~s}, \mathrm{CH} 3) .31 \mathrm{P}\{1 \mathrm{H}\}$ NMR (121 MHz): +67.5 (br, s). HRMS: calcd for C28H27NO2P ([M] + H - BH3), 440.1779; found, 440.1771. $[\alpha] \mathrm{D}=+66.2^{\circ}$.

2-DBT, (1R,2S)-2-\{[(S)-(4-dibenzothiophenyl)phenylphosphanyl] methylamino\}-1-phenylpropan-1-olborane. Dibenzothiophene (2.03 g, $11.0 \mathrm{mmol})$ was dissolved in $30 \mathrm{~mL}$ of THF in a Schlenk flask. The solution was cooled to $-78{ }^{\circ} \mathrm{C}$ and then $1.6 \mathrm{M} \mathrm{n}$-BuLi solution in hexanes $(6.9 \mathrm{~mL}, 11.0 \mathrm{mmol})$ was added using a syringe. The resulting brown solution was removed from the cold bath, left stirring at $0{ }^{\circ} \mathrm{C}$ for $5 \mathrm{~h}$ and recooled to $-78^{\circ} \mathrm{C}$. At the same time oxazaphospholidineborane $1(2.85 \mathrm{~g}, 10.0 \mathrm{mmol})$ was dissolved in $40 \mathrm{~mL}$ of THF and the solution was cooled down to $-78^{\circ} \mathrm{C}$. The content of the first flask was slowly transferred to the second Schlenk flask via cannula and the resulting mixture was stirred for $14 \mathrm{~h}$. Around $30 \mathrm{~mL}$ of water were added to the brownyellow solution and THF was evaporated. The white residue was extracted with dichloromethane $(3 \times 30 \mathrm{~mL})$ and the combined organic phases were washed with water and dried with anhydrous sodium sulfate. The suspension was filtered and the solvents were evaporated to dryness, leaving a white pasty solid, which was purified by column chromatography (flash $\mathrm{SiO} 2$, from $95: 5$ to $80: 20$ of hexane/ethyl acetate). The title product was obtained as a white solid. Yield: $4.11 \mathrm{~g}(87 \%)$. 
$(\mathrm{d}, 3 \mathrm{JHH}=6.8,3 \mathrm{H}) .13 \mathrm{C}\{1 \mathrm{H}\} \mathrm{NMR}(101 \mathrm{MHz}): 142.4-121.4(\mathrm{C}, \mathrm{CH}, \mathrm{Ar}), 78.9(\mathrm{~d}, 3 \mathrm{JCP}=2.7, \mathrm{CH})$, $58.5(\mathrm{~d}, 2 \mathrm{JCP}=10.4, \mathrm{CH}), 31.6(\mathrm{~d}, 2 \mathrm{JCP}=4.3, \mathrm{CH} 3), 11.3(\mathrm{~d}, 3 \mathrm{JCP}=5.4, \mathrm{CH} 3) .31 \mathrm{P}\{1 \mathrm{H}\} \mathrm{NMR}(121$ MHz): +70.1 (br, s). HRMS: calcd for C28H27NOPS ([M] + H - BH3), 456.1551; found, 456.1540. $[\alpha] \mathrm{D}=+52.2^{\circ}$.

2-TA, (1R,2S)-2-\{[(S)-(1-thianthrenyl)phenylphosphanyl] methylamino\}-1-phenylpropan-1-ol-borane. Thianthrene (600 mg, $2.8 \mathrm{mmol}$ ) was dissolved in $40 \mathrm{~mL}$ of THF in a Schlenk flask. The solution was cooled to $-78{ }^{\circ} \mathrm{C}$ and then $1.6 \mathrm{M} \mathrm{n}$-BuLi solution in hexanes $(2.3 \mathrm{~mL}, 3.7 \mathrm{mmol})$ was added using a syringe. The resulting brown solution was allowed to reach room temperature and then was refluxed for $1 \mathrm{~h}$, cooled to room temperature and then to $-78^{\circ} \mathrm{C}$. At the same time oxazaphospholidine-borane 1 (720 mg, $2.5 \mathrm{mmol}$ ) was dissolved in $40 \mathrm{~mL}$ of THF and the solution was cooled down to $-78{ }^{\circ} \mathrm{C}$. The content of the first flask was slowly transferred to the second Schlenk flask via cannula and the resulting mixture was stirred for $14 \mathrm{~h}$. Around $30 \mathrm{~mL}$ of water were added to the brown-yellow solution and THF was evaporated. The white residue was extracted with dichloromethane $(3 \times 30 \mathrm{~mL})$ and the combined organic phases were washed with water and dried with anhydrous sodium sulfate. The suspension was filtered and the solvents were evaporated to dryness, leaving a white pasty solid, which was purified by column chromatography (flash $\mathrm{SiO} 2$, from $95: 5$ to $80: 20$ of hexane/ethyl acetate). The title product was obtained as a white solid. Yield: $1.15 \mathrm{~g}(91 \%)$.

1H NMR (400 MHz): 7.67 (dt, J = 7.6, 1.2, 1H), 7.52-7.43 (m, Ar, 7H), 7.39-7.27 (m, Ar, 6H), 7.22 (td, $\mathrm{J}=7.6,1.6,1 \mathrm{H}), 7.15(\mathrm{td}, \mathrm{J}=7.6,1.6,1 \mathrm{H}), 7.02(\mathrm{dd}, \mathrm{J}=7.6,1.6,1 \mathrm{H}), 4.98(\mathrm{~d}, \mathrm{~J}=4.4,1 \mathrm{H}), 4.45(\mathrm{~m}$, $1 \mathrm{H}), 2.63(\mathrm{~d}, 3 \mathrm{JHP}=7.2,3 \mathrm{H}), 1.32(\mathrm{~d}, 3 \mathrm{JHH}=6.8,3 \mathrm{H}) .13 \mathrm{C}\{1 \mathrm{H}\} \mathrm{NMR}(101 \mathrm{MHz}): 142.4-126.2(\mathrm{C}$, $\mathrm{CH}, \mathrm{Ar}), 79.0(\mathrm{~d}, 3 \mathrm{JCP}=2.8, \mathrm{CH}), 58.4(\mathrm{~d}, 2 \mathrm{JCP}=10.7, \mathrm{CH}), 31.4(\mathrm{~d}, 2 \mathrm{JCP}=4.1, \mathrm{CH} 3), 12.0(\mathrm{~d}, 3 \mathrm{JCP}$ $=4.1, \mathrm{CH} 3) .31 \mathrm{P}\{1 \mathrm{H}\}$ NMR (162 MHz): +71.9 (br, s). HRMS: calcd for C28H27NOPS2 ([M] + H BH3), 488.1272; found, 488.1267. [ $\alpha] \mathrm{D}=+40.4^{\circ}$.

2-DBTO2, (1R,2S)-2-\{[(S)-(4-dibenzothiophenyldioxide)phenylphosphanyl] methylamino\}-1phenylpropan-1-ol-borane. Dibenzothiophene- S,S-dioxide (1.19 g, $5.5 \mathrm{mmol})$ was dissolved in $40 \mathrm{~mL}$ of THF in a Schlenk flask. The solution was cooled to $-78^{\circ} \mathrm{C}$ and then $1.6 \mathrm{M} \mathrm{n}$-BuLi solution in hexanes $(3.4 \mathrm{~mL}, 5.5 \mathrm{mmol})$ was added using a syringe. The resulting brown solution was removed from the cold bath, left stirring at room temperature for $3 \mathrm{~h}$ and recooled to $-78^{\circ} \mathrm{C}$. At the same time oxazaphospholidine-borane 1 (1.43 g, $5.5 \mathrm{mmol})$ was dissolved in $35 \mathrm{~mL}$ of THF and the solution was cooled down to $-78^{\circ} \mathrm{C}$. The content of the first flask was slowly transferred to the second Schlenk flask via cannula and the resulting mixture was stirred for $14 \mathrm{~h}$. Around $30 \mathrm{~mL}$ of water were added to the brown-yellow solution and THF was evaporated. The white residue was extracted with dichloromethane $(3 \times 30 \mathrm{~mL})$ and the combined organic phases were washed with water and dried with anhydrous sodium sulfate. The suspension was filtered and the solvents were evaporated to dryness, leaving a white solid. Yield: $1.25 \mathrm{~g}(45 \%)$.

1H NMR (400 MHz): 7.97 (m, 2H), 7.91. (dt, J = 7.6, 1.2, 1H), 7.79 (d, J = 8.0, 1H), 7.75 (d, J = 7.6, 1H), $7.62(\mathrm{td}, \mathrm{J}=7.6,1.2,1 \mathrm{H}), 7.57(\mathrm{~m}, 1 \mathrm{H}), 7.55-7.50(\mathrm{~m}, 4 \mathrm{H}), 7.45(\mathrm{~m}, 1 \mathrm{H}), 7.39(\mathrm{~d}, \mathrm{~J}=7.6,2 \mathrm{H})$, 
$7.29(\mathrm{td}, \mathrm{J}=7.6,2.0,2 \mathrm{H}), 7.20(\mathrm{tt}, \mathrm{J}=7.2,1.2,1 \mathrm{H}), 5.11(\mathrm{~d}, \mathrm{~J}=2.8,1 \mathrm{H}), 4.30(\mathrm{~m}, 1 \mathrm{H}), 2.84(\mathrm{~d}, 3 \mathrm{JHP}=$ 8.4, 3H), $1.24(\mathrm{~d}, 3 \mathrm{JHH}=6.8,3 \mathrm{H}) .13 \mathrm{C}\{1 \mathrm{H}\} \mathrm{NMR}(101 \mathrm{MHz}): 142.4-121.2(\mathrm{C}, \mathrm{CH}, \mathrm{Ar}), 78.7(\mathrm{~d}, 3 \mathrm{JCP}$ $=1.5, \mathrm{CH}), 59.3(\mathrm{~d}, 2 \mathrm{JCP}=9.9, \mathrm{CH}), 33.9(\mathrm{~d}, 2 \mathrm{JCP}=3.9, \mathrm{CH} 3), 9.6(\mathrm{~d}, 3 \mathrm{JCP}=7.2, \mathrm{CH} 3) .31 \mathrm{P}\{1 \mathrm{H}\}$ NMR (162 MHz): +73.4 (br, s). HRMS: calcd for C28H27NO3PS ([M] + H - BH3), 488.1449; found, 488.1457. $[\alpha] \mathrm{D}=+66.1^{\circ}$.

3-DBF, (R)-(4-dibenzofuranyl)methoxyphenylphosphineborane. Aminophosphine-borane 2-DBF (3.52 g, $7.7 \mathrm{mmol})$ was dissolved in $200 \mathrm{~mL}$ of freshly distilled methanol, concentrated $\mathrm{H} 2 \mathrm{SO} 4(0.84 \mathrm{~mL}$, $1.51 \mathrm{~g}, 15.4 \mathrm{mmol}$ ) was carefully added and the solution was stirred for $14 \mathrm{~h}$. The solvent was removed in vacuo and the crude was purified by column chromatography (flash $\mathrm{SiO} 2,95: 5$ hexane/ethyl acetate). The title product was obtained as a pale brown oil. Yield: $1.67 \mathrm{~g}(67 \%)$. 1H NMR (400 MHz): 8.13 (dt, J = 7.6, 1.2, 1H), 7.98-7.91 (m, 4H), 7.58 (d, J = 12.0, 1H), 7.56 (d, J = 12.0, 1H), 7.51-7.43 (m, 4H), $7.36(\mathrm{~m}, 1 \mathrm{H}), 3.85(\mathrm{~d}, 3 \mathrm{JHP}=12.4,3 \mathrm{H}) .13 \mathrm{C}\{1 \mathrm{H}\} \mathrm{NMR}(101 \mathrm{MHz})$ : 156.1-111.6 (C, CH, Ar), $54.3(\mathrm{~d}, 2 \mathrm{JCP}=2.7, \mathrm{CH} 3) .31 \mathrm{P}\{1 \mathrm{H}\} \mathrm{NMR}(121 \mathrm{MHz}):+106.6(\mathrm{~d}, \mathrm{br}, \mathrm{J} \approx 88)$. HRMS: calcd for C19H22BNO2P ([M] + NH4), 338.1481; found, 338.1472. [ $\alpha] \mathrm{D}=-81.9^{\circ}$. 3-DBT, (R)-(4-dibenzothiophenyl)methoxyphenylphosphineborane. The procedure was the same as that used to prepare 3-DBF but starting from precursor 2-DBT (2.06 g, $4.4 \mathrm{mmol})$. The desired phosphiniteborane was obtained as a colourless oil. Yield: $1.19 \mathrm{~g}(81 \%)$.

1H NMR (400 MHz): 8.32 (d, J = 8.0, 1H), 8.17 (m, 1H), 8.09 (dd, J = 13.2, 7.6, 1H), 7.82-7.76 (m, $3 \mathrm{H}), 7.60(\mathrm{td}, \mathrm{J}=7.2,2.0,1 \mathrm{H}), 7.53-7.40(\mathrm{~m}, 5 \mathrm{H}), 3.86(\mathrm{~d}, 3 \mathrm{JHP}=12.4,3 \mathrm{H}) .13 \mathrm{C}\{1 \mathrm{H}\} \mathrm{NMR}(101$ MHz): 141.1-121.5 (C, CH, Ar), $54.2(\mathrm{~d}, 2 \mathrm{JCP}=2.3, \mathrm{CH} 3) .31 \mathrm{P}\{1 \mathrm{H}\}$ NMR $(121 \mathrm{MHz}):+110.6(\mathrm{~d}, \mathrm{br}$, $\mathrm{J} \approx 89$ ). HRMS: calcd for C19H22BNOPS ([M] + NH4), 354.1253; found, 354.1252. [ $\alpha] \mathrm{D}=-78.0^{\circ}$. 3-TA, (R)-methoxyphenyl(1-thianthrenyl)phosphine-borane. The procedure was similar to that used to prepare 3-DBF but starting from precursor 2-TA $(1.15 \mathrm{~g}, 2.3 \mathrm{mmol})$ and stirring for 3 days. The desired phosphinite-borane was obtained as a white pasty solid. Yield: $447 \mathrm{mg}(53 \%)$.

1H NMR (400 MHz): 7.91 (ddd, J = 11.2, 7.6, 1.2, 1H), 7.74-7.69 (m, 3H), 7.52 (td, J = 7.2, 1.2, 1H), 7.46-7.37 (m, 4H), $7.21(\mathrm{td}, \mathrm{J}=7.6,1.6,1 \mathrm{H}), 7.12(\mathrm{td}, \mathrm{J}=7.6,1.2,1 \mathrm{H}), 6.96(\mathrm{dd}, \mathrm{J}=7.6,1.2,1 \mathrm{H}), 3.80$ $(\mathrm{d}, 3 \mathrm{JHP}=12.4,3 \mathrm{H}) .13 \mathrm{C}\{1 \mathrm{H}\} \mathrm{NMR}(101 \mathrm{MHz}): 140.0-127.0(\mathrm{C}, \mathrm{CH}, \mathrm{Ar}), 54.1(\mathrm{~d}, 2 \mathrm{JCP}=2.5, \mathrm{CH})$. 31P $\{1 \mathrm{H}\}$ NMR (162 MHz): +109.3 (d, br, J $\approx 83)$. HRMS: calcd for C19H22BNOPS2 ([M] + NH4), 386.0973; found, 386.0976. $[\alpha] \mathrm{D}=-10.5^{\circ}$.

3-DBTO2, (R)-(4-dibenzothiophenyl dioxide)methoxyphenylphosphine- borane. The procedure was the same as that used to prepare 3-DBF but starting from precursor 2-DBTO2 (1.00 g, $3.0 \mathrm{mmol})$. The desired phosphinite-borane was obtained as a white solid. Yield: $433 \mathrm{mg}(59 \%)$. 1H NMR (400 MHz): 7.93-7.78 (m, 6H), 7.68-7.62 (m, 2H), 7.56 (td, J = 7.6, 0.8, 1H), 7.52-7.42 (m, 3H), $3.99(\mathrm{~d}, 3 \mathrm{JHP}=12.0,3 \mathrm{H}) .13 \mathrm{C}\{1 \mathrm{H}\} \mathrm{NMR}(101 \mathrm{MHz}): 139.4-121.3(\mathrm{C}, \mathrm{CH}, \mathrm{Ar}), 55.4(\mathrm{~d}, 2 \mathrm{JCP}=$ 2.0, CH3). 31P $\{1 \mathrm{H}\}$ NMR (162 MHz): +112.0 (d, br, J $\approx 73$ ). HRMS: calcd for C19H22BNO3PS ([M] + NH4), 386.1151; found, 386.1156. [ $\alpha] \mathrm{D}=-291.1^{\circ}$. 
4-DBF-Me, (S)-(4-dibenzofuranyl)methylphenylphosphineborane. Methoxyphosphine-borane 3-DBF (673 mg, $2.1 \mathrm{mmol}$ ) was dissolved in $30 \mathrm{~mL}$ diethyl ether, and the solution was cooled down to $-30{ }^{\circ} \mathrm{C}$. A 1.6 M MeLi solution in diethyl ether $(2.6 \mathrm{~mL}, 4.2 \mathrm{mmol})$ was added using a syringe and the mixture was stirred for $1 \mathrm{~h}$ before slowly warming it to room temperature. About $15 \mathrm{~mL}$ of water were added and the mixture was extracted with diethyl ether $(3 \times 10 \mathrm{~mL})$, the combined organic phases were washed with $20 \mathrm{~mL}$ of water and dried with anhydrous sodium sulfate. After filtration, the solvent was removed in vacuo and the crude product was purified by column chromatography (flash $\mathrm{SiO} 2,95: 5$ hexane/ethyl acetate). The title product was obtained as a colourless oil. Yield: $523 \mathrm{mg}(82 \%)$.

1H NMR (400 MHz): 8.11 (d, J = 7.6, 1H), 8.00-7.95 (m, 2H), 7.85-7.80 (m, 2H), 7.59-7.55 (m, 2H), 7.52-7.33 (m, 5H), $2.23(\mathrm{~d}, 2 \mathrm{JHP}=10.8,3 \mathrm{H}) .13 \mathrm{C}\{1 \mathrm{H}\}$ NMR (101 MHz): 156.9-111.6 (C, CH, Ar), $11.1(\mathrm{~d}, 1 \mathrm{JCP}=41.6, \mathrm{CH} 3) .31 \mathrm{P}\{1 \mathrm{H}\} \mathrm{NMR}(121 \mathrm{MHz}):+7.7(\mathrm{~d}, \mathrm{br}, \mathrm{J} \approx 81)$. HRMS: calcd for

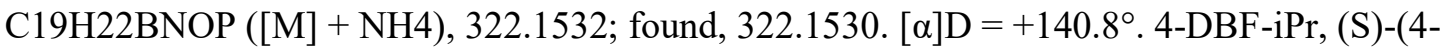
dibenzofuranyl)isopropylphenylphosphineborane. The procedure was the same as that used to prepare 4-DBF-Me. Starting from 3-DBF (1.15 g, $3.6 \mathrm{mmol})$ and 0.7 M i-PrLi solution in pentane $(15.2 \mathrm{~mL}$, $10.8 \mathrm{mmol})$ the desired phosphinite-borane was obtained as a colourless oil. Yield: $897 \mathrm{mg}(75 \%)$. 1H NMR (400 MHz): 8.15-7.97 (m, 5H), $7.66(\mathrm{~d}, \mathrm{~J}=8.0,1 \mathrm{H}), 7.53(\mathrm{td}, \mathrm{J}=7.6,1.2,1 \mathrm{H}), 7.45-7.38(\mathrm{~m}$, $5 \mathrm{H}), 3.67(\mathrm{~m}, 1 \mathrm{H}), 1.29(\mathrm{dd}, 3 \mathrm{JHP}, 3 \mathrm{JHH}=17.2,7.2,3 \mathrm{H}), 1.16(\mathrm{dd}, 3 \mathrm{JHP}, 3 \mathrm{JHH}=17.2,6.8,3 \mathrm{H})$. 13C $\{1 \mathrm{H}\}$ NMR (101 MHz): 156.7-111.7 (C, CH, Ar), 22.6 (d, 1JCP = 37.9, CH), $17.1(\mathrm{~d}, 2 \mathrm{JCP}=2.8$, CH3), $16.8(\mathrm{~d}, 2 \mathrm{JCP}=2.9, \mathrm{CH} 3) .31 \mathrm{P}\{1 \mathrm{H}\} \mathrm{NMR}(121 \mathrm{MHz}):+26.1(\mathrm{~d}, \mathrm{br}, \mathrm{J} \approx 77)$. HRMS: calcd for C21H26BNOP ([M] + NH4), 350.1845; found, 350.1842. [ $\alpha] \mathrm{D}=+228.9^{\circ}$.

4-DBF-tBu, (S)-(tert-butyl)(4-dibenzofuranyl)phenylphosphine- borane. The procedure was the same as that used to prepare 4-DBF-Me. Starting from 3-DBF (732 mg, $2.1 \mathrm{mmol}$ ) and 1.6 M t-BuLi solution $(1.5 \mathrm{~mL}, 2.3 \mathrm{mmol})$ the desired phosphinite-borane was obtained as a colourless oil. Yield: $440 \mathrm{mg}$ $(60 \%)$.

1H NMR (400 MHz): 8.17-8.12 (m, 2H), 7.98 (td, J = 7.6, 0.8, 1H), 7.90-7.85 (m, 2H), 7.49-7.43 (m, 4H), 7.42-7.36 (m, 3H), $1.41(\mathrm{~d}, 3 \mathrm{JHP}=14.8,9 \mathrm{H}) .13 \mathrm{C}\{1 \mathrm{H}\} \mathrm{NMR}(101 \mathrm{MHz}): 155.4-111.7(\mathrm{C}, \mathrm{CH}$, Ar), $31.8(\mathrm{~d}, 1 \mathrm{JCP}=31.3, \mathrm{C}), 27.8(\mathrm{~d}, 2 \mathrm{JCP}=3.0, \mathrm{CH} 3) .31 \mathrm{P}\{1 \mathrm{H}\} \mathrm{NMR}(121 \mathrm{MHz}):+36.7(\mathrm{~d}, \mathrm{br}, \mathrm{J} \approx$ 70). HRMS: calcd for C22H28BNOP ([M] + NH4), 364.2002; found, 350.2014. [ $\alpha] \mathrm{D}=+82.3^{\circ}$. 4-DBF-Fc, (S)-(4-dibenzofuranyl)ferrocenylphenylphosphineborane. Ferrocene (2.5 g, $13.4 \mathrm{mmol}$ ) was dissolved in $20 \mathrm{Ml}$ of THF in a Schlenk flask. The solution was cooled to $0{ }^{\circ} \mathrm{C}, 1.6 \mathrm{M} \mathrm{t}$-BuLi solution in pentane $(16.7 \mathrm{~mL}, 26.9 \mathrm{mmol})$ was added using a syringe and the mixture was left stirring for $2 \mathrm{~h}$. At this point $40 \mathrm{~mL}$ of hexane were added and the solution was cooled down to $-78^{\circ} \mathrm{C}$, which caused the precipitation of FcLi. The solid was filtered under nitrogen, washed with hexane and dried in vacuo. In parallel, 3-DBF (2.15 g, $6.7 \mathrm{mmol}$ ) was dissolved in $20 \mathrm{~mL}$ of THF and the solution was cooled down to $-78{ }^{\circ} \mathrm{C}$. Solid FcLi was rapidly added to that solution and the mixture was left stirring for $14 \mathrm{~h}$. About $15 \mathrm{~mL}$ of water were added and most of the THF was removed in vacuo. The mixture was extracted with dichloromethane $(3 \times 10 \mathrm{~mL})$, the combined organic phases were washed with $20 \mathrm{~mL}$ of water and 
dried with anhydrous sodium sulfate. After filtration, the solvent was removed in vacuo and the red crude product was purified by column chromatography (flash $\mathrm{SiO} 2,70: 30$ hexane/dichloromethane) and recrystallized in dichloromethane/hexane. The title product was obtained as an orange solid. Yield: $1.80 \mathrm{~g}(56 \%)$.

501 1H NMR (400 MHz): $8.13(\mathrm{~d}, \mathrm{~J}=7.6,1 \mathrm{H}), 8.04(\mathrm{dd}, \mathrm{J}=12.8,7.61 \mathrm{H}), 7.96(\mathrm{~d}, \mathrm{~J}=6.8,1 \mathrm{H}), 7.67-7.62$ (m, 2H), 7.48 (t, J = 7.6, 1H), 7.44-7.35 (m, 6H), 4.69 (s, br, 2H), 4.53 (s, br, 1H), 4.49 (s, br, 1H), 4.00 (s, br, 5H). 13C $\{1 \mathrm{H}\}$ NMR (101 MHz): 156.6-111.8 (C, CH, Ar), 74.1 (d, JCP = 13.5, CH), 73.0 (d, $\mathrm{JCP}=7.8, \mathrm{CH}), 71.9(\mathrm{~d}, \mathrm{JCP}=7.7, \mathrm{CH}), 71.6(\mathrm{~d}, \mathrm{JCP}=8.5, \mathrm{CH}), 69.7(\mathrm{~s}, 5 \mathrm{CH}), 67.7(\mathrm{~d}, \mathrm{JCP}=70.5$, C). 31P $\{1 \mathrm{H}\}$ NMR $(162 \mathrm{MHz}):+12.6(\mathrm{~d}, \mathrm{br}, \mathrm{J} \approx 43)$. HRMS: calcd for $\mathrm{C} 28 \mathrm{H} 21 \mathrm{FeOP}([\mathrm{M}]-\mathrm{BH})$, 460.0679; found, 460.0663. $[\alpha] \mathrm{D}=+65.4^{\circ}$. 4-DBT-Me, (S)-(4-dibenzothiophenyl)methylphenylphosphine-borane. The procedure was the same as that used to prepare 4-DBF-Me. Starting from 3-DBT (580 mg, $1.7 \mathrm{mmol})$ and $1.6 \mathrm{M}$ MeLi solution (1.2 $\mathrm{mL}, 1.7 \mathrm{mmol})$ the desired phosphine-borane was obtained as a colourless oil. Yield: $357 \mathrm{mg}(70 \%)$. 1H NMR (400 MHz): 8.31 (dt, J = 8.0, 1.2, 1H), $8.16(\mathrm{~m}, 1 \mathrm{H}), 8.08(\mathrm{ddd}, \mathrm{J}=12.8,7.2,1.2,1 \mathrm{H}), 7.74$ (m, 1H), 7.70-7.64 (m, 2H), 7.61 (td, J = 7.6, 1.6, 1H), 7.52-7.40 (m, 5H), $2.09(\mathrm{~d}, 2 \mathrm{JHP}=10.0,3 \mathrm{H})$. 13C $\{1 \mathrm{H}\}$ NMR (101 MHz): 142.2-121.5 (C, CH, Ar), 10.0 (d, 1JCP = 40.2, CH3). 31P $\{1 \mathrm{H}\}$ NMR (121 MHz): +13.2 (d, br, $\mathrm{J} \approx 77$ ). HRMS: calcd for C19H22BNPS ([M] + NH4), 338.1304; found, 338.1293. $[\alpha] \mathrm{D}=+41.5^{\circ}$.

4-DBT-iPr, (S)-(4-dibenzothiophenyl)isopropylphenylphosphine-borane. The procedure was the same as that used to prepare 4-DBF-iPr. Starting from 3-DBT $(1.00 \mathrm{~g}, 3.0 \mathrm{mmol})$ and $0.7 \mathrm{M}$ i-PrLi solution in pentane (6.4 mL, $4.5 \mathrm{mmol})$ the desired phosphine-borane was obtained as a colourless oil. Yield: 985 $\operatorname{mg}(95 \%)$. 1H NMR (400 MHz): $8.10(\mathrm{dt}, \mathrm{J}=8.0,1.6,1 \mathrm{H}), 8.02(\mathrm{dd}, \mathrm{J}=7.6,1.2,1 \mathrm{H}), 7.96(\mathrm{~m}, 1 \mathrm{H}), 7.71-7.66(\mathrm{~m}$, 2H), $7.58(\mathrm{~m}, 1 \mathrm{H}), 7.41(\mathrm{td}, \mathrm{J}=7.6,2.0,1 \mathrm{H}), 7.34-7.24(\mathrm{~m}, 3 \mathrm{H}), 7.11(\mathrm{~d}, \mathrm{~J}=7.2,1 \mathrm{H}), 7.04(\mathrm{~d}, \mathrm{br}, \mathrm{J}=$ 8.4, 1H), $3.17(\mathrm{~m}, 1 \mathrm{H}), 1.23(\mathrm{dd}, 3 \mathrm{JHP}, 3 \mathrm{JHH}=16.0,6.8,3 \mathrm{H}), 1.01(\mathrm{dd}, 3 \mathrm{JHP}, 3 \mathrm{JHH}=16.8,6.8,3 \mathrm{H})$. 13C $\{1 \mathrm{H}\}$ NMR (101 MHz): 142.3-121.5 (C, CH, Ar), $21.3(\mathrm{~d}, 1 \mathrm{JCP}=36.0, \mathrm{CH}), 17.3(\mathrm{~d}, 2 \mathrm{JCP}=1.6$, CH3), $17.1(\mathrm{~d}, 2 \mathrm{JCP}=2.5, \mathrm{CH} 3) .31 \mathrm{P}\{1 \mathrm{H}\} \mathrm{NMR}(121 \mathrm{MHz}):+29.7(\mathrm{~d}, \mathrm{br}, \mathrm{J} \approx 50)$. HRMS: calcd for C21H26BNPS ([M] + NH4), 366.1617; found, 366.1622. [ $\alpha] \mathrm{D}=+40.4^{\circ}$. as that used to prepare 4-DBT-Fc. Starting from ferrocene $(1.31 \mathrm{~g}, 7.0 \mathrm{mmol})$ and 3-DBT $(1.18 \mathrm{~g}, 3.5$ $\mathrm{mmol})$ the desired phosphine-borane was obtained as an orange solid. Yield: $1.36 \mathrm{~g} \mathrm{(79 \% ).}$ 1H NMR (400 MHz): 8.26 (d, J = 7.6, 1H), 8.14 (dd, J = 6.4, 2.4, 1H), 7.76-7.67 (m, 4H), 7.56-7.39 (m, $6 \mathrm{H}), 4.75$ (s, br, 1H), $4.56(\mathrm{~s}, \mathrm{br}, 2 \mathrm{H}), 4.43$ (s, br, 1H), 4.08 (s, br, 5H). 13C $\{1 \mathrm{H}\}$ NMR $(101 \mathrm{MHz})$ : 139.9-121.5 (C, CH, Ar), 74.1 (d, JCP = 12.4, CH), 72.8 (d, JCP = 7.9, CH), $72.1(\mathrm{~d}, \mathrm{JCP}=7.3, \mathrm{CH})$, $71.9(\mathrm{~d}, \mathrm{JCP}=8.4, \mathrm{CH}), 69.9(\mathrm{~s}, 5 \mathrm{CH}), 67.8(\mathrm{~d}, \mathrm{JCP}=69.7, \mathrm{C}) .31 \mathrm{P}\{1 \mathrm{H}\} \mathrm{NMR}(162 \mathrm{MHz}):+18.9(\mathrm{~s}$, br). HRMS: calcd for C28H22FePS ([M] + H - BH3), 477.0529; found, 477.0537. $[\alpha] \mathrm{D}=-98.2^{\circ}$. 
4-TA-Me, (S)-methylphenyl(1-thianthrenyl)phosphineborane. The procedure was the same as that used to prepare 4-DBF-Me. Starting from 3-TA (200 mg, $0.5 \mathrm{mmol})$ and $1.6 \mathrm{M} \mathrm{MeLi}$ solution $(0.7 \mathrm{~mL}, 1.1$ $\mathrm{mmol})$ the desired phosphineborane was obtained as a white pasty solid. Yield: $166 \mathrm{mg}(87 \%)$. 1H NMR (400 MHz): 7.94 (ddd, $\mathrm{J}=12.8,8.0,1.6,1 \mathrm{H}), 7.71(\mathrm{dt}, \mathrm{J}=7.6,1.6,1 \mathrm{H}), 7.57(\mathrm{dt}, \mathrm{J}=11.2$, 1.6, 1H), $7.55(\mathrm{dd}, \mathrm{J}=11.2,1.6,4 \mathrm{H}), 7.44-7.36(\mathrm{~m}, 2 \mathrm{H}), 7.23(\mathrm{~m}, 1 \mathrm{H}), 7.16(\mathrm{td}, \mathrm{J}=7.6,1.2,1 \mathrm{H}), 7.06$ $(\mathrm{dd}, \mathrm{J}=7.6,1.6,1 \mathrm{H}), 2.09(\mathrm{~d}, 2 \mathrm{JHP}=10.0,3 \mathrm{H}) .13 \mathrm{C}\{1 \mathrm{H}\} \mathrm{NMR}(101 \mathrm{MHz}): 140.7-126.3(\mathrm{C}, \mathrm{CH}, \mathrm{Ar})$, $11.8(\mathrm{~d}, 1 \mathrm{JCP}=40.5, \mathrm{CH} 3) .31 \mathrm{P}\{1 \mathrm{H}\}$ NMR $(162 \mathrm{MHz}):+15.9(\mathrm{~d}, \mathrm{br}, \mathrm{J} \approx 51)$. HRMS: calcd for

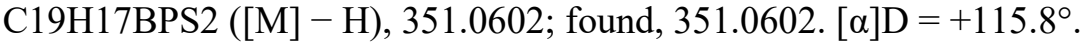
L1 (5-DBF-OMe), (R)-(4-dibenzofuranyl)methoxyphenylphosphine. Phosphinite-borane 3-DBF (240 $\mathrm{mg}, 0.72 \mathrm{mmol}$ ) was dissolved in $5 \mathrm{~mL}$ of morpholine and the solution was stirred at $40{ }^{\circ} \mathrm{C}$ for $14 \mathrm{~h}$. Morpholine was removed under vacuum and the gummy residue was purified by column chromatography (A12O3, toluene) to yield the title product as a dense, colourless oil. Yield: $190 \mathrm{mg}$ $(81 \%)$.

1H NMR (400 MHz): 7.98-7.93 (m, 3H), $7.64(\mathrm{td}, \mathrm{J}=8.0,2.0,1 \mathrm{H}), 7.58(\mathrm{~d}, \mathrm{~J}=8.0,1 \mathrm{H}), 7.53(\mathrm{~m}, 1 \mathrm{H})$, 7.49-7.42 (m, 2H), 7.40-7.31 (m, 4H), $3.80(\mathrm{~d}, 3 \mathrm{JHP}=14.0,3 \mathrm{H}) .13 \mathrm{C}\{1 \mathrm{H}\}$ NMR (101 MHz): 156.2111.0 (C, CH, Ar), 57.3 (d, 2JCP = 20.6, CH3). 31P $\{1 \mathrm{H}\}$ NMR (121 MHz): +106.8 (s). L2 (5-DBT-OMe), (R)-(4-dibenzothiophenyl)methoxyphenylphosphine. The procedure was the same as that used to prepare 5-DBF-OMe. Starting from 3-DBT $(328 \mathrm{mg}, 0.98 \mathrm{mmol})$ the desired phosphineborane was obtained as a colourless oil. Yield: $220 \mathrm{mg}(70 \%)$. 1H NMR (400 MHz): 8.19-8.13 (m, 3H), 7.88-7.83 (m, 2H), 7.65-7.57 (m, 2H), 7.53-7.43 (m, 3H), 7.37-7.34 (m, 2H), $3.78(\mathrm{~d}, 3 \mathrm{JHP}=14.0,3 \mathrm{H}) .13 \mathrm{C}\{1 \mathrm{H}\}$ NMR $(101 \mathrm{MHz}): 139.4-121.5(\mathrm{C}, \mathrm{CH}, \mathrm{Ar})$, $57.2(\mathrm{~d}, 2 \mathrm{JCP}=20.0, \mathrm{CH} 3) .31 \mathrm{P}\{1 \mathrm{H}\} \mathrm{NMR}(162 \mathrm{MHz}):+114.2(\mathrm{~s})$. L3 (5-TA-OMe), (R)-Methoxyphenyl(1-thianthrenyl)phosphine. The procedure was the same as that used to prepare 5-DBF-OMe. Starting from 3-TA $(630 \mathrm{mg}, 1.71 \mathrm{mmol})$ the desired phosphine-borane was obtained as a colourless oil. Yield: $510 \mathrm{mg}(84 \%)$. 1H NMR (400 MHz): 7.61-7.41 (m, 5H), 7.38-7.30 (m, 4H), 7.26-7.17 (m, 2H), $3.71(\mathrm{~d}, 3 \mathrm{JHP}=14.0$, 3H). 13C $\{1 \mathrm{H}\}$ NMR (101 MHz): 142.3-127.4 (C, CH, Ar), 57.1 (d, 2JCP = 21.8, CH3). 31P $\{1 \mathrm{H}\} \mathrm{NMR}$ (162 MHz): +104.4 (s).

L4 (5-DBTO2-OMe), (R)-(4-dibenzothiophenyl-S,S-dioxide) methoxyphenylphosphine. The procedure was the same as that used to prepare 5-DBF-OMe. Starting from 3-DBTO2 (200 mg, $0.54 \mathrm{mmol})$ the desired phosphine-borane was obtained as a white solid. Yield: $150 \mathrm{mg}(78 \%)$. 1H NMR (400 MHz): 7.82 (dq, J = 7.6, 0.4, 1H), 7.75-7.63 (m, 5H), 7.59 (tt, J = 8.0, 0.8, 1H), 7.56$7.47(\mathrm{~m}, 2 \mathrm{H}), 7.41-7.30(\mathrm{~m}, 3 \mathrm{H}), 3.78(\mathrm{~d}, 3 \mathrm{JHP}=14.4,3 \mathrm{H}) .13 \mathrm{C}\{1 \mathrm{H}\}$ NMR $(101 \mathrm{MHz}): 141.1-121.4$ (C, $\mathrm{CH}, \mathrm{Ar}), 57.2(\mathrm{~d}, 2 \mathrm{JCP}=21.9, \mathrm{CH} 3) .31 \mathrm{P}\{1 \mathrm{H}\} \mathrm{NMR}(162 \mathrm{MHz}):+101.4(\mathrm{~s})$. L5 (5-DBF-Me), (S)-(4-dibenzofuranyl)methylphenylphosphine. The procedure was the same as that used to prepare 5-DBF-OMe. Starting from 4-DBF-Me $(500 \mathrm{mg}, 1.56 \mathrm{mmol})$ the desired phosphine- 
1H NMR (300 MHz): 8.00-7.92 (m, 2H), 7.62-7.54 (m, 3H), 7.51-7.43 (m, 2H), 7.40-7.30 (m, 5H), $1.86(\mathrm{~d}, 2 \mathrm{JHP}=3.9,3 \mathrm{H}) .13 \mathrm{C}\{1 \mathrm{H}\} \mathrm{NMR}(101 \mathrm{MHz}): 158.0-111.6(\mathrm{C}, \mathrm{CH}, \mathrm{Ar}), 11.1(\mathrm{~d}, 1 \mathrm{JCP}=12.8$, CH3). 31P $\{1 \mathrm{H}\}$ NMR (121 MHz): -37.0 (s) L6 (5-DBF-iPr), (S)-(4-dibenzofuranyl)isopropylphenylphosphine. The procedure was the same as that used to prepare 5-DBF-OMe. Starting from 4-DBF-iPr $(185 \mathrm{mg}, 0.56 \mathrm{mmol})$ the desired phosphineborane was obtained as a colourless oil. Yield: $120 \mathrm{mg}(68 \%)$.

576 1H NMR (300 MHz): 7.94 (d, J = 7.5, 2H), 7.67-7.52 (m, 4H), 7.45 (td, J = 7.2, 1.2, 1H), 7.37-7.29 (m, $5 \mathrm{H}), 2.91(\mathrm{dd}, \mathrm{J}=7.2,6.9,1 \mathrm{H}), 1.16(\mathrm{dd}, \mathrm{J}=13.2,6.9,3 \mathrm{H}), 1.11(\mathrm{dd}, \mathrm{J}=13.2,6.9,3 \mathrm{H}) .13 \mathrm{C}\{1 \mathrm{H}\} \mathrm{NMR}$ (101 MHz): 159.7-110.0 (C, CH, Ar), 22.4 (d, 1JCP = 6.7, CH), 19.9 (d, 2JCP = 7.1, CH3), 19.7 (d, $2 \mathrm{JCP}=8.8, \mathrm{CH} 3) .31 \mathrm{P}\{1 \mathrm{H}\} \mathrm{NMR}(121 \mathrm{MHz}):-10.7(\mathrm{~s})$. L7 (5-DBF-tBu), (S)-(tert-butyl)(4-dibenzofuranyl)phenylphosphine. The procedure was the same as that used to prepare 5-DBF-OMe. Starting from 4-DBF-tBu $(600 \mathrm{mg}, 1.73 \mathrm{mmol})$ the desired phosphine-borane was obtained as a colourless oil. Yield: $488 \mathrm{mg}(85 \%)$. 1H NMR (300 MHz): 7.97 (dd, J = 7.5, 1.2, 1H), 7.95 (ddd, J = 7.8, 1.5, 0.8, 1H), 7.68-7.57 (m, 4H), $7.44(\mathrm{td}, \mathrm{J}=7.2,1.5,1 \mathrm{H}), 7.38-7.30(\mathrm{~m}, 5 \mathrm{H}), 1.28(\mathrm{~d}, 3 \mathrm{JHP}=13.2,9 \mathrm{H}) .31 \mathrm{P}\{1 \mathrm{H}\} \mathrm{NMR}(121 \mathrm{MHz})$ : $+0.6(\mathrm{~s})$.

L8 (5-DBF-Fc), (S)-(4-dibenzofuranyl)ferrocenylphenylphosphine. The procedure was the same as that used to prepare 5-DBF-OMe. Starting from 4-DBF-Fc $(600 \mathrm{mg}, 1.26 \mathrm{mmol})$ the desired phosphineborane was obtained as an orange solid. Yield: $490 \mathrm{mg}(84 \%)$.

589 1H NMR (400 MHz): 7.95 (dq, J = 7.6, 0.8 1H), 7.94 (ddd, J = 7.6, 1.2, 0.4, 1H), 7.57 (d, J = 8.0, 1H), 7.48-7.41 (m, 3H), 7.35-7.29 (m, 4H), 7.27 (d, J = 7.2, 1H), 7.15 (m, 1H), 4.39 (m, 2H), 4.18 (m, 1H), $4.15(\mathrm{~m}, 1 \mathrm{H}), 4.08(\mathrm{~m}, 5 \mathrm{H}) .13 \mathrm{C}\{1 \mathrm{H}\}$ NMR (101 MHz): 156.0-111.6 (C, CH, Ar), 73.1 (d, JCP = 15.0, $\mathrm{CH}), 73.0(\mathrm{~d}, \mathrm{JCP}=15.4, \mathrm{CH}), 70.9(\mathrm{~d}, \mathrm{JCP}=4.0, \mathrm{CH}), 70.7(\mathrm{~d}, \mathrm{JCP}=4.0, \mathrm{CH}), 69.1(\mathrm{~s}, 5 \mathrm{CH}), 67.9(\mathrm{~s}$, C). $31 \mathrm{P}\{1 \mathrm{H}\} \operatorname{NMR}(162 \mathrm{MHz}):-32.1(\mathrm{~s})$.

L9 (5-DBF-DBT), (S)-(4-dibenzofuranyl)(4-dibenzothiophenyl) phenylphosphine. Dibenzothiophene (210 mg, $1.1 \mathrm{mmol}$ ) was dissolved in $20 \mathrm{~mL}$ of THF in a Schlenk flask. The solution was cooled to -78 ${ }^{\circ} \mathrm{C}$ and then 1.6 M n-BuLi solution in hexanes $(0.7 \mathrm{~mL}, 1.1 \mathrm{mmol})$ was added using a syringe. The resulting brown solution was removed from the cold bath, left stirring at $0{ }^{\circ} \mathrm{C}$ for $5 \mathrm{~h}$ and recooled to $-78^{\circ} \mathrm{C}$. At the same time phosphinite-borane 5-DBF-OMe (350 mg, $\left.1.1 \mathrm{mmol}\right)$ was dissolved in $20 \mathrm{~mL}$ of THF and the solution was cooled down to $-78^{\circ} \mathrm{C}$. The content of the first flask was slowly transferred to the second Schlenk flask via cannula and the resulting mixture was stirred for $14 \mathrm{~h}$. Around $20 \mathrm{~mL}$ of deoxygenated water were added to the brown-yellow solution and THF was atmosphere and the combined organic phases were washed with deoxygenated water and dried with anhydrous sodium sulfate. The suspension was filtered under nitrogen and the solvent was evaporated to dryness, leaving a white pasty solid. $10 \mathrm{~mL}$ of morpholine were added and the solution was stirred at 
$40^{\circ} \mathrm{C}$ for $14 \mathrm{~h}$. Morpholine was removed under vacuum and the gummy residue was purified by column chromatography (A12O3, toluene) to yield the title product as a pale brown solid. Yield: $307 \mathrm{mg}(61 \%)$. 1H NMR (400.1 MHz): 8.17 (m, 2H), 7.96 (m, 2H), 7.86 (m, 1H), $7.58(\mathrm{~d}, \mathrm{~J}=8.4,1 \mathrm{H}), 7.46$ (m, 7H), $7.35(\mathrm{~m}, 3 \mathrm{H}), 7.27(\mathrm{t}, \mathrm{J}=7.6,1 \mathrm{H}), 7.10(\mathrm{~m}, 1 \mathrm{H}), 7.02(\mathrm{~m}, 1 \mathrm{H}) .31 \mathrm{P}\{1 \mathrm{H}\}$ NMR $(162 \mathrm{MHz}):-23.1(\mathrm{~s})$. HRMS: calcd for C30H20OPS ([M] + H), 459.0972; found, 459.0975.

L10 (5-DBT-Me), (S)-(4-dibenzothiophenyl)methylphenylphosphine. The procedure was the same as that used to prepare 5-DBF-OMe. Starting from 4-DBT-Me $(450 \mathrm{mg}, 1.41 \mathrm{mmol})$ the desired phosphineborane was obtained as a colourless oil. Yield: $380 \mathrm{mg}(88 \%)$.

1H NMR (400 MHz): 8.17-8.13 (m, 2H), 7.84 (m, 1H), 7.51-7.42 (m, 6H), 7.35-7.31 (m, 3H), 1.78 (d, $2 \mathrm{JHP}=3.2,3 \mathrm{H}) .13 \mathrm{C}\{1 \mathrm{H}\} \mathrm{NMR}(101 \mathrm{MHz}): 145.0-121.5(\mathrm{C}, \mathrm{CH}, \mathrm{Ar}), 11.2(\mathrm{~d}, 1 \mathrm{JCP}=13.1, \mathrm{CH} 3)$. $31 \mathrm{P}\{1 \mathrm{H}\}$ NMR (162 MHz): -30.6 (s).

L11 (5-DBT-iPr), (S)-(4-dibenzothiophenyl)isopropylphenylphosphine. The procedure was the same as that used to prepare 5-DBF-OMe. Starting from 4-DBT-iPr (490 mg, $1.41 \mathrm{mmol}$ ) the desired phosphineborane was obtained as a colourless oil. Yield: $400 \mathrm{mg}(85 \%)$.

1H NMR (400 MHz): 8.19-8.10 (m, 3H), 7.85 (m, 1H), 7.61-7.55 (m, 2H), 7.52-7.41 (m, 4H), 7.33$7.29(\mathrm{~m}, 2 \mathrm{H}), 2.70(\mathrm{~m}, 1 \mathrm{H}), 1.18(\mathrm{dd}, 3 \mathrm{JHP}, 3 \mathrm{JHH}=6.8,2.4,3 \mathrm{H}), 1.14(\mathrm{dd}, 3 \mathrm{JHP}, 3 \mathrm{JHH}=6.8,2.4$, 3H). 13C $\{1 \mathrm{H}\} \mathrm{NMR}(101 \mathrm{MHz}): 147.2-121.5(\mathrm{C}, \mathrm{CH}, \mathrm{Ar}), 25.0(\mathrm{~d}, 1 \mathrm{JCP}=7.7, \mathrm{CH}), 19.8(\mathrm{~d}, 2 \mathrm{JCP}=$ 6.7, $\mathrm{CH} 3), 19.6(\mathrm{~d}, 2 \mathrm{JCP}=7.8, \mathrm{CH} 3) .31 \mathrm{P}\{1 \mathrm{H}\} \mathrm{NMR}(162 \mathrm{MHz}):-5.1(\mathrm{~s})$.

L12 (5-DBT-Fc), (S)-(4-dibenzothiophenyl)ferrocenylphenylphosphine. The procedure was the same as that used to prepare 5-DBF-OMe. Starting from 4-DBT-Fc (350 mg, $0.71 \mathrm{mmol})$ the desired phosphineborane was obtained as an orange solid. Yield: $300 \mathrm{mg}(89 \%)$.

1H NMR (400 MHz): 8.14 (d, J = 4.4, 1H), $8.11(\mathrm{~d}, \mathrm{~J}=7.2,1 \mathrm{H}), 7.80(\mathrm{t}, \mathrm{J}=4.8,1 \mathrm{H}), 7.54-7.48(\mathrm{~m}$, 2H), 7.45-7.38 (m, 3H), 7.35-7.30 (m, 3H), $7.22(\mathrm{~m}, 1 \mathrm{H}), 4.45$ (s, br, 1H), 4.41 (s, br, 1H), 4.38 (s, br, 1H), 4.09 (s, br, 5H), 4.06 (s, br, 1H). 13C $\{1 \mathrm{H}\}$ NMR (101 MHz): 144.6-121.6 (C, CH, Ar), $74.2(\mathrm{~d}$, $\mathrm{JCP}=4.2, \mathrm{C}), 73.9(\mathrm{~d}, \mathrm{JCP}=23.2, \mathrm{CH}), 72.4(\mathrm{~d}, \mathrm{JCP}=6.8, \mathrm{CH}), 71.2(\mathrm{~d}, \mathrm{JCP}=5.9, \mathrm{CH}), 70.7(\mathrm{~d}, \mathrm{JCP}$ $=2.4, \mathrm{CH}), 69.2(\mathrm{~s}, 5 \mathrm{CH}) .31 \mathrm{P}\{1 \mathrm{H}\} \mathrm{NMR}(162 \mathrm{MHz}):-20.5(\mathrm{~s})$.

L13 (5-TA-Me), (S)-methylphenyl(1-thianthrenyl)phosphine. The procedure was the same as that used to prepare 5-DBF-OMe. Starting from 4-TA-Me $(350 \mathrm{mg}, 0.99 \mathrm{mmol})$ the desired phosphine-borane was obtained as colourless, dense oil. Yield: $280 \mathrm{mg}(83 \%)$.

1H NMR (400 MHz): 7.50-7.41 (m, 4H), 7.36-7.33 (m, 3H), 7.26-7.18 (m, 4H), 7.15 (ddd, J = 7.6, 4.4, 1.2, 1H), $1.65(\mathrm{~d}, 2 \mathrm{JHP}=4.8,3 \mathrm{H}) .13 \mathrm{C}\{1 \mathrm{H}\} \mathrm{NMR}(101 \mathrm{MHz}): 140.8-126.6(\mathrm{C}, \mathrm{CH}, \mathrm{Ar}), 12.3(\mathrm{~d}, 1 \mathrm{JCP}$ $=14.6, \mathrm{CH} 3) .31 \mathrm{P}\{1 \mathrm{H}\}$ NMR $(162 \mathrm{MHz}):-32.1(\mathrm{~s})$.

\section{Synthesis of the Ru complexes}

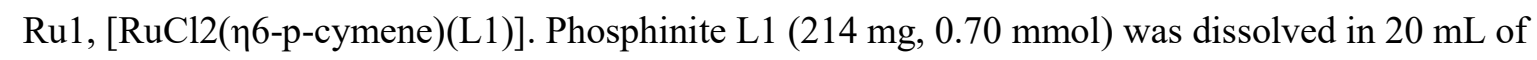
dichloromethane, Ru dimer D1 (150 mg, $0.25 \mathrm{mmol}$ ) was added and the dark red solution was stirred for 
$1 \mathrm{~h}$. The solvent was removed under vacuum and the residue was recrystallised in dichloromethane/hexane to furnish the title product as a dark red solid. Yield: $246 \mathrm{mg}(80 \%)$. IR: $3051,2958,2869,1580,1469,1450,1400,1185,1109,1032,845,804,757,696,562$. 1H NMR (400 MHz): 8.37 (ddd, J = 11.2, 7.6, 1.2, 1H), 8.05-8.00 (m, 3H), 7.93 (dt, J = 7.6, 1.2, 1H), 7.43-7.32 $(\mathrm{m}, 7 \mathrm{H}), 5.41(\mathrm{~d}, \mathrm{~J}=6.6,1 \mathrm{H}), 5.37(\mathrm{~d}, \mathrm{~J}=6.0,1 \mathrm{H}), 5.33(\mathrm{~d}, \mathrm{~J}=6.0,1 \mathrm{H}), 5.05(\mathrm{~d}, \mathrm{~J}=6.0,1 \mathrm{H}), 3.63(\mathrm{~d}$, $3 \mathrm{JHP}=12.0,3 \mathrm{H}), 2.72(\mathrm{sept}, 3 \mathrm{JHH}=6.8,1 \mathrm{H}), 1.97(\mathrm{~s}, 3 \mathrm{H}), 1.01(\mathrm{~d}, 3 \mathrm{JHH}=6.8,3 \mathrm{H}), 0.88(\mathrm{~d}, 3 \mathrm{JHH}=$ 6.8, 3H). 13C $\{1 \mathrm{H}\}$ NMR (101 MHz): 155.6-111.6 (C, CH, Ar), $110.9(\mathrm{~d}, 2 \mathrm{JCP}=1.7, \mathrm{C}), 96.5(\mathrm{~s}, \mathrm{C})$, $92.6(\mathrm{~d}, 2 \mathrm{JCP}=5.6, \mathrm{CH}), 90.3(\mathrm{~d}, 2 \mathrm{JCP}=3.9, \mathrm{CH}), 88.3(\mathrm{~d}, 2 \mathrm{JCP}=7.2, \mathrm{CH}), 86.5(\mathrm{~d}, 2 \mathrm{JCP}=5.6, \mathrm{CH})$, $55.1(\mathrm{~d}, 2 \mathrm{JCP}=5.1, \mathrm{CH} 3), 30.0(\mathrm{~s}, \mathrm{CH}), 21.8(\mathrm{~s}, \mathrm{CH} 3), 21.0(\mathrm{~s}, \mathrm{CH} 3), 17.6(\mathrm{~s}, \mathrm{CH} 3) .31 \mathrm{P}\{1 \mathrm{H}\} \mathrm{NMR}$ (121 MHz): +112.7 (s). Anal.: calcd for C29H29Cl2O2PRu, C 56.87\%, H 4.77\%; found, C 57.29\%, H 652 $5.03 \%$.

653

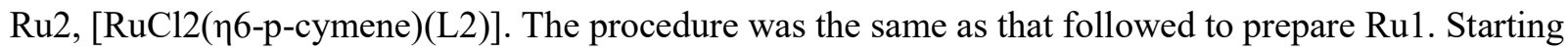
654 from L2 (220 mg, $0.68 \mathrm{mmol}$ ) and Ru dimer D1 (149 mg, $0.24 \mathrm{mmol}$ ), the desired complex was obtained as a dark red solid. Yield: 217 mg (72\%). IR: 3053, 2958, 2870, 1439, 1375, 1103, 1028, 756, 656 $695,554$.

1H NMR (300 MHz): 8.34 (ddd, J = 13.2, 7.5, 0.9, 1H), $8.23(\mathrm{dt}, \mathrm{J}=8.0,1.5,1 \mathrm{H}), 8.18-8.14(\mathrm{~m}, 1 \mathrm{H})$, 658 7.99-7.93 (m, 2H), 7.84-7.81 (m, 1H), 7.53-7.45 (m, 3H), 7.39-7.32 (m, 3H), $5.44(\mathrm{~d}, \mathrm{~J}=6.0,1 \mathrm{H})$, $5.36(\mathrm{~d}, \mathrm{~J}=6.9,1 \mathrm{H}), 5.33(\mathrm{~d}, \mathrm{~J}=7.8,1 \mathrm{H}), 5.24(\mathrm{~d}, \mathrm{~J}=6.0,1 \mathrm{H}), 3.70(\mathrm{~d}, 3 \mathrm{JHP}=11.7,3 \mathrm{H}), 2.70$ (sept, $3 \mathrm{JHH}=7.2,1 \mathrm{H}), 1.89(\mathrm{~s}, 3 \mathrm{H}), 1.02(\mathrm{~d}, 3 \mathrm{JHH}=6.9,3 \mathrm{H}), 1.00(\mathrm{~d}, 3 \mathrm{JHH}=6.9,3 \mathrm{H}) .13 \mathrm{C}\{1 \mathrm{H}\} \mathrm{NMR}$ 661 (101 MHz): 140.0-121.4 (C, CH, Ar), $111.6(\mathrm{~d}, 2 \mathrm{JCP}=1.1, \mathrm{C}), 96.9(\mathrm{~s}, \mathrm{C}), 91.7(\mathrm{~d}, 2 \mathrm{JCP}=4.1, \mathrm{CH})$, $91.4(\mathrm{~d}, 2 \mathrm{JCP}=4.6, \mathrm{CH}), 87.5(\mathrm{~d}, 2 \mathrm{JCP}=6.6, \mathrm{CH}), 87.2(\mathrm{~d}, 2 \mathrm{JCP}=5.9, \mathrm{CH}), 54.6(\mathrm{~d}, 2 \mathrm{JCP}=3.6$, 663 CH3), 30.1 (s, CH), 21.7 (s, CH3), 21.5 (s, CH3), 17.5 (s, CH3). 31P\{1H\} NMR (121 MHz): +118.3 (s). Anal.: calcd for C29H29C12OPRuS, C 55.42\%, H 4.65\%, S 5.10\%; found, C 55.97\%, H 5.01\%, S 665 $4.89 \%$.

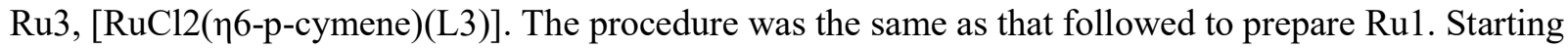
from L3 (270 mg, $0.76 \mathrm{mmol})$ and Ru dimer D1 (186 mg, $0.30 \mathrm{mmol})$, the desired complex was obtained as a dark red solid. Yield: $217 \mathrm{mg}(55 \%)$.

IR: 3052, 2959, 2869, 1470, 1448, 1435, 1378, 1109, 1029, 752, 694, 550. 1H NMR (400 MHz): 8.30 $(\mathrm{dd}, \mathrm{J}=11.6,7.6,1 \mathrm{H}), 7.84(\mathrm{t}, \mathrm{J}=9.2,2 \mathrm{H}), 7.64(\mathrm{~d}, \mathrm{~J}=7.6,1 \mathrm{H}), 7.46-7.34(\mathrm{~m}, 5 \mathrm{H}), 7.21(\mathrm{td}, \mathrm{J}=7.2$, $1.2,1 \mathrm{H}), 7.11(\mathrm{td}, \mathrm{J}=7.6,1.2,1 \mathrm{H}), 7.00(\mathrm{dd}, \mathrm{J}=7.6,1.2,1 \mathrm{H}), 5.41(\mathrm{~d}, \mathrm{~J}=6.4,1 \mathrm{H}), 5.31(\mathrm{~d}, \mathrm{~J}=6.0$, $1 \mathrm{H}), 5.27(\mathrm{~d}, \mathrm{~J}=6.0,1 \mathrm{H}), 5.18(\mathrm{~d}, \mathrm{~J}=5.6,1 \mathrm{H}), 3.61(\mathrm{~d}, 3 \mathrm{JHP}=11.6,3 \mathrm{H}), 2.63(\mathrm{sept}, 3 \mathrm{JHH}=6.8,1 \mathrm{H})$, $1.93(\mathrm{~s}, 3 \mathrm{H}), 0.92(\mathrm{~d}, 3 \mathrm{JHH}=7.2,3 \mathrm{H}), 0.86(\mathrm{~d}, 3 \mathrm{JHH}=7.2,3 \mathrm{H}) .31 \mathrm{P}\{1 \mathrm{H}\} \mathrm{NMR}(162 \mathrm{MHz}):+110.2$ (s). HRMS: calcd for C29H29ClOPRuS2 ([M] - Cl), 625.0123; found, 625.0126.

$675 \mathrm{Ru} 4,[\mathrm{RuCl} 2(\eta 6-\mathrm{p}-\mathrm{cymene})(\mathrm{L} 4)]$. The procedure was the same as that followed to prepare Ru1. Starting 676 from L4 (70 mg, $0.20 \mathrm{mmol}$ ) and Ru dimer D1 (48 mg, $0.08 \mathrm{mmol})$, the desired complex was obtained 677 as a dark red solid. Yield: $70 \mathrm{mg}(68 \%)$. 
IR: 3060, 2959, 2869, 1446, 1436, 1387, 1308, 1154, 1095, 1045, 815, 764, 721, 701, 584, 568, 468. $1 \mathrm{H}$ NMR (400 MHz): 8.13 (tt, J = 8.4, 1.6, 2H), 7.98 (ddd, J = 13.2, 7.6, 0.8, 1H), $7.91(\mathrm{~d}, \mathrm{~J}=6.8,1 \mathrm{H}), 7.86$ $(\mathrm{t}, \mathrm{J}=7.6,2 \mathrm{H}), 7.71(\mathrm{td}, \mathrm{J}=7.6,1.2,1 \mathrm{H}), 7.64(\mathrm{td}, \mathrm{J}=7.6,0.8,1 \mathrm{H}), 7.52(\mathrm{td}, \mathrm{J}=7.6,2.0,1 \mathrm{H}), 7.37-$ $7.27(\mathrm{~m}, 3 \mathrm{H}), 5.68(\mathrm{~d}, \mathrm{~J}=6.0,1 \mathrm{H}), 5.62(\mathrm{dd}, \mathrm{J}=6.4,1.2,1 \mathrm{H}), 5.50(\mathrm{~d}, \mathrm{~J}=6.0,1 \mathrm{H}), 5.31(\mathrm{~d}, \mathrm{~J}=6.0$, $1 \mathrm{H}), 3.72(\mathrm{~d}, 3 \mathrm{JHP}=11.6,3 \mathrm{H}), 2.72(\mathrm{sept}, 3 \mathrm{JHH}=6.8,1 \mathrm{H}), 1.87(\mathrm{~s}, 3 \mathrm{H}), 1.17(\mathrm{~d}, 3 \mathrm{JHH}=6.8,3 \mathrm{H})$, $0.97(\mathrm{~d}, 3 \mathrm{JHH}=6.8,3 \mathrm{H}) .13 \mathrm{C}\{1 \mathrm{H}\} \mathrm{NMR}(101 \mathrm{MHz}): 141.9-121.2(\mathrm{C}, \mathrm{CH}, \mathrm{Ar}), 112.1(\mathrm{~s}, \mathrm{C}), 97.4(\mathrm{~s}$, C), $93.8(\mathrm{~d}, 2 \mathrm{JCP}=5.4, \mathrm{CH}), 90.9(\mathrm{~d}, 2 \mathrm{JCP}=3.8, \mathrm{CH}), 87.6(\mathrm{~d}, 2 \mathrm{JCP}=6.3, \mathrm{CH}), 86.7(\mathrm{~d}, 2 \mathrm{JCP}=5.9$, $\mathrm{CH}), 54.2(\mathrm{~d}, 2 \mathrm{JCP}=4.0, \mathrm{CH} 3), 30.1(\mathrm{~s}, \mathrm{CH}), 22.3(\mathrm{~s}, \mathrm{CH} 3), 21.1(\mathrm{~s}, \mathrm{CH} 3), 17.5(\mathrm{~s}, \mathrm{CH} 3) .31 \mathrm{P}\{1 \mathrm{H}\}$ NMR (162 MHz): +117.0 (s). Anal.: calcd for C29H29Cl2O3PRuS, C 52.73\%, H 4.42\%, S 4.85\%; found, C $51.15 \%$, H $4.51 \%$, S $4.42 \%$.

$\mathrm{Ru} 5,[\mathrm{RuCl} 2(\eta 6-\mathrm{p}-\mathrm{cymene})(\mathrm{L} 5)]$. The procedure was the same as that followed to prepare Ru1. Starting from L5 (185 mg, $0.64 \mathrm{mmol}$ ) and Ru dimer D1 (162 mg, $0.26 \mathrm{mmol}$ ), the desired complex was obtained as a dark red solid. Yield: $201 \mathrm{mg}(65 \%)$.

IR: 3049, 2958, 2919, 2868, 1583, 1469, 1449, 1399, 1185, 1109, 1057, 898, 843, 802, 755, 725, 696, 556, 424. 1H NMR (300 MHz): $8.11(\mathrm{dt}, \mathrm{J}=7.8,1.2,1 \mathrm{H}), 8.04-8.00(\mathrm{~m}, 1 \mathrm{H}), 7.96(\mathrm{ddd}, \mathrm{J}=7.8,1.5$, 0.9, 1H), 7.89 (ddd, $\mathrm{J}=11.1,7.8,1.2,1 \mathrm{H}), 7.78-7.71(\mathrm{~m}, 2 \mathrm{H}), 7.59-7.56(\mathrm{~m}, 1 \mathrm{H}), 7.52-7.31(\mathrm{~m}, 5 \mathrm{H})$, $5.59(\mathrm{~d}, \mathrm{~J}=6.3,1 \mathrm{H}), 5.49(\mathrm{~d}, \mathrm{~J}=6.3,1 \mathrm{H}), 5.47(\mathrm{~m}, 1 \mathrm{H}), 4.76(\mathrm{~d}, \mathrm{~J}=5.7,1 \mathrm{H}), 2.54($ sept, 3JHH = 6.9, $1 \mathrm{H}), 2.06(\mathrm{~s}, 3 \mathrm{H}), 2.04(\mathrm{~d}, 2 \mathrm{JHP}=11.4,3 \mathrm{H}), 0.90(\mathrm{~d}, 3 \mathrm{JHH}=6.9,3 \mathrm{H}), 0.38(\mathrm{~d}, 3 \mathrm{JHH}=6.9,3 \mathrm{H}) .13 \mathrm{C}$ $\{1 \mathrm{H}\}$ NMR (101 MHz): 156.1-111.6 (C, CH, Ar), 107.8 (s, C), 94.2 (s, C), 93.8 (d, 2JCP = 6.7, CH), $89.6(\mathrm{~d}, 2 \mathrm{JCP}=8.8, \mathrm{CH}), 86.4(\mathrm{~d}, 2 \mathrm{JCP}=2.6, \mathrm{CH}), 81.4(\mathrm{~d}, 2 \mathrm{JCP}=3.2, \mathrm{CH}), 29.8(\mathrm{~s}, \mathrm{CH}), 22.8(\mathrm{~s}$, CH3), 19.1 (s, CH3), 17.5 (s, CH3), 12.1 (d, 1JCP = 37.4, CH3). 31P $\{1 \mathrm{H}\}$ NMR (121 MHz): +15.2 (s). Anal.: calcd for C29H29Cl2OPRu, C 58.39\%, H 4.90\%; found, C 60.59\%, H 5.04\%.

$\mathrm{Ru} 6,[\mathrm{RuCl} 2(\eta 6-\mathrm{p}-\mathrm{cymene})(\mathrm{L} 6)]$. The procedure was the same as that followed to prepare Ru1. Starting from L6 (166 mg, $0.52 \mathrm{mmol}$ ) and Ru dimer D1 (114 mg, $0.19 \mathrm{mmol})$, the desired complex was obtained as a dark red solid. Yield: $145 \mathrm{mg}(62 \%)$.

IR: 3054, 2958, 2925, 2867, 1581, 1469, 1449, 1434, 1398, 1264, 1182, 1109, 1039, 844, 802, 759, 699, 533, 516. 1H NMR (400 MHz): $8.10(\mathrm{dt}, \mathrm{J}=7.6,1.2,1 \mathrm{H}), 8.04(\mathrm{~d}, \mathrm{~J}=8.0,1 \mathrm{H}), 8.01-7.94(\mathrm{~m}, 3 \mathrm{H})$, $7.51-7.38(\mathrm{~m}, 7 \mathrm{H}), 5.23(\mathrm{~d}, \mathrm{~J}=6.0,2 \mathrm{H}), 5.11(\mathrm{~d}, \mathrm{~J}=6.0,1 \mathrm{H}), 4.51(\mathrm{~d}, \mathrm{~J}=5.6,1 \mathrm{H}), 3.71(\mathrm{~m}, 1 \mathrm{H}), 2.66$ $(\mathrm{sept}, 3 \mathrm{JHH}=7.2,1 \mathrm{H}), 1.89(\mathrm{~s}, 3 \mathrm{H}), 1.10(\mathrm{dd}, \mathrm{J}=18.0,7.2,3 \mathrm{H}), 0.97(\mathrm{dd}, \mathrm{J}=14.0,6.8,3 \mathrm{H}), 0.92(\mathrm{~d}$, $3 \mathrm{JHH}=6.8,3 \mathrm{H}), 0.68(\mathrm{~d}, 3 \mathrm{JHH}=6.8,3 \mathrm{H}) .13 \mathrm{C}\{1 \mathrm{H}\} \mathrm{NMR}(101 \mathrm{MHz}): 155.3-111.7(\mathrm{C}, \mathrm{CH}, \mathrm{Ar})$, $109.2(\mathrm{~s}, \mathrm{C}), 93.9(\mathrm{~d}, 2 \mathrm{JCP}=4.5, \mathrm{C}), 93.6(\mathrm{~s}, \mathrm{CH}), 88.9(\mathrm{~d}, 2 \mathrm{JCP}=2.4, \mathrm{CH}), 86.1(\mathrm{~d}, 2 \mathrm{JCP}=7.4, \mathrm{CH})$, $83.4(\mathrm{~d}, 2 \mathrm{JCP}=4.6, \mathrm{CH}), 29.9(\mathrm{~s}, \mathrm{CH}), 26.2(\mathrm{~d}, 1 \mathrm{JCP}=23.5, \mathrm{CH}), 22.3(\mathrm{~s}, \mathrm{CH} 3), 20.3(\mathrm{~s}, \mathrm{CH} 3), 19.1(\mathrm{~d}$, 2JCP = 6.2, CH3), 18.7 (s, CH3), 17.5 (s, CH3). 31P $\{1 \mathrm{H}\}$ NMR (121 MHz): +21.5 (s). Anal.: calcd for C31H33Cl2OPRu, C 59.62\%, H 5.33\%; found, C 59.08\%, H 5.64\%.

$\mathrm{Ru} 8,[\mathrm{RuCl} 2(\eta 6-\mathrm{p}-\mathrm{cymene})(\mathrm{L} 8)]$. The procedure was the same as that followed to prepare Ru1. Starting from L8 (180 mg, $0.39 \mathrm{mmol}$ ) and Ru dimer D1 (96 mg, $0.16 \mathrm{mmol}$ ), the desired complex was obtained as a dark red solid. Yield: $180 \mathrm{mg}(75 \%)$. 
729

730

731

732

733

734

735

736

737

738

739

740

741

742

743

744

745

746

747

748

749

750

IR: 3051, 2957, 2924, 2868, 1624, 1579, 1469, 1449, 1435, 1398, 1306, 1263, 1183, 1158, 1108, 1058, 1028, 1002, 844, 821, 801, 755, 699, 560, 458. 1H NMR (400 MHz): 8.03-8.00 (m, 2H), 7.96 (d, J = 8.0, 1H), $7.93(\mathrm{~d}, \mathrm{~J}=7.2,1 \mathrm{H}), 7.74(\mathrm{dd}, \mathrm{J}=10.8,7.6,1 \mathrm{H}), 7.53-7.47(\mathrm{~m}, 1 \mathrm{H}), 7.46-7.41(\mathrm{~m}, 3 \mathrm{H}), 7.40$ $7.29(\mathrm{~m}, 3 \mathrm{H}), 5.56(\mathrm{~d}, \mathrm{~J}=6.4,1 \mathrm{H}), 5.38(\mathrm{~d}, \mathrm{~J}=6.8,1 \mathrm{H}), 5.37-5.35(\mathrm{~m}, 1 \mathrm{H}), 4.97(\mathrm{~m}, 1 \mathrm{H}), 4.61(\mathrm{~d}, \mathrm{~J}=$ 5.6, 1H), $4.38(\mathrm{~m}, 1 \mathrm{H}), 4.34(\mathrm{~m}, 1 \mathrm{H}), 4.26(\mathrm{~m}, 1 \mathrm{H}), 3.66(\mathrm{~s}, 5 \mathrm{H}), 2.55(\mathrm{sept}, 3 \mathrm{JHH}=6.8,1 \mathrm{H}), 2.03(\mathrm{~s}$, $3 \mathrm{H}), 0.89(\mathrm{~d}, 3 \mathrm{JHH}=7.2,3 \mathrm{H}), 0.33(\mathrm{~d}, 3 \mathrm{JHH}=6.8,3 \mathrm{H}) .13 \mathrm{C}\{1 \mathrm{H}\} \mathrm{NMR}(101 \mathrm{MHz}): 155.0-111.4(\mathrm{C}$, $\mathrm{CH}, \mathrm{Ar}), 109.1(\mathrm{~s}, \mathrm{C}), 94.6(\mathrm{~d}, 2 \mathrm{JCP}=4.4, \mathrm{C}), 93.8(\mathrm{~s}, \mathrm{CH}), 88.9(\mathrm{~d}, 2 \mathrm{JCP}=9.1, \mathrm{CH}), 87.8(\mathrm{~s}, \mathrm{CH}), 81.5$ $(\mathrm{s}, \mathrm{CH}), 78.0(\mathrm{~d}, \mathrm{JCP}=12.1, \mathrm{CH}), 75.0(\mathrm{~d}, 1 \mathrm{JCP}=54.0, \mathrm{C}), 74.3(\mathrm{~d}, 2 \mathrm{JCP}=8.2, \mathrm{CH}), 70.0(\mathrm{~s}, \mathrm{ov}, 6 \mathrm{CH})$, $69.6(\mathrm{~d}, \mathrm{JCP}=8.1, \mathrm{CH}), 29.6(\mathrm{~s}, \mathrm{CH}), 22.6(\mathrm{~s}, \mathrm{CH} 3), 19.0$ (s, CH3), 17.1 (s, CH3). 31P $\{1 \mathrm{H}\} \mathrm{NMR}(162$ $\mathrm{MHz}$ ): +15.8 (s). Anal.: calcd for $\mathrm{C} 38 \mathrm{H} 35 \mathrm{Cl} 2 \mathrm{FeOPRu}, \mathrm{C} 59.55 \%$, H 4.60\%; found, C $59.59 \%$, H $5.00 \%$.

$\mathrm{Ru} 9$, [RuCl2(76-p-cymene)(L9)]. The procedure was the same as that followed to prepare Ru1. Starting from L9 (140 mg, $0.31 \mathrm{mmol}$ ) and Ru dimer D1 (74 mg, $0.12 \mathrm{mmol})$, the desired complex was obtained as a dark red solid. Yield: $101 \mathrm{mg}(55 \%)$.

1H NMR (400 MHz): 8.43 (dd, J = 13.2, 7.6 1H), 8.30-8.22 (m, 3H), 8.16-8.07 (m, 3H), 7.94 (d, J = 6.8, 1H), $7.59(\mathrm{~d}, \mathrm{~J}=6.4,1 \mathrm{H}), 7.55(\mathrm{~d}, \mathrm{~J}=7.6,1 \mathrm{H}), 7.43-7.20(\mathrm{~m}, 9 \mathrm{H}), 5.27(\mathrm{~d}, \mathrm{~J}=6.0,2 \mathrm{H}), 5.20(\mathrm{~d}, \mathrm{~J}$ $=6.0,1 \mathrm{H}), 5.04(\mathrm{~d}, \mathrm{~J}=6.0,1 \mathrm{H}), 2.80(\mathrm{sept}, 3 \mathrm{JHH}=6.8,1 \mathrm{H}), 1.90(\mathrm{~s}, 3 \mathrm{H}), 0.94(\mathrm{~d}, 3 \mathrm{JHH}=6.8,3 \mathrm{H})$, $0.86(\mathrm{~d}, 3 \mathrm{JHH}=6.8,3 \mathrm{H}) .13 \mathrm{C}\{1 \mathrm{H}\} \mathrm{NMR}(101 \mathrm{MHz}): 155.9-120.7(\mathrm{C}, \mathrm{CH}, \mathrm{Ar}), 111.5(\mathrm{~s}, \mathrm{C}), 95.7$ (s, C), $91.1(\mathrm{~d}, 2 \mathrm{JCP}=2.4, \mathrm{CH}), 89.7(\mathrm{~d}, 2 \mathrm{JCP}=3.4, \mathrm{CH}), 86.2(\mathrm{~d}, 2 \mathrm{JCP}=6.5, \mathrm{CH}), 85.8(\mathrm{~d}, 2 \mathrm{JCP}=5.7$, $\mathrm{CH}), 30.0$ (s, CH), 21.6 (s, CH3), 21.3 (s, CH3), 17.6 (s, CH3). 31P $\{1 \mathrm{H}\}$ NMR (162 MHz): +19.8 (s). HRMS: calcd for C40H33ClOPRuS ([M] - Cl), 729.0716; found, 729.0745.

$\mathrm{Ru} 10,[\mathrm{RuCl} 2(\eta 6-\mathrm{p}-\mathrm{cymene})(\mathrm{L} 10)]$. The procedure was the same as that followed to prepare Ru1. Starting from L10 (190 mg, $0.62 \mathrm{mmol})$ and Ru dimer D1 (140 mg, $0.23 \mathrm{mmol})$, the desired complex was obtained as a dark red solid. Yield: $251 \mathrm{mg}(89 \%)$.

IR: 3051, 2958, 2868, 2838, 1438, 1374, 1103, 1027, 817, 755, 694, 554. 1H NMR (400 MHz): 8.28 (dt, $\mathrm{J}=7.6,1.6,1 \mathrm{H}), 8.19(\mathrm{~m}, 1 \mathrm{H}), 8.15(\mathrm{ddd}, \mathrm{J}=12.4,7.6,1.2,1 \mathrm{H}), 7.79-7.74(\mathrm{~m}, 2 \mathrm{H}), 7.70(\mathrm{dd}, \mathrm{J}=7.2$, 2.0,1H), $7.61(\mathrm{td}, \mathrm{J}=7.6,1.6,1 \mathrm{H}), 7.54-7.42(\mathrm{~m}, 5 \mathrm{H}), 5.64(\mathrm{~d}, \mathrm{~J}=5.6,1 \mathrm{H}), 5.57(\mathrm{~d}, \mathrm{~J}=6.0,1 \mathrm{H}), 5.34$ $(\mathrm{d}, \mathrm{J}=6.0,1 \mathrm{H}), 5.17(\mathrm{~d}, \mathrm{~J}=5.6,1 \mathrm{H}), 2.55(\mathrm{sept}, 3 \mathrm{JHH}=7.2,1 \mathrm{H}), 2.08(\mathrm{~d}, 2 \mathrm{JHP}=9.6,3 \mathrm{H}), 2.07(\mathrm{~s}$, $3 \mathrm{H}), 0.83(\mathrm{~d}, 3 \mathrm{JHH}=7.2,3 \mathrm{H}), 0.57(\mathrm{~d}, 3 \mathrm{JHH}=7.2,3 \mathrm{H}) .13 \mathrm{C}\{1 \mathrm{H}\} \mathrm{NMR}(101 \mathrm{MHz}): 140.7-121.7(\mathrm{C}$, $\mathrm{CH}, \mathrm{Ar}), 107.2(\mathrm{~s}, \mathrm{C}), 94.5(\mathrm{~s}, \mathrm{C}), 91.7(\mathrm{~d}, 2 \mathrm{JCP}=5.8, \mathrm{CH}), 88.7(\mathrm{~d}, 2 \mathrm{JCP}=6.9, \mathrm{CH}), 88.1(\mathrm{~d}, 2 \mathrm{JCP}=$ 3.7, CH), 83.1 (d, 2JCP = 4.6, CH), 29.8 (s, CH), 22.0 (s, CH3), 20.0 (s, CH3), 17.5 (s, CH3), 11.2 (d, $1 \mathrm{JCP}=37.1, \mathrm{CH} 3) .31 \mathrm{P}\{1 \mathrm{H}\}$ NMR $(162 \mathrm{MHz}):+22.6$ (s). Anal.: calcd for C29H29Cl2PRuS, C $56.86 \%$, H 4.77\%, S 5.24\%; found, C 56.69\%, H 5.07\%, S 5.26\%.

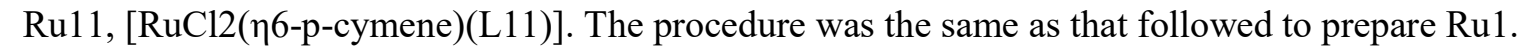
Starting from L11 (400 mg, $1.20 \mathrm{mmol}$ ) and Ru dimer D1 (244 mg, $0.40 \mathrm{mmol}$ ), the desired complex was obtained as a dark red solid. Yield: $405 \mathrm{mg}(79 \%)$. 
IR: 3044, 2959, 2923, 2866, 1467, 1435, 1371, 1102, 1034, 801, 752, 704, 546, 528. 1H NMR (400 MHz): $8.28(\mathrm{~d}, \mathrm{~J}=8.0,1 \mathrm{H}), 8.21(\mathrm{~d}, \mathrm{~J}=9.2,1 \mathrm{H}), 7.99(\mathrm{~m}, \mathrm{br}, 2 \mathrm{H}), 7.78(\mathrm{~m}, 1 \mathrm{H}), 7.62-7.57(\mathrm{~m}, 3 \mathrm{H})$, 7.53-7.47 (m, 4H), $5.42(\mathrm{~d}, \mathrm{~J}=6.0,2 \mathrm{H}), 4.94(\mathrm{~d}, \mathrm{~J}=6.0,1 \mathrm{H}), 4.67(\mathrm{~d}, \mathrm{~J}=5.6,1 \mathrm{H}), 3.76(\mathrm{~m}, 1 \mathrm{H}), 2.71$ $($ sept, $3 \mathrm{JHH}=7.2,1 \mathrm{H}), 1.86(\mathrm{~s}, 3 \mathrm{H}), 1.07-1.02(\mathrm{~m}, 6 \mathrm{H}), 1.01(\mathrm{dd}, 3 \mathrm{JHP}=15.6,3 \mathrm{JHH}=6.8,3 \mathrm{H}), 0.78$ (d, 3JHH = 7.2, 3H). 13C $\{1 \mathrm{H}\}$ NMR (101 MHz): 141.0-121.6 (C, CH, Ar), 108.4 (s, C), 94.4 (s, br, C), $93.2(\mathrm{~s}, \mathrm{br}, \mathrm{CH}), 88.3(\mathrm{~d}, 2 \mathrm{JCP}=3.9, \mathrm{CH}), 88.3(\mathrm{~d}, 2 \mathrm{JCP}=3.6, \mathrm{CH}), 85.5(\mathrm{~s}, \mathrm{br}, \mathrm{CH}), 85.0(\mathrm{~s}, \mathrm{br}, \mathrm{CH})$, 29.8 (s, CH), 25.1 (d, 1JCP = 22.7, CH), 22.2 (s, CH3), 21.0 (s, CH3), 19.9 (s, CH3), 19.0 (s, CH3), 17.6 (s, CH3). 31P $\{1 \mathrm{H}\}$ NMR (162 MHz): +25.4 (s, br). Anal.: calcd for C31H33Cl2PRuS, C 58.12\%, H $5.19 \%$, S 5.00\%; found, C 57.92\%, H 5.47\%, S 4.64\%.

760

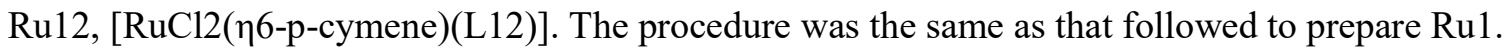

Starting from L12 (80 mg, $0.17 \mathrm{mmol}$ ) and Ru dimer D1 (42 mg, $0.07 \mathrm{mmol}$ ), the desired complex was

762 obtained as a dark red solid. Yield: $78 \mathrm{mg}(73 \%)$.

763 IR: 2960, 1636, 1436, 1401, 1372, 1158, 1106, 1030, 754, 694, 549, 492. 1H NMR (400 MHz): 8.21$8.16(\mathrm{~m}, 2 \mathrm{H}), 8.09$ (s, br, 1H), 7.80-7.72 (m, 2H), 7.55 (m, 1H), 7.49-7.45 (m, 6H), 5.47 (d, J = 6.4, $1 \mathrm{H}), 5.33(\mathrm{~d}, \mathrm{~J}=6.0,1 \mathrm{H}), 5.21(\mathrm{~d}, \mathrm{~J}=6.4,1 \mathrm{H}), 5.06(\mathrm{~d}, \mathrm{~J}=6.0,1 \mathrm{H}), 5.01(\mathrm{~s}, 1 \mathrm{H}), 4.46(\mathrm{~s}, 1 \mathrm{H}), 4.42(\mathrm{~s}$, $1 \mathrm{H}), 4.35(\mathrm{~s}, 1 \mathrm{H}), 3.69(\mathrm{~s}, 5 \mathrm{H}), 2.53(\mathrm{sept}, 3 \mathrm{JHH}=7.2,1 \mathrm{H}), 1.95(\mathrm{~s}, 3 \mathrm{H}), 0.86(\mathrm{~d}, 3 \mathrm{JHH}=7.2,3 \mathrm{H}), 0.55$ $(\mathrm{d}, 3 \mathrm{JHH}=6.8,3 \mathrm{H}) .13 \mathrm{C}\{1 \mathrm{H}\} \mathrm{NMR}(101 \mathrm{MHz}): 140.5-121.5(\mathrm{C}, \mathrm{CH}, \mathrm{Ar}), 108.9$ (s, C), 95.0 (s, C), 92.8 (s, br, CH), 88.7 (s, br, CH), 88.3 (s, br, CH), 82.6 (s, br, CH), 79.1 (d, JCP = 15.9, CH), 74.1 (s, br, CH), 70.6 (s, br, CH), 70.3 (s, 5CH), 69.7 (m, br, CH), 29.7 (s, CH), 22.4 (s, CH3), 19.9 (s, br, CH3), 17.2 (s, CH3). 31P $\{1 \mathrm{H}\}$ NMR (162 MHz): +20.6 (s). Anal.: calcd for C38H35Cl2FePRuS, C 58.32\%, H $4.51 \%$, S $4.10 \%$; found, C $56.75 \%$, H 4.75\%, S 3.76\%.

772 $\mathrm{Ru} 13,[\mathrm{RuCl} 2(\eta 6-\mathrm{p}-\mathrm{cymene})(\mathrm{L} 13)]$. The procedure was the same as that followed to prepare Ru1. Starting from L13 (180 mg, $0.53 \mathrm{mmol}$ ) and Ru dimer D1 (125 mg, $0.20 \mathrm{mmol})$, the desired complex was obtained as a dark red solid. Yield: $250 \mathrm{mg}(97 \%)$. 1H NMR (400 MHz): 7.97 (dd, J = 12.0, 8.4, 2H), 7.71-7.66 (m, 2H), 7.52-7.44 (m, 4H), 7.37 (tt, J = 8.0, 1.6, 1H), $7.28(\mathrm{~d}, \mathrm{~J}=7.6,1 \mathrm{H}), 7.18(\mathrm{t}, \mathrm{J}=7.6,1 \mathrm{H}), 7.12(\mathrm{~d}, \mathrm{~J}=8.0,1 \mathrm{H}), 5.63(\mathrm{~d}, \mathrm{~J}=6.0,2 \mathrm{H}), 5.45$ $(\mathrm{d}, \mathrm{J}=6.4,1 \mathrm{H}), 5.19(\mathrm{~d}, \mathrm{~J}=5.2,1 \mathrm{H}), 2.47(\mathrm{sept}, 3 \mathrm{JHH}=7.2,1 \mathrm{H}), 2.15(\mathrm{~s}, 3 \mathrm{H}), 2.01(\mathrm{~d}, 2 \mathrm{JHP}=10.8$, $3 \mathrm{H}), 0.81(\mathrm{~d}, 3 \mathrm{JHH}=7.2,3 \mathrm{H}), 0.29(\mathrm{~d}, 3 \mathrm{JHH}=6.8,3 \mathrm{H}) .13 \mathrm{C}\{1 \mathrm{H}\} \mathrm{NMR}(101 \mathrm{MHz}): 138.9-126.2(\mathrm{C}$, CH, Ar), 106.5 (s, C), 95.1 (s, C), 93.7 (s, br, CH), 91.0 (s, br, CH), 85.6 (s, CH), 81.3 (s, CH), 29.6 (s, $\mathrm{CH}), 22.7$ (s, CH3), 19.1 (s, CH3), 17.7 (s, CH3), 13.5 (d, 1JCP = 37.2, CH3). 31P $\{1 \mathrm{H}\}$ NMR (162 $\mathrm{MHz}$ ): +24.6 (s). Anal.: calcd for C29H29Cl2PRuS2, C 54.03\%, H 4.54\%, S 9.95\%; found, C 53.28\%, H $4.96 \%$, S 9.50\%.

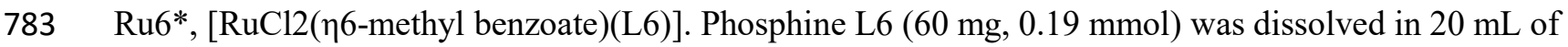
784 dichloromethane, Ru dimer D2 (48 mg, $0.077 \mathrm{mmol}$ ) was added and the dark suspension was stirred for $1 \mathrm{~h}$ and filtered. The solvent was removed under vacuum and the residue was recrystallized in dichloromethane/hexane to furnish the title product as a brown solid. Yield: $87 \mathrm{mg}(87 \%)$. 
IR: 3039, 2959, 2869, $1728 v(\mathrm{CvO}), 1625,1583,1470,1450,1435,1400,1294,1277,1185,1110,845$, 803, 759, 698. 1H NMR (400 MHz): 8.14 (dt, J = 7.6, 1.6, 1H), 8.04 (d, J = 7.2, 2H), 7.96 (d, J = 7.2 $1 \mathrm{H}), 7.93(\mathrm{~d}, \mathrm{~J}=8.81 \mathrm{H}), 7.52-7.39(\mathrm{~m}, 7 \mathrm{H}), 6.43(\mathrm{~d}, \mathrm{~J}=6.4,1 \mathrm{H}), 6.31(\mathrm{~d}, \mathrm{~J}=5.6,1 \mathrm{H}), 5.52(\mathrm{~m}, 1 \mathrm{H})$, $4.96(\mathrm{t}, \mathrm{J}=6.0,1 \mathrm{H}), 4.72(\mathrm{t}, \mathrm{J}=6.0,1 \mathrm{H}), 3.87(\mathrm{~s}, 3 \mathrm{H}), 3.81(\mathrm{~m}, 1 \mathrm{H}), 1.13(\mathrm{dd}, \mathrm{J}=18.0,7.2,3 \mathrm{H}), 1.03$

791 $(\mathrm{dd}, \mathrm{J}=15.6,7.2,3 \mathrm{H}) .13 \mathrm{C}\{1 \mathrm{H}\} \mathrm{NMR}(101 \mathrm{MHz}): 167.1$ (s, CvO), 164.5 (s, CvO), 155.3-111.8 (C, CH, Ar), 96.6 (s, CH), 94.4 (s, CH), 90.7 (s, CH), 85.5 (s, CH), 83.8 (s, CH), 53.2 (s, CH3), 52.1 (s, $\mathrm{CH} 3), 27.0(\mathrm{~d}, 1 \mathrm{JCP}=24.6, \mathrm{CH}), 19.5(\mathrm{~d}, 2 \mathrm{JCP}=4.9, \mathrm{CH} 3), 19.0(\mathrm{~s}, \mathrm{CH} 3) .31 \mathrm{P}\{1 \mathrm{H}\} \mathrm{NMR}(162 \mathrm{MHz})$ : +25.8 (s). Anal.: calcd for C29H27Cl2O3PRu, C 55.60\%, H 4.34\%; found, C 54.91\%, H 4.34\%.

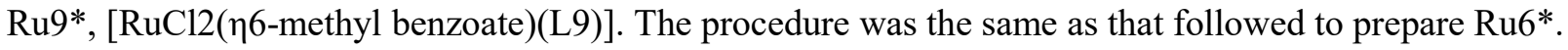
Starting from L9 (200 mg, $0.44 \mathrm{mmol})$ and Ru dimer D2 (90 mg, $0.15 \mathrm{mmol})$, the desired complex was obtained as a brownish solid. Yield: $140 \mathrm{mg}(63 \%)$.

798 IR: 3083, 3073, 2951, $1728 v(\mathrm{CvO}), 1618,1581,1469,1449,1435,1400,1374,1281,1187,1110,846$, 802, 755. 1H NMR (400 MHz): $8.36(\mathrm{~d}, \mathrm{~J}=8.0,1 \mathrm{H}), 8.19(\mathrm{~d}, \mathrm{~J}=6.8,1 \mathrm{H}), 8.13(\mathrm{~d}, \mathrm{~J}=8.0,1 \mathrm{H}), 8.07$ $(\mathrm{dd}, \mathrm{J}=13.0,7.6,1 \mathrm{H}), 8.04-7.95(\mathrm{~m}, 3 \mathrm{H}), 7.78(\mathrm{dd}, \mathrm{J}=13.2,8.0,1 \mathrm{H}), 7.63(\mathrm{~d}, \mathrm{~J}=7.6,1 \mathrm{H}), 7.58(\mathrm{dd}, \mathrm{J}$ $=8.0,2.0,1 \mathrm{H}), 7.47-7.31(\mathrm{~m}, 7 \mathrm{H}), 7.28-7.21(\mathrm{~m}, 2 \mathrm{H}), 6.53(\mathrm{~d}, \mathrm{~J}=6.4,1 \mathrm{H}), 6.48(\mathrm{~d}, \mathrm{~J}=6.0,1 \mathrm{H}), 5.49$ $(\mathrm{tt}, \mathrm{J}=9.6,4.8,1 \mathrm{H}), 5.20(\mathrm{t}, \mathrm{J}=6.0,1 \mathrm{H}), 5.03(\mathrm{t}, \mathrm{J}=5.6,1 \mathrm{H}), 3.95(\mathrm{~s}, 3 \mathrm{H}) .13 \mathrm{C}\{1 \mathrm{H}\} \mathrm{NMR}(101 \mathrm{MHz})$ : 167.1 (s, $\mathrm{CvO}$ ), 156.2-111.4 (C, CH, Ar), 95.89 (s, CH), 95.85 (s, CH), 89.2 (s, CH), 85.3 (s, CH), 84.4 (s, CH), 53.3 (s, CH3), 52.1 (s, CH3). 31P $\{1 \mathrm{H}\}$ NMR (162 MHz): +22.4 (s). HRMS: calcd for C38H27ClO3PRuS ([M] - Cl), 731.0151; found, 731.0144.

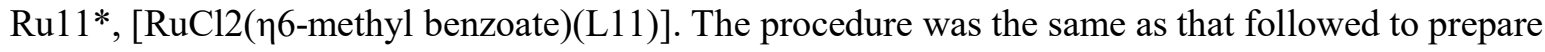
Ru6*. Starting from L11 (214 mg, $0.64 \mathrm{mmol}$ ) and Ru dimer D2 (150 mg, $0.24 \mathrm{mmol})$, the desired complex was obtained as a brown solid. Yield: $246 \mathrm{mg}(80 \%)$. IR: 3036, 2952, 2866, $1730 v(\mathrm{CvO}), 1433,1372,1293,1277,1106,760,695,545,516.1 \mathrm{H}$ NMR (400 MHz): $8.31(\mathrm{~d}, \mathrm{~J}=9.2,1 \mathrm{H}), 8.22(\mathrm{~m}, 1 \mathrm{H}), 8.03(\mathrm{~d}, \mathrm{~J}=9.2,1 \mathrm{H}), 8.01(\mathrm{~d}, \mathrm{~J}=8.8,1 \mathrm{H}), 7.93(\mathrm{dd}, \mathrm{J}=10.8$, $8.01 \mathrm{H}), 7.80(\mathrm{~m}, 1 \mathrm{H}), 7.63-7.56(\mathrm{~m}, 2 \mathrm{H}), 7.52-7.46(\mathrm{~m}, 4 \mathrm{H}), 6.45(\mathrm{~d}, \mathrm{~J}=6.0,1 \mathrm{H}), 6.26(\mathrm{~d}, \mathrm{~J}=6.0,1 \mathrm{H})$, $5.33(\mathrm{~m}, 1 \mathrm{H}), 5.20(\mathrm{t}, \mathrm{J}=6.0,2 \mathrm{H}), 3.91(\mathrm{~s}, 3 \mathrm{H}), 3.82(\mathrm{~m}, 1 \mathrm{H}), 1.15(\mathrm{dd}, \mathrm{J}=14.4,6.8,3 \mathrm{H}), 1.07(\mathrm{dd}, \mathrm{J}=$ 18.0, 6.8, 3H). 13C $\{1 \mathrm{H}\}$ NMR (101 MHz): $167.1(\mathrm{CvO}), 164.4(\mathrm{CvO}), 139.4-121.6(\mathrm{C}, \mathrm{CH}, \mathrm{Ar}), 95.1$ $(\mathrm{d}, 2 \mathrm{JCP}=3.5, \mathrm{CH}), 94.5(\mathrm{~d}, 2 \mathrm{JCP}=3.8, \mathrm{CH}), 89.5(\mathrm{~s}, \mathrm{CH}), 85.2(\mathrm{~d}, 2 \mathrm{JCP}=3.6, \mathrm{CH}), 84.9(\mathrm{~d}, 2 \mathrm{JCP}=$ 2.0, CH), 53.3 (s, CH3), 52.1 (s, CH3), 25.7 (d, 1JCP = 24.2, CH), 19.3 (d, 2JCP = 6.2, CH3), 18.7 (s, CH3). 31P $\{1 \mathrm{H}\}$ NMR (162 MHz): +31.3 (s). Anal.: calcd for C29H27Cl2O2PRuS, C 54.21\%, H $4.23 \%$, S $4.99 \%$; found, C $54.17 \%$, H $4.39 \%$, S $4.98 \%$.

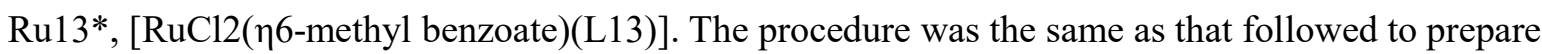
Ru6*. Starting from L13 (200 mg, $0.59 \mathrm{mmol}$ ) and Ru dimer D2 (134 mg, $0.22 \mathrm{mmol})$, the desired complex was obtained as a dark red solid. Yield: $213 \mathrm{mg}(76 \%)$. IR: 3053, 2950, 1728 v(CvO), 1434, 1377, 1110, 896, 749, 503. 1H NMR (400 MHz): 8.00 (ddd, J = 12.4, 7.6, 1.2, 1H), $7.74(\mathrm{~d}, \mathrm{~J}=7.6,1 \mathrm{H}), 7.69-7.64(\mathrm{~m}, 2 \mathrm{H}), 7.52-7.41(\mathrm{~m}, 5 \mathrm{H}), 7.27(\mathrm{~m}, 1 \mathrm{H}), 7.21-7.13$ $(\mathrm{m}, 2 \mathrm{H}), 6.41(\mathrm{~d}, \mathrm{~J}=6.0,1 \mathrm{H}), 6.35(\mathrm{~d}, \mathrm{~J}=5.6,1 \mathrm{H}), 5.54(\mathrm{~m}, 1 \mathrm{H}), 5.42(\mathrm{~d}, \mathrm{~J}=5.6,1 \mathrm{H}), 5.39(\mathrm{~d}, \mathrm{~J}=5.6$, 
1H), $3.83(\mathrm{~s}, 3 \mathrm{H}), 2.14(\mathrm{~d}, 2 \mathrm{JHP}=11.6,3 \mathrm{H}) .31 \mathrm{P}\{1 \mathrm{H}\}$ NMR $(162 \mathrm{MHz}):+25.4$ (s). HRMS: calcd for C27H23ClO2PRuS2 ([M] - Cl), 610.9603; found, 610.9595.

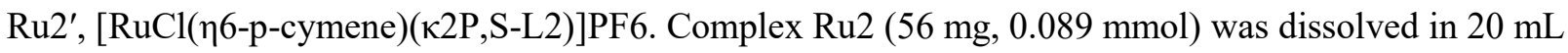
of dichloromethane, thallium hexafluorophosphate $(34 \mathrm{mg}, 0.094 \mathrm{mmol})$ was added and the reddish suspension was stirred for $2 \mathrm{~h}$. Water $(20 \mathrm{~mL})$ was added and the mixture was extracted with dichloromethane $(3 \times 10 \mathrm{~mL})$. The combined organic phases were washed with water, dried with anhydrous sodium sulfate, filtered and the solvent was removed under vacuum. The crude yellow product was recrystallised in dichloromethane/hexane. Yield: $53 \mathrm{mg}(81 \%)$.

832 IR: 3089, 2968, 2876, 1618, 1471, 1438, 1391, 1108, 1020, 839 v(PF6 -), 762, 558. 1H NMR (400 MHz): $8.21(\mathrm{dd}, \mathrm{J}=6.0,3.2,1 \mathrm{H}), 8.11(\mathrm{dd}, \mathrm{J}=7.6,1.6,1 \mathrm{H}), 8.06(\mathrm{dd}, \mathrm{J}=6.4,3.2,1 \mathrm{H}), 7.75-7.71(\mathrm{~m}$, 2H), 7.66-7.54 (m, 6H), $7.48(\mathrm{t}, \mathrm{J}=8.0,1 \mathrm{H}), 6.34(\mathrm{~d}, \mathrm{~J}=6.4,1 \mathrm{H}), 6.14(\mathrm{~d}, \mathrm{~J}=6.4,1 \mathrm{H}), 6.09(\mathrm{~d}, \mathrm{~J}=6.0$, $1 \mathrm{H}), 6.04(\mathrm{~d}, \mathrm{~J}=6.0,1 \mathrm{H}), 3.89(\mathrm{~d}, 3 \mathrm{JHP}=12.4,3 \mathrm{H}), 2.56(\mathrm{sept}, 3 \mathrm{JHH}=6.8,1 \mathrm{H}), 2.06(\mathrm{~s}, 3 \mathrm{H}), 1.13(\mathrm{~d}$, $3 \mathrm{JHH}=6.8,3 \mathrm{H}), 0.83(\mathrm{~d}, 3 \mathrm{JHH}=6.8,3 \mathrm{H}) .13 \mathrm{C}\{1 \mathrm{H}\} \mathrm{NMR}(101 \mathrm{MHz}): 152.9-123.9(\mathrm{C}, \mathrm{CH}, \mathrm{Ar})$, $114.2(\mathrm{~s}, \mathrm{C}), 103.1(\mathrm{~s}, \mathrm{C}), 92.8(\mathrm{~d}, 2 \mathrm{JCP}=6.0, \mathrm{CH}), 92.2(\mathrm{~d}, 2 \mathrm{JCP}=3.4, \mathrm{CH}), 91.8(\mathrm{~d}, 2 \mathrm{JCP}=4.1, \mathrm{CH})$, $88.4(\mathrm{~d}, 2 \mathrm{JCP}=2.7, \mathrm{CH}), 56.6(\mathrm{~d}, 2 \mathrm{JCP}=12.1, \mathrm{CH} 3), 31.4(\mathrm{~s}, \mathrm{CH}), 22.1$ (s, CH3), 20.7 (s, CH3), 18.7 (s, CH3). 31P $\{1 \mathrm{H}\}$ NMR (162 MHz): +138.7 (s). HRMS: calcd for C29H29ClOPRuS ([M] - PF6), 593.0403; found, 593.0406.

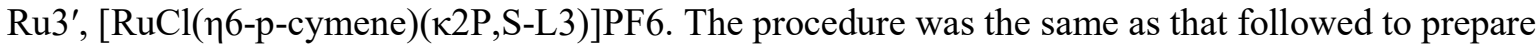
obtained as a pale red solid. Yield: $95 \mathrm{mg}(82 \%)$.

IR: 3085, 2967, 1471, 1437, 1389, 1146, 1108, 1018, 840 v(PF6-) , 756, 705, 558. 1H NMR (400 MHz): $7.97(\mathrm{dd}, \mathrm{J}=8.0,1.2,1 \mathrm{H}), 7.86-7.78(\mathrm{~m}, 3 \mathrm{H}), 7.67(\mathrm{dd}, \mathrm{J}=7.6,1.2,1 \mathrm{H}), 7.62-7.51(\mathrm{~m}, 6 \mathrm{H}), 7.46(\mathrm{td}, \mathrm{J}$ $=7.6,1.2,1 \mathrm{H}), 6.54(\mathrm{~d}, \mathrm{~J}=6.4,1 \mathrm{H}), 6.43(\mathrm{~d}, \mathrm{~J}=6.0,1 \mathrm{H}), 6.30(\mathrm{dd}, \mathrm{J}=6.4,1.2,1 \mathrm{H}), 6.19(\mathrm{~d}, \mathrm{~J}=6.0$, $1 \mathrm{H}), 3.62(\mathrm{~d}, 3 \mathrm{JHP}=11.6,3 \mathrm{H}), 2.57(\mathrm{sept}, 3 \mathrm{JHH}=6.8,1 \mathrm{H}), 2.01(\mathrm{~s}, 3 \mathrm{H}), 1.14(\mathrm{~d}, 3 \mathrm{JHH}=6.8,3 \mathrm{H})$, $0.84(\mathrm{~d}, 3 \mathrm{JHH}=6.8,3 \mathrm{H}) .13 \mathrm{C}\{1 \mathrm{H}\} \mathrm{NMR}(101 \mathrm{MHz}):$ 140.5-127.4 (C, CH, Ar), $114.2(\mathrm{~s}, \mathrm{C}), 103.2(\mathrm{~s}$, C), $95.2(\mathrm{~d}, 2 \mathrm{JCP}=4.9, \mathrm{CH}), 94.5(\mathrm{~d}, 2 \mathrm{JCP}=3.7, \mathrm{CH}), 94.4(\mathrm{~d}, 2 \mathrm{JCP}=5.6, \mathrm{CH}), 90.8(\mathrm{~d}, 2 \mathrm{JCP}=3.3$, $\mathrm{CH}), 56.2(\mathrm{~d}, 2 \mathrm{JCP}=12.5, \mathrm{CH} 3), 31.2(\mathrm{~s}, \mathrm{CH}), 22.1(\mathrm{~s}, \mathrm{CH} 3), 20.8(\mathrm{~s}, \mathrm{CH} 3), 18.3(\mathrm{~s}, \mathrm{CH} 3) .31 \mathrm{P}\{1 \mathrm{H}\}$ NMR (162 MHz): +145.5 (s). Anal.: calcd for C29H29ClF6OP2RuS2, C 45.23\%, H 3.80\%, S 8.33\%; found, C $44.35 \%$, H $4.05 \%$, S $7.79 \%$.

$853 \mathrm{Ru} 9{ }^{\prime},[\mathrm{RuCl}(\eta 6-\mathrm{p}-\mathrm{cymene})(\kappa 2 \mathrm{P}, \mathrm{S}-\mathrm{L} 9)] \mathrm{PF} 6$. The procedure was the same as that followed to prepare Ru2'. Starting from Ru9 (30 mg, $0.039 \mathrm{mmol})$ and TlPF6 (14 mg, $0.040 \mathrm{mmol})$, the desired complex was obtained as a red solid. Yield: $30 \mathrm{mg}(88 \%)$. (m, M + m), 7.42-7.27 (m, M + m), $7.18(\mathrm{t}, \mathrm{J}=7.7,1 \mathrm{H}, \mathrm{M}), 6.71(\mathrm{~d}, \mathrm{~J}=6.4,1 \mathrm{H}, \mathrm{M}), 6.44(\mathrm{~d}, \mathrm{~J}=6.4$, $8581 \mathrm{H}, \mathrm{m}), 6.38(\mathrm{~d}, \mathrm{~J}=5.6,1 \mathrm{H}, \mathrm{m}), 6.36(\mathrm{~d}, \mathrm{~J}=5.6,1 \mathrm{H}, \mathrm{M}), 5.87(\mathrm{~d}, \mathrm{~J}=6.4,1 \mathrm{H}, \mathrm{m}), 5.83(\mathrm{~d}, \mathrm{~J}=6.8,1 \mathrm{H}$, $859 \mathrm{M}), 5.66(\mathrm{~d}, \mathrm{~J}=6.4,1 \mathrm{H}, \mathrm{m}), 5.10(\mathrm{~d}, \mathrm{~J}=6.0,1 \mathrm{H}, \mathrm{M}), 2.44(\mathrm{sept}, 3 \mathrm{JHH}=6.8,1 \mathrm{H}, \mathrm{M}), 2.34$ (sept, 3JHH 860 $=6.0,1 \mathrm{H}, \mathrm{m}), 2.06(\mathrm{~s}, 3 \mathrm{H}, \mathrm{M}), 1.99(\mathrm{~s}, 3 \mathrm{H}, \mathrm{m}), 1.28(\mathrm{~d}, 3 \mathrm{JHH}=6.8,3 \mathrm{H}, \mathrm{m}), 1.07(\mathrm{~d}, 3 \mathrm{JHH}=7.2,3 \mathrm{H}$, 
M), $0.85(\mathrm{~d}, 3 \mathrm{JHH}=6.8,3 \mathrm{H}, \mathrm{m}), 0.44(\mathrm{~d}, 3 \mathrm{JHH}=6.8,3 \mathrm{H}, \mathrm{M}) .13 \mathrm{C}\{1 \mathrm{H}\}$ NMR $(101 \mathrm{MHz}$, major isomer): 155.6-121.5 (C, CH, Ar), $112.0(\mathrm{~s}, \mathrm{C}), 105.3(\mathrm{~s}, \mathrm{C}), 96.9$ (d, 2JCP = 7.6, CH), $89.0(\mathrm{~d}, 2 \mathrm{JCP}=$ 5.2, CH), 86.9 (s, CH), 86.6 (s, CH), 31.3 (s, CH), 23.2 (s, CH3), 18.8 (s, br, CH3), 18.3 (s, CH3). 31P $\{1 \mathrm{H}\}$ NMR $(162 \mathrm{MHz}):+50.1(\mathrm{~s}, \mathrm{~m}),+44.4$ (s, M). HRMS: calcd for C40H33ClOPRuS ([M] PF6), 729.0716; found, 729.0742.

$\mathrm{Ru} 10^{\prime},[\mathrm{RuCl}(\eta 6-\mathrm{p}-\mathrm{cymene})(\kappa 2 \mathrm{P}, \mathrm{S}-\mathrm{L} 10)] \mathrm{BF} 4$. The procedure was the same as that followed to prepare Ru2'. Starting from Ru10 (60 mg, $0.098 \mathrm{mmol})$ and TlBF4 (29 mg, $0.10 \mathrm{mmol}$ ), the desired complex was obtained as a pale red solid. Yield: $50 \mathrm{mg}(71 \%)$.

IR: 3063, 2961, 2862, 1437, 1392, 1103, 1084, 1046 v(BF4-), 898, 759, 696, 522. 1H NMR (400 MHz): $8.18(\mathrm{~d}, \mathrm{~J}=7.2,1 \mathrm{H}), 8.09-8.00(\mathrm{~m}, 2 \mathrm{H}), 7.85-7.77(\mathrm{~m}, 2 \mathrm{H}), 7.69-7.53(\mathrm{~m}, 7 \mathrm{H}), 6.45(\mathrm{~d}, \mathrm{~J}=6.0,1 \mathrm{H}$, M), $6.41(\mathrm{~d}, \mathrm{~J}=6.4,1 \mathrm{H}, \mathrm{m}), 6.35(\mathrm{~d}, \mathrm{~J}=6.4,1 \mathrm{H}, \mathrm{M}), 6.27(\mathrm{~d}, \mathrm{~J}=6.4,1 \mathrm{H}, \mathrm{m}), 6.04(\mathrm{~d}, \mathrm{~J}=6.0,1 \mathrm{H}, \mathrm{m})$, $6.00(\mathrm{~d}, \mathrm{~J}=6.4,1 \mathrm{H}, \mathrm{m}), 5.74(\mathrm{~d}, \mathrm{~J}=6.4,1 \mathrm{H}, \mathrm{M}), 5.64(\mathrm{~d}, \mathrm{~J}=6.8,1 \mathrm{H}, \mathrm{M}), 2.70(\mathrm{~d}, 2 \mathrm{JHP}=10.4,3 \mathrm{H}, \mathrm{m})$, $2.51(\mathrm{sept}, 3 \mathrm{JHH}=6.8,1 \mathrm{H}, \mathrm{m}), 2.45(\mathrm{~d}, 2 \mathrm{JHP}=11.6,3 \mathrm{H}, \mathrm{M}), 2.30(\mathrm{sept}, 3 \mathrm{JHH}=7.2,1 \mathrm{H}, \mathrm{M}), 1.97(\mathrm{~s}$, $3 \mathrm{H}, \mathrm{m}), 1.88(\mathrm{~s}, 3 \mathrm{H}, \mathrm{M}), 1.18(\mathrm{~d}, 3 \mathrm{JHH}=6.8,3 \mathrm{H}, \mathrm{M}), 1.16(\mathrm{~d}, 3 \mathrm{JHH}=6.4,3 \mathrm{H}, \mathrm{m}), 0.95(\mathrm{~d}, 3 \mathrm{JHH}=6.8$, $3 \mathrm{H}, \mathrm{M}), 0.90(\mathrm{~d}, 3 \mathrm{JHH}=6.8,3 \mathrm{H}, \mathrm{m}) .13 \mathrm{C}\{1 \mathrm{H}\} \mathrm{NMR}(101 \mathrm{MHz}$, only the major isomer peaks are listed): 152.0-124.0 (C, CH, Ar), 112.9 (s, C), 104.3 (s, C), 94.5 (d, 2JCP = 5.8, CH), 89.8 (d, 2JCP = 4.5, CH), $88.0(\mathrm{~d}, 2 \mathrm{JCP}=2.0, \mathrm{CH}), 86.2(\mathrm{~d}, 2 \mathrm{JCP}=3.4, \mathrm{CH}), 31.1(\mathrm{~s}, \mathrm{CH}), 22.0(\mathrm{~s}, \mathrm{CH} 3), 21.4(\mathrm{~s}$, CH3), $17.9(\mathrm{~s}, \mathrm{CH} 3), 12.2(\mathrm{~d}, 1 \mathrm{JCP}=36.9, \mathrm{CH} 3) .31 \mathrm{P}\{1 \mathrm{H}\} \mathrm{NMR}(162 \mathrm{MHz}):+47.4(\mathrm{~s}, \mathrm{M}),+39.8(\mathrm{~s}$, m). HRMS: calcd for C29H29CIPRuS ([M] - BF4), 577.0454; found, 577.0449.

$\mathrm{Ru} 11^{\prime},[\mathrm{RuCl}(\eta 6-\mathrm{p}-\mathrm{cymene})(\kappa 2 \mathrm{P}, \mathrm{S}-\mathrm{L} 11)] \mathrm{PF} 6$. The procedure was the same as that followed to prepare Ru2'. Starting from Ru11 (50 mg, $0.078 \mathrm{mmol}$ ) and TIPF6 (31 mg, $0.090 \mathrm{mmol}$ ), the desired complex was obtained as a dark red solid. Yield: $49 \mathrm{mg}(84 \%)$.

IR: 3062, 2965, 1470, 1436, 1390, 842 v(PF6-), 760, 695, 558, 505. 1H NMR (400 MHz): 8.07 (t, J = 8.0, 2H), $8.00(\mathrm{~d}, \mathrm{~J}=7.6,1 \mathrm{H}), 7.71-7.59(\mathrm{~m}, 5 \mathrm{H}), 7.51-7.43(\mathrm{~m}, 4 \mathrm{H}), 6.58(\mathrm{~d}, \mathrm{~J}=6.8,1 \mathrm{H}), 6.08(\mathrm{~d}, \mathrm{~J}=$ $6.0,1 \mathrm{H}), 6.03(\mathrm{~d}, \mathrm{~J}=6.0,1 \mathrm{H}), 5.87(\mathrm{~d}, \mathrm{~J}=6.4,1 \mathrm{H}), 3.75(\mathrm{~m}, \mathrm{br}, 1 \mathrm{H}), 2.36(\mathrm{sept}, 3 \mathrm{JHH}=6.8,1 \mathrm{H}), 2.07$ $(\mathrm{s}, 3 \mathrm{H}), 1.43(\mathrm{dd}, 3 \mathrm{JHH}+3 \mathrm{JHP}=14.4,6.4,3 \mathrm{H}), 1.35(\mathrm{dd}, 3 \mathrm{JHH}+3 \mathrm{JHP}=20.4,7.2,3 \mathrm{H}), 1.11(\mathrm{~d}, 3 \mathrm{JHH}$ $=7.2,3 \mathrm{H}), 0.56(\mathrm{~d}, 3 \mathrm{JHH}=6.8,3 \mathrm{H}) .13 \mathrm{C}\{1 \mathrm{H}\} \mathrm{NMR}(101 \mathrm{MHz}): 153.0-123.2(\mathrm{C}, \mathrm{CH}, \mathrm{Ar}), 113.3(\mathrm{~s}$, C), $97.9(\mathrm{~s}, \mathrm{br}, \mathrm{C}), 93.7(\mathrm{~d}, 2 \mathrm{JCP}=6.3, \mathrm{CH}), 91.6(\mathrm{~d}, 2 \mathrm{JCP}=5.7, \mathrm{CH}), 91.3(\mathrm{~s}, \mathrm{CH}), 85.7(\mathrm{~s}, \mathrm{CH}), 31.4$ (s, CH), 29.3 (d, 1JCP = 27.0, CH), 23.1 (s, CH3), 19.4 (s, CH3), 18.4 (s, CH3), 18.2 (d, 2JCP = 4.5, $\mathrm{CH} 3), 17.8(\mathrm{~d}, 2 \mathrm{JCP}=7.2, \mathrm{CH} 3) .31 \mathrm{P}\{1 \mathrm{H}\} \mathrm{NMR}(162 \mathrm{MHz}):+68.1$ (s). Anal.: calcd for C31H33ClF6P2RuS, C 49.64\%, H 4.43\%, S 4.27\%; found, C 49.68\%, H 4.89\%, S 4.09\%. $\mathrm{Ru} 12^{\prime},[\mathrm{RuCl}(\eta 6-\mathrm{p}-\mathrm{cymene})(\kappa 2 \mathrm{P}, \mathrm{S}-\mathrm{L} 12)] \mathrm{PF} 6$. The procedure was the same as that followed to prepare Ru2'. Starting from Ru12 (50 mg, $0.064 \mathrm{mmol}$ ) and TlPF6 (24 mg, $0.069 \mathrm{mmol}$ ), the desired complex was obtained as a red solid. Yield: $35 \mathrm{mg}(61 \%)$.

1H NMR (400 MHz): 8.20-8.00 (m, 4H), 7.76-7.47 (m, 8H), 6.27-6.22 (m, 3H, 1M + 2 m), 6.07 (d, J = 6.4, 1H, M), $5.74(\mathrm{~d}, \mathrm{~J}=6.0,1 \mathrm{H}, \mathrm{m}), 5.63(\mathrm{~d}, \mathrm{~J}=7.2,1 \mathrm{H}, \mathrm{m}), 5.53(\mathrm{~d}, \mathrm{~J}=5.2,2 \mathrm{H}, \mathrm{M}), 5.18(\mathrm{~s}, 1 \mathrm{H}, \mathrm{M})$, 4.94 (s, 1H, M), 4.71 (s, 1H, m), 4.66 (s, 2H, M + m), 4.58 (s, 1H, M), 4.36 (s, 1H, m), 4.17 (s, 5H, M), 
905

906

907

908

909

910

911

912

913

914

915

916

917

918

919

920

921

922

923

924

925

926

927

928

929

930

931

932

933

934

$4.01(\mathrm{~s}, 5 \mathrm{H}, \mathrm{m}), 3.99(\mathrm{~s}, 1 \mathrm{H}, \mathrm{m}), 2.43(\mathrm{sept}, 3 \mathrm{JHH}=7.6,1 \mathrm{H}, \mathrm{M}), 2.30(\mathrm{sept}, 3 \mathrm{JHH}=8.4,1 \mathrm{H}, \mathrm{m}), 1.77$ $(\mathrm{s}, 3 \mathrm{H}, \mathrm{m}), 1.71(\mathrm{~s}, 3 \mathrm{H}, \mathrm{M}), 1.17(\mathrm{~d}, 3 \mathrm{JHH}=7.2,3 \mathrm{H}, \mathrm{m}), 0.97(\mathrm{~d}, 3 \mathrm{JHH}=6.8,3 \mathrm{H}, \mathrm{M}), 0.93(\mathrm{~d}, 3 \mathrm{JHH}=$ 7.2, 3H, M), $0.88(\mathrm{~d}, 3 \mathrm{JHH}=6.4,3 \mathrm{H}, \mathrm{m}) .13 \mathrm{C}\{1 \mathrm{H}\} \mathrm{NMR}(101 \mathrm{MHz}): 151.7-123.9(\mathrm{C}, \mathrm{CH}, \mathrm{Ar}), 113.1$ (s, C, m), 111.8 (s, C, M), 104.4 (s, C, m), 100.2 (s, C, M), 95.3 (d, 2JCP = 3.1, CH, M), 94.9 (d, 2JCP = 5.6, $\mathrm{CH}, \mathrm{m}), 90.5(\mathrm{~d}, 2 \mathrm{JCP}=3.8, \mathrm{CH}, \mathrm{M}), 90.1(\mathrm{~d}, 2 \mathrm{JCP}=3.4, \mathrm{CH}, \mathrm{M}), 89.2(\mathrm{~d}, 2 \mathrm{JCP}=3.9, \mathrm{CH}, \mathrm{m})$, $88.4(\mathrm{~s}, \mathrm{CH}, \mathrm{m}), 86.8(\mathrm{~d}, 2 \mathrm{JCP}=3.8, \mathrm{CH}, \mathrm{M}), 86.7(\mathrm{~d}, 2 \mathrm{JCP}=3.5, \mathrm{CH}, \mathrm{m}), 76.5(\mathrm{~d}, \mathrm{JCP}=10.4, \mathrm{CH}, \mathrm{m})$, $74.6(\mathrm{~d}, \mathrm{JCP}=8.1, \mathrm{CH}, \mathrm{M}), 73.0(\mathrm{~d}, \mathrm{JCP}=8.5, \mathrm{CH}, \mathrm{m}), 72.6(\mathrm{~d}, \mathrm{JCP}=10.6, \mathrm{CH}, \mathrm{m}), 72.2(\mathrm{~d}, \mathrm{JCP}=$ 14.4, CH, M), 71.5 (d, JCP = 9.4, CH, M), $71.3(\mathrm{~d}, \mathrm{JCP}=11.8, \mathrm{CH}, \mathrm{m}), 70.9$ (s, 5CH, m), 70.8 (d, JCP = 6.2, CH, M), 70.3 (s, 5CH, M), 31.6 (s, CH, M), 31.2 (s, CH, M), 22.4 (s, CH3, m), 21.7 (s, CH3, M), 21.2 (s, CH3, M), 20.9 (s, CH3, m), 18.1 (s, CH3, M), 17.6 (s, CH3, m). 31P $\{1 \mathrm{H}\}$ NMR (162 MHz): +53.0 (s, m), +48.8 (s, M). HRMS: calcd for C38H35ClFePRuS ([M] - PF6), 747.0279; found, 747.0293.

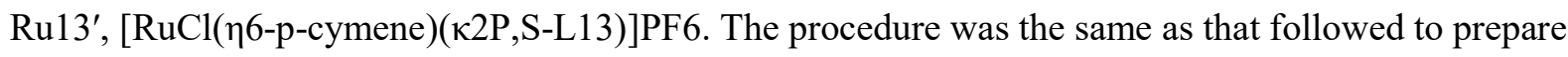
Ru2'. Starting from Ru13 (136 mg, $0.21 \mathrm{mmol})$ and TlPF6 (81 mg, $0.23 \mathrm{mmol})$, the desired complex was obtained as a pale red solid. Yield: $100 \mathrm{mg}(63 \%)$.

IR: 3057, 2964, 2925, 1437, 1391, 1147, 1103, 841 v(PF6-), 749, 694, 558. 1H NMR (400 MHz): 7.90 $(\mathrm{dt}, \mathrm{J}=8.0,1.6,2 \mathrm{H}), 7.80-7.65(\mathrm{~m}, 6 \mathrm{H}), 7.65-7.42(\mathrm{~m}, 14 \mathrm{H}), 7.36(\mathrm{dd}, \mathrm{J}=12.0,7.6,2 \mathrm{H}), 6.62(\mathrm{~d}, \mathrm{~J}=$ 6.0, 1H, M), $6.57(\mathrm{~d}, \mathrm{~J}=6.4,1 \mathrm{H}, \mathrm{M}), 6.44(\mathrm{~d}, \mathrm{~J}=6.4,1 \mathrm{H}, \mathrm{m}), 6.39(\mathrm{~d}, \mathrm{~J}=6.4,1 \mathrm{H}, \mathrm{m}), 6.13(\mathrm{~d}, \mathrm{~J}=6.4$, $1 \mathrm{H}, \mathrm{M}), 6.08(\mathrm{~d}, \mathrm{~J}=6.0,1 \mathrm{H}, \mathrm{M}), 5.53(\mathrm{~d}, \mathrm{~J}=6.4,1 \mathrm{H}, \mathrm{m}), 5.35(\mathrm{~d}, \mathrm{~J}=6.0,1 \mathrm{H}, \mathrm{m}), 2.53(\mathrm{~m}, 1 \mathrm{H}, \mathrm{M}), 2.41$ $(\mathrm{m}, 1 \mathrm{H}, \mathrm{m}), 2.50(\mathrm{~d}, 2 \mathrm{JHP}=18.4,3 \mathrm{H}, \mathrm{m}), 2.46(\mathrm{~d}, 2 \mathrm{JHP}=10.0,3 \mathrm{H}, \mathrm{M}), 2.01(\mathrm{~s}, 3 \mathrm{H}, \mathrm{m}), 1.95(\mathrm{~s}, 3 \mathrm{H}$, M), $1.19(\mathrm{~d}, 3 \mathrm{JHH}=6.8,3 \mathrm{H}, \mathrm{m}), 1.15(\mathrm{~d}, 3 \mathrm{JHH}=6.8,3 \mathrm{H}, \mathrm{M}), 1.00(\mathrm{~d}, 3 \mathrm{JHH}=6.8,3 \mathrm{H}, \mathrm{m}), 0.88(\mathrm{~d}$, $3 \mathrm{JHH}=6.8,3 \mathrm{H}, \mathrm{M}) .13 \mathrm{C}\{1 \mathrm{H}\} \mathrm{NMR}(101 \mathrm{MHz}): 146.2-127.7(\mathrm{C}, \mathrm{CH}, \mathrm{Ar}), 113.5$ (s, C, m), 113.1 (s, C, M), 104.0 (s, C, m), 101.4 (s, C, M), 97.4 (d, 2JCP = 5.8, CH, m), 94.8 (s, br, CH, M), 93.8 (d, 2JCP = 4.5, CH, M), 92.5 (s, br, CH, M), 91.9 (d, 2JCP = 3.8, 2CH, 2 m), 89.9 (d, 2JCP = 3.8, CH, M), 89.3 (d, 2JCP = 4.2, CH, m), 31.2 (s, CH, M), 30.9 (s, CH, m), 21.9 (s, CH3, M), 21.8 (s, CH3, m), 21.6 (s, CH3, m), $21.5(\mathrm{~d}, 1 \mathrm{JCP}=34.6, \mathrm{CH} 3, \mathrm{M}), 21.0(\mathrm{~s}, \mathrm{CH} 3, \mathrm{M}), 18.1$ (s, CH3, M), 18.0 (s, CH3, m), 11.8 (d, 1JCP $=40.2, \mathrm{CH} 3, \mathrm{~m}) .31 \mathrm{P}\{1 \mathrm{H}\}$ NMR $(162 \mathrm{MHz}):+54.9(\mathrm{~s}, \mathrm{~m}),+50.0(\mathrm{~s}, \mathrm{M})$. Anal.: calcd for C27H23ClF6O2P2RuS2, C 42.89\%, H 3.07\%, S 8.48\%; found, C 42.95\%, H 2.85\%, S 7.75\%.

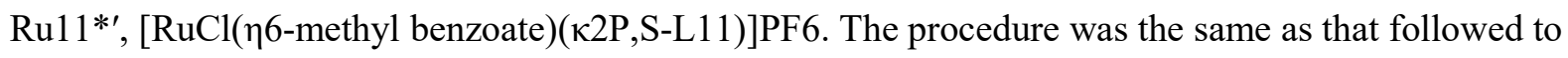
prepare Ru2'. Starting from Ru11* (130 mg, $0.20 \mathrm{mmol})$ and TlPF6 (78 mg, $0.22 \mathrm{mmol})$, the desired complex was obtained as a brown solid. Yield: $120 \mathrm{mg}(73 \%)$.

IR: 3092, 2959, 2872, $1734 v(\mathrm{CvO}), 1436,1390,1298,1280,1114,840 v\left(\mathrm{PF}^{-}\right), 761,695,558.1 \mathrm{H}$ NMR (400 MHz): $8.19(\mathrm{~d}, \mathrm{~J}=6.8,1 \mathrm{H}), 8.04(\mathrm{~d}, \mathrm{~J}=8.0,2 \mathrm{H}), 7.69-7.56(\mathrm{~m}, 5 \mathrm{H}), 7.55-7.44(\mathrm{~m}, 4 \mathrm{H})$, $7.21(\mathrm{~d}, \mathrm{br}, \mathrm{J}=5.2,1 \mathrm{H}), 6.75(\mathrm{~d}, \mathrm{~J}=6.0,1 \mathrm{H}), 6.49(\mathrm{~s}, \mathrm{br}, 2 \mathrm{H}), 5.84(\mathrm{t}, \mathrm{br}, \mathrm{J}=5.2,1 \mathrm{H}), 3.75(\mathrm{~m}, 1 \mathrm{H})$, $3.73(\mathrm{~s}, 3 \mathrm{H}), 1.43-1.33(\mathrm{~m}, 6 \mathrm{H}) .13 \mathrm{C}\{1 \mathrm{H}\}$ NMR (101 MHz): $163.3(\mathrm{CvO}), 152.8-122.3$ (C, CH, Ar), $96.6(\mathrm{~d}, 2 \mathrm{JCP}=1.8, \mathrm{CH}), 94.6(\mathrm{~d}, 2 \mathrm{JCP}=3.8, \mathrm{CH}), 90.5(\mathrm{~s}, \mathrm{CH}), 89.3(\mathrm{~d}, 2 \mathrm{JCP}=5.4, \mathrm{C}), 88.7(\mathrm{~d}, 2 \mathrm{JCP}$ $=1.0, \mathrm{CH}), 87.9(\mathrm{~d}, 2 \mathrm{JCP}=2.6, \mathrm{CH}), 53.7(\mathrm{~s}, \mathrm{CH} 3), 30.2(\mathrm{~d}, 1 \mathrm{JCP}=27.2, \mathrm{CH}), 18.3(\mathrm{~d}, 2 \mathrm{JCP}=4.4$, 
$935 \mathrm{CH} 3), 17.8(\mathrm{~d}, 2 \mathrm{JCP}=7.1, \mathrm{CH} 3) .31 \mathrm{P}\{1 \mathrm{H}\} \mathrm{NMR}(162 \mathrm{MHz}):+67.8$ (s). HRMS: calcd for

$936 \mathrm{C} 29 \mathrm{H} 27 \mathrm{ClO} 2 \mathrm{PRuS}([\mathrm{M}]-\mathrm{PF} 6), 607.0201$; found, 607.0205.

937

938 Ru-catalysed transfer hydrogenation

939 A $100 \mathrm{ml}$ Schlenk flask was charged with the ruthenium precursor $(0.02 \mathrm{mmol})$ and potassium tert940 butoxide $(11.2 \mathrm{mg}, 0.1 \mathrm{mmol})$ and purged with three vacuum/nitrogen cycles. Under a gentle flow of 941 nitrogen, $25 \mathrm{ml}$ of 2-propanol were added and the flask heated to reflux $\left(85^{\circ} \mathrm{C}\right)$ for 15 minutes. After 942 that time, acetophenone $(0.47 \mathrm{~mL}, 4.0 \mathrm{mmol})$ was rapidly added to start the catalytic run. The reaction 943 was monitored at the allotted times by taking aliquots of around $0.1 \mathrm{~mL}$ and analysing them by GC. 


\section{ACKNOWLEDGMENTS}

946

947 We thank the Ministerio de Economía y Competitividad (grant number CTQ2015-65040-P) for financial 948 support of this work.

949

950 


\section{REFERENCES}

952

9531 K. M. Pietrusiewicz and M. Zablocka, Chem. Rev., 1994, 94, 1375-1411.

9542 J. Meisenheimer and L. Lichtenstadt, Chem. Ber., 1911, 44, 356-359.

9553 A. Grabulosa, J. Granell and G. Muller, Coord. Chem. Rev., 2007, 251, 25-90.

9564 A. Grabulosa, P-Stereogenic Ligands in Enantioselective Catalysis, Royal Society of Chemistry, $957 \quad$ Cambridge, 2011.

9585 O. I. Kolodiazhnyi, Tetrahedron: Asymmetry, 2012, 23, 1-46.

9596 J. J. Gammon, V. H. Gessner, G. R. Barker, J. Granander, A. C. Withwood, C. Strohmann, P. 960 O’Brien and B. Kelly, J. Am. Chem. Soc., 2010, 132, 13922-13927.

9617 D. Gau, R. Rodriguez, T. Kato, N. Saffon-Merceron and A. Baceiredo, J. Am. Chem. Soc., 2010, $962 \quad 132,12841-12843$.

9638 X. Zhang, K. Huang, G. Hou, B. Cao and X. Zhang, Angew. Chem., Int. Ed., 2010, 49, 6421$964 \quad 6424$.

9659 J. S. Harvey and V. Gouverneur, Chem. Commun., 2010, 46, 7477-7485.

96610 M. Revés, C. Ferrer, T. León, S. Doran, P. Etayo, A. Vidal-Ferran, A. Riera and X. Verdaguer, 967 Angew. Chem., Int. Ed., 2010, 49, 9452-9455.

96811 D. Gatineau, L. Giordano and G. Buono, J. Am. Chem. Soc., 2011, 133, 10728-10731.

96912 W. Chen, F. Spindler, B. Pugin and U. Nettekoven, Angew. Chem., Int. Ed., 2013, 52, 8652$970 \quad 8656$.

97113 O. Berger and J.-L. Montchamp, Angew. Chem., Int. Ed., 2013, 52, 11377-11380.

97214 D. Gatineau, D. H. Nguyen, D. Hérault, N. Vanthuyne, J. Leclaire, L. Giordano and G. Buono, J. $973 \quad$ Org. Chem., 2015, 80, 4132-4141.

97415 Z. S. Han, L. Zhang, Y. Xu, J. D. Sieber, M. A. Marsini, Z. Li, J. T. Reeves, K. R. Fandrick, N. D. 975 Patel, J.-N. Desrosiers, B. Qu, A. Chen, D. M. Rudzinski, L. P. Samankumara, S. Ma, N.

976 Grinberg, F. Roschangar, N. K. Yee, G. Wang, J. J. Song and C. H. Senanayake, Angew. Chem., Int. Ed., 2015, 54, 5474-5477. 
16 A. D’Onofrio, L. Copey, L. Jean-Gerard, C. Goux-Henry, G. Pilet, B. Andrioletti and E. Framery, Org. Biomol. Chem., 2015, 13, 9029-9034.

98017 K. V. Rajendran, K. V. Nikitin and D. G. Gilheany, J. Am. Chem. Soc., 2015, 137, 9375-9381.

98118 J. M. Brunel, B. Faure and M. Maffei, Coord. Chem. Rev., 1998, 178-180, 665-698.

98219 M. Ohff, J. Holz, M. Quirmbach and A. Börner, Synthesis, 1998, 1391-1415.

98320 A. Staubitz, A. P. M. Robertson, M. E. Sloan and I. Manners, Chem. Rev., 2010, 110, 4023-4078.

98421 S. Jugé, M. Stephan, J. A. Laffitte and J. P. Genêt, Tetrahedron Lett., 1990, 31, 6357-6360.

98522 J. Bayardon and S. Jugé, in Phosphorus(III) Ligands in Homogeneous Catalysis. Design and 986

987 synthesis, ed. P. C. J. Kamer and P. W. N. M. van Leeuwen, Wiley, Chichester, 2012, pp. 355 390.

A. R. Muci, K. R. Campos and D. A. Evans, J. Am. Chem. Soc., 1995, 117, 9075-9076.

989

T. Imamoto, J. Watanabe, Y. Wada, H. Masuda, H. Yamada, H. Tsuruta, S. Matsukawa and K.

990 Yamaguchi, J. Am. Chem. Soc., 1998, 120, 1635-1636.

99125 Y. Yamanoi and T. Imamoto, J. Org. Chem., 1999, 64, 2988-2989.

J. Albert, J. M. Cadena, J. R. Granell, G. Muller, J. I. Ordinas, D. Panyella, C. Puerta, C. Sañudo 993 and P. Valerga, Organometallics, 1999, 18, 3511-3518.

J. Albert, R. Bosque, J. Magali Cadena, J. R. Granell, G. Muller and J. I. Ordinas, Tetrahedron:

995

996 Asymmetry, 2000, 11, 3335-3343.

28 J. Albert, R. Bosque, J. Magali Cadena, S. Delgado, J. R. Granell, G. Muller, J. I. Ordinas, M. Font Bardia and X. Solans, Chem. - Eur. J., 2002, 8, 2279-2287.

A. Grabulosa, G. Muller, J. I. Ordinas, A. Mezzetti, M. A. Maestro, M. Font-Bardia and X. Solans, Organometallics, 2005, 24, 4961-4973. 2006, 25, 1368-1376.

100231 A. Grabulosa, G. Muller, R. Ceder and M. A. Maestro, Eur. J. Inorg. Chem., 2010, 3372-3383.

100332 A. Grabulosa, A. Mannu, G. Muller, T. Calvet and M. Font-Bardia, J. Organomet. Chem., 2011, $696,2338-2345$. 
100533 A. Grabulosa, A. Mannu, A. Mezzetti and G. Muller, J. Organomet. Chem., 2012, 696, 4221$1006 \quad 4228$.

100734 P. Clavero, A. Grabulosa, M. Font-Bardia and G. Muller, J. Mol. Catal. A: Chem., 2014, 391, $1008 \quad 183-190$.

100935 M. Navarro, D. Vidal, P. Clavero, A. Grabulosa and G. Muller, Organometallics, 2015, 34, 9731010994.

101136 R. Aznar, G. Muller, D. Sainz, M. Font-Bardia and X. Solans, Organometallics, 2008, 27, 1967$1012 \quad 1969$

101337 R. Aznar, A. Grabulosa, A. Mannu, G. Muller, D. Sainz, V. Moreno, M. Font-Bardia, T. Calvet 1014 and J. Lorenzo, Organometallics, 2013, 32, 2344-2362.

101538 H. Sun, J. S. Ritch and P. G. Hayes, Inorg. Chem., 2011, 50, 8063-8072.

101639 M. W. Haenel, D. Jakubik, E. Rothenberger and G. Schroth, Chem. Ber., 1991, 124, 1705-1710.

101740 C. Han, G. Xie, J. Li, Z. Zhang, H. Xu, Z. Deng, Y. Zhao, P. Yan and S. Liu, Chem. - Eur. J., $1018 \quad 2011,17,8947-8956$.

101941 C. Han, Z. Zhang, H. Xu, J. Li, G. Xie, R. Chen, Y. Zhao and W. Huang, Angew. Chem., Int. Ed., $1020 \quad 2012,51,10104-10108$.

102142 C. Han, Z. Zhang, H. Xu, J. Li, Y. Zhao, P. Yan and S. Liu, Chem. - Eur. J., 2013, 19, 1385$1022 \quad 1396$

102343 S. H. Jeong and J. Y. Lee, Synth. Met., 2013, 172, 1-4.

102444 H. Tye, D. Smyth, C. Eldred and M. Wills, Chem. Commun., 1997, 1053-1054.

102545 D. Smyth, H. Tye, C. Eldred, N. W. Alcock and M. Wills, J. Chem. Soc., Perkin Trans. 1, 2001, $1026 \quad 2840-2849$

$102746 \quad$ S. M. Bucknor, M. Draganjac, T. B. Rauchfuss, C. J. Ruffing, W. C. Fultz and A. L. Rheingold, J. 1028 Am. Chem. Soc., 1984, 106, 5379-5381.

102947 P. D. Robinson, L. V. Dunkerton, A. Pandey and C. C. Hinckley, Acta Crystallogr., Sect. C: $1030 \quad$ Cryst. Struct. Commun., 1989, 45, 587-591.

103148 M. Toffano, C. Dobrota and J.-C. Fiaud, Eur. J. Org. Chem., 2006, 650-656. 
L. V. Dunkerton, A. Pandey and P. D. Robinson, Acta Crystallogr. Sect. C: Cryst. Struct. $67,5239-5249$.

J. M. Brown and J. C. P. Laing, J. Organomet. Chem., 1997, 529, 435-444.

R. M. Stoop, A. Mezzetti and F. Spindler, Organometallics, 1998, 17, 668-675.

H. Tsuruta and T. Imamoto, Tetrahedron: Asymmetry, 1999, 10, 877-882.

N. Oohara, K. Katagiri and T. Imamoto, Tetrahedron: Asymmetry, 2003, 14, 2171-2175.

B. L. May, H. Yee and D. G. Lee, Can. J. Chem., 1994, 72, 2249-2254. and R. M. Toscano, J. Org. Chem., 1995, 60, 4475-4480.

M. Nag and W. S. Jenks, J. Org. Chem., 2004, 69, 8177-8182.

S. Ogawa, H. Muraoka and R. Sato, Tetrahedron Lett., 2006, 47, 2479-2483.

A. Rostami and J. Akradi, Tetrahedron Lett., 2010, 51, 3501-3503.

S. Palazzo, L. H. Giannola and S. Caronna, J. Heterocycl. Chem., 1974, 11, 839-841.

A. McKillop and D. Kemp, Tetrahedron, 1989, 45, 3299-3306.

L. Xu, J. Cheng and M. L. Trudell, J. Org. Chem., 2003, 68, 5388-5391. $4499-4506$.

K. Lee, K. Morino, A. Sudo and T. Endo, Polym. Bull., 2011, 67, 227-236.

Z. Duan, X. Huang, S. Fujii, H. Kataura and Y. Nishioka, Chem. Lett., 2012, 41, 363-365.

M. Jereb, Green Chem., 2012, 14, 3047-3052. L. H. Delmau, Inorg. Chem., 2014, 53, 5698-5711.

105769 M. Stankevič and K. M. Pietrusiewicz, Tetrahedron Lett., 2009, 50, 7093-7095.

$105870 \quad$ X. Wu, P. O’Brien, S. Ellwood, F. Secci and B. Kelly, Org. Lett., 2013, 15, 192-195.

105971 M. Stankevič, J. Pisklak and K. Włodarczyk, Tetrahedron, 2016, 72, 810-824. 
106072 J. Wolf, K. Thommes, O. Briel, R. Scopelliti and K. Severin, Organometallics, 2008, 27, 446410614474

106273 J. Baraut, A. Massard, F. Chotard, E. Bodio, M. Picquet, P. Richard, Y. Borguet, F. Nicks, A. 1063 Demonceau and P. Le Gendre, Eur. J. Inorg. Chem., 2015, 2671-2682.

106474 V. Cadierno, P. Crochet, J. García-Álvarez, S. E. García-Garrido and J. Gimeno, J. Organomet. 1065 Chem., 2002, 663, 32-39.

106675 A. Caballero, F. A. Jalón, B. R. Manzano, G. Espino, M. Pérez-Manrique, A. Mucientes, F. J. 1067 Poblete and M. Maestro, Organometallics, 2004, 23, 5694-5706.

106876 A. E. Diaz-Alvarez, P. Crochet, M. Zablocka, V. Cadierno, C. Duhayon, J. Gimeno and J. P. 1069 Majoral, New J. Chem., 2006, 30, 1295-1306.

107077 P. E. Garrou, Chem. Rev., 1981, 81, 229-266.

107178 J. S. M. Samec, J. E. Bäckvall, P. G. Andersson and P. Brandt, Chem. Soc. Rev., 2006, 35, $237-$ $1072 \quad 248$

107379 D. Wang and D. Astruc, Chem. Rev., 2015, 115, 6621-6686.

107480 G. Zassinovich, G. Mestroni and S. Gladiali, Chem. Rev., 1992, 92, 1051-1089.

107581 S. E. Clapham, A. Hadzovic and R. H. Morris, Coord. Chem. Rev., 2004, 248, 2201-2237.

107682 S. Gladiali and E. Alberico, Chem. Soc. Rev., 2006, 35, 226-236.

107783 L. Wang, Q. Yang, H.-Y. Fu, H. Chen, M.-L. Yuan and R.-X. Li, Appl. Organomet. Chem., 2011, $1078 \quad 25,626-631$.

107984 M. Aydemir, A. Baysal and Y. Turgut, Appl. Organomet. Chem., 2011, 25, 270-275.

108085 Y.-Y. Kuo, M. Haddow, A. Jamieson and G. Owen, Transition Met. Chem., 2013, 38, 641-648.

108186 C. Kayan, N. Meriç, M. Aydemir, Y. S. Ocak, A. Baysal and H. Temel, Appl. Organomet. Chem., $1082 \quad 2014,28,127-133$.

108387 A. Grabulosa, A. Mannu, E. Alberico, S. Denurra, S. Gladiali and G. Muller, J. Mol. Catal. A: $1084 \quad$ Chem., 2012, 363-364, 49-57.

108588 W. L. F. Armarego and C. L. L. Chai, Purification of Laboratory Chemicals, Butterworth $1086 \quad$ Heinemann, Oxford, 7th edn, 2013.

108789 P. Pinto, G. Marconi, F. W. Heinemann and U. Zenneck, Organometallics, 2004, 23, 374-380. 


\section{Legends to figures}

1089 Scheme 1 Described preparation of rac-P(4-dibenzofuranyl)MePh.

1090

1091

Scheme 2 Heterocyclic P-stereogenic phosphines described in this paper.

1092

1093

Scheme 3 Lithiation of the heterocycles.

1094

1095

Scheme 4 Preparation of the heterocyclic P-stereogenic phosphine-boranes by the Jugé-Stephan

method.

1099

Fig. 1 ORTEP representation (thermal ellipsoids are drawn at the 50\% probability level, $\mathrm{H}$ atoms are removed for clarity) of 4-DBF-Fc (left) and 4-DBT-Fc (right). Distances $(\AA)$ and angles $\left(^{\circ}\right)$ for 4-DBFFc: $\mathrm{P}(1)-\mathrm{B}(1), 1.913(4) ; \mathrm{P}(1)-\mathrm{C}(4), 1.779(3) ; \mathrm{P}(1)-\mathrm{C}(17), 1.816(3) ; \mathrm{P}(1)-\mathrm{C}(5), 1.812(3) ; \mathrm{O}(1)-\mathrm{C}(15)$, 1.388(4); $\mathrm{O}(1)-\mathrm{C}(16), 1.392(3) ; \mathrm{B}(1)-\mathrm{P}(1)-\mathrm{C}(4), 114.32(16) ; \mathrm{B}(1)-\mathrm{P}(1)-\mathrm{C}(17), 110.02(16) ; \mathrm{B}(1)-\mathrm{P}(1)-$ 91.6(2).

Scheme 5 Unsuccessful synthesis of 4-DBTO2-Me.

Scheme 6 Preparation of 3-DBTO2.

Scheme 7 Free phosphinites and phosphines L1-13.

Scheme 8 Preparation of neutral ruthenium complexes.

Scheme 9 Two possible isomers of the Ru complexes observed by $13 \mathrm{C}\{1 \mathrm{H}\}$ NMR spectroscopy.

Fig. 2 ORTEP representations (thermal ellipsoids are drawn at the 50\% probability level, $\mathrm{H}$ atoms are are given in Table 1.

Scheme 10 Preparation of cationic ruthenium complexes.

Scheme 11 Ru-catalysed enantioselective transfer hydrogenation of acetophenone. 


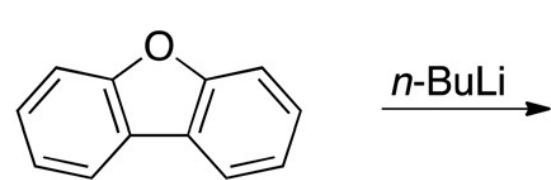

Dibenzofuran DBF

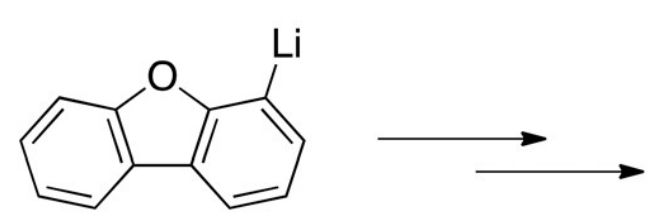

DBFLi

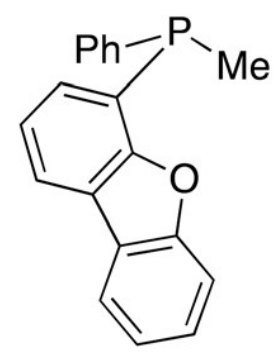

rac-DBF-Me

1127

1128 
SCHEME 2

1130

1131

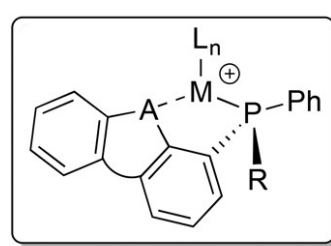

New monodentate $(P)$ or

bidentate $(P, A)$ ligands<smiles>[R]Pc1cccc2c1[nH]c1ccccc12</smiles><smiles>c1ccc2c(c1)oc1ccccc12</smiles>

Dibenzofuran DBF
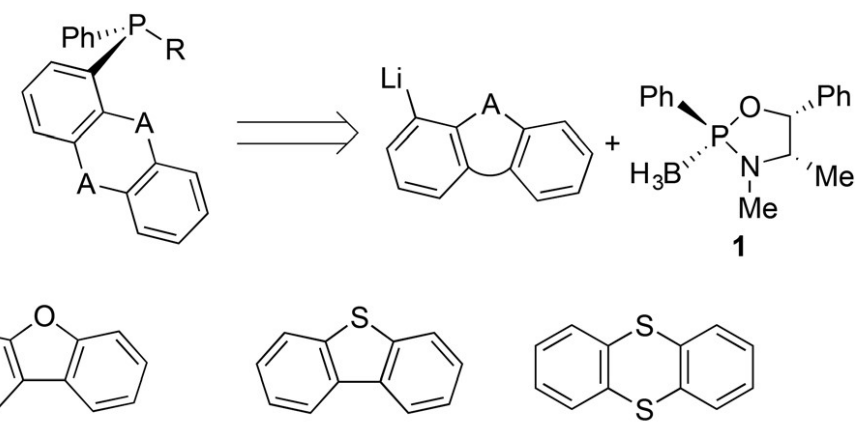

Dibenzothiophene DBT<smiles>c1ccc2c(c1)Sc1ccccc1S2</smiles>

Thianthrene 


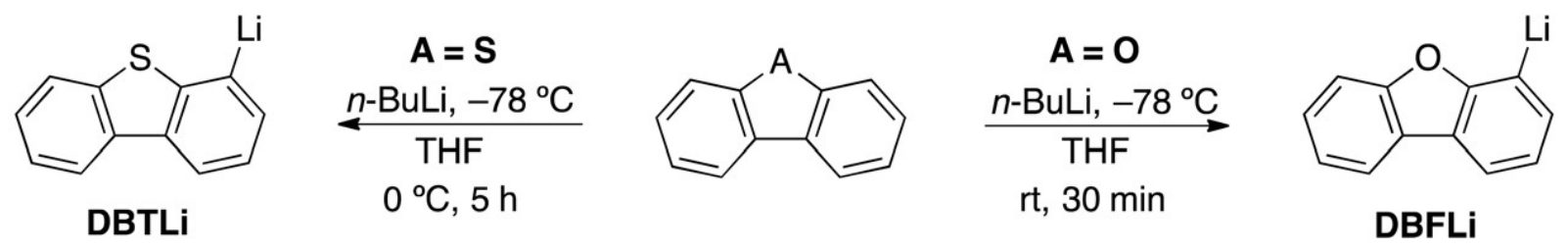<smiles>c1ccc2c(c1)Sc1ccccc1S2</smiles>

TA
SCHEME 3

1140
$\underset{\mathrm{THF}}{\stackrel{n \text {-BuLi, }-78^{\circ} \mathrm{C}}{\longrightarrow}}$

Reflux, $1 \mathrm{~h}$<smiles>Clc1cccc2c1Sc1ccccc1S2</smiles>

TALi 
SCHEME 4 
1148

1149

1150

1151

1152
FIGURE 1

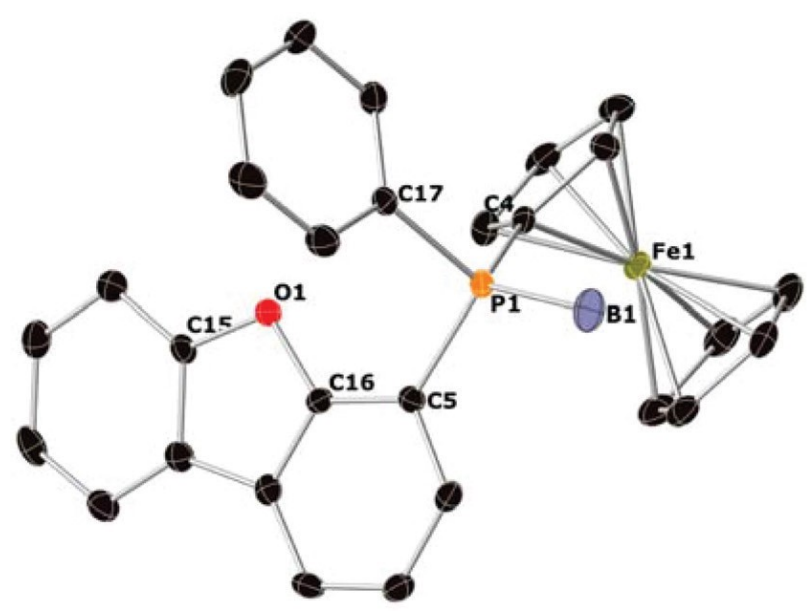


<smiles>CC(C)(O)[C@H]1CCCCC1(O)c1cccc2c1S(=O)(=O)c1ccccc1-2</smiles>
SCHEME 5

1156 4-DBTO $-\mathrm{Me}$<smiles>[B][PH](C)(c1ccccc1)c1cccc2c1sc1ccccc12</smiles>

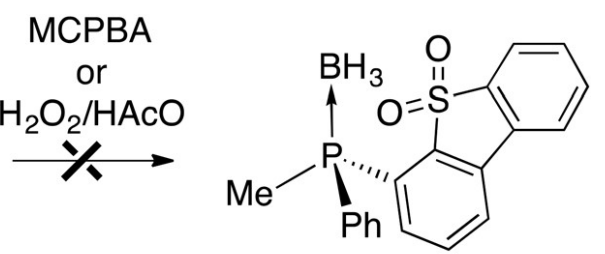
4-DBT-Me 4-DBTO 2 -Me 
<smiles>O=C(O)c1ccc2c(c1)sc1ccccc12</smiles>
DBT

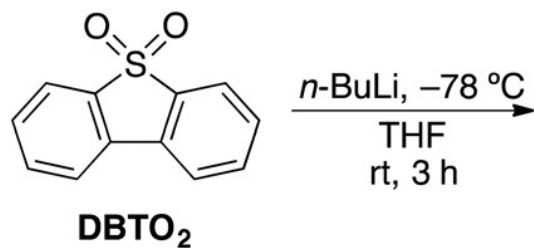

$\mathrm{DBTO}_{2}$

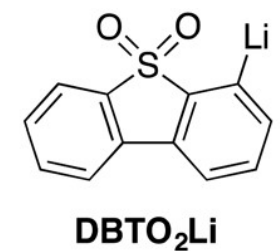

$\mathrm{DBTO}_{2} \mathrm{Li}$

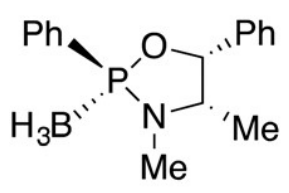

1161
$\underset{\mathrm{THF}}{\stackrel{\mathrm{DBTO}_{2} \mathrm{Li},-78^{\circ} \mathrm{C}}{\longrightarrow}}$

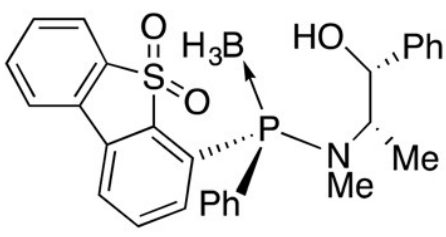

2-DBTO 2<smiles>[B][P@@](OC)(c1ccccc1)c1cccc2c1S(=O)(=O)c1ccccc1-2</smiles>

3-DBTO 


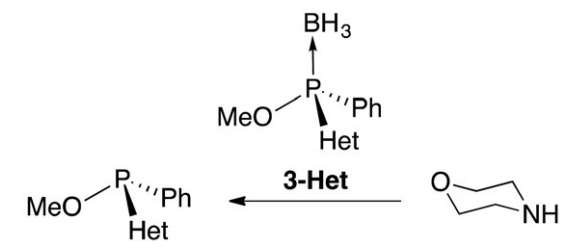

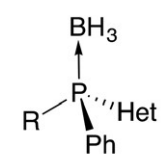

5-Het-OMe (L1-4)

$\stackrel{\text { 4-Het-R }}{\longrightarrow} \mathrm{R}^{-} \mathrm{P}_{\mathrm{Ph}}^{\mathrm{P}}{ }^{\prime \prime H e t}$
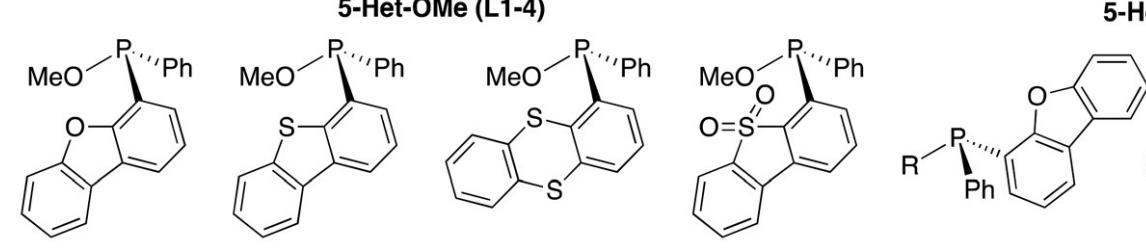

5-Het-R (L5-13)

5-DBF-OMe (L1) 5-DBT-OMe (L2)

5-TA-OMe (L3) 5-DBTO ${ }_{2}$-OMe (L4)

5-DBF-R

$\mathrm{R}=\mathrm{Me}(\mathrm{L}$ )

$\mathrm{R}=i-\operatorname{Pr}(\mathbf{L 6})$

$\mathrm{R}=t-\mathrm{Bu}(\mathbf{L 7})$

$\mathrm{R}=\mathrm{FC}(\mathbf{L} \mathbf{8})$

1166

$\mathrm{R}=\mathrm{DBT}(\mathbf{L} \mathbf{9})$ 
SCHEME 8
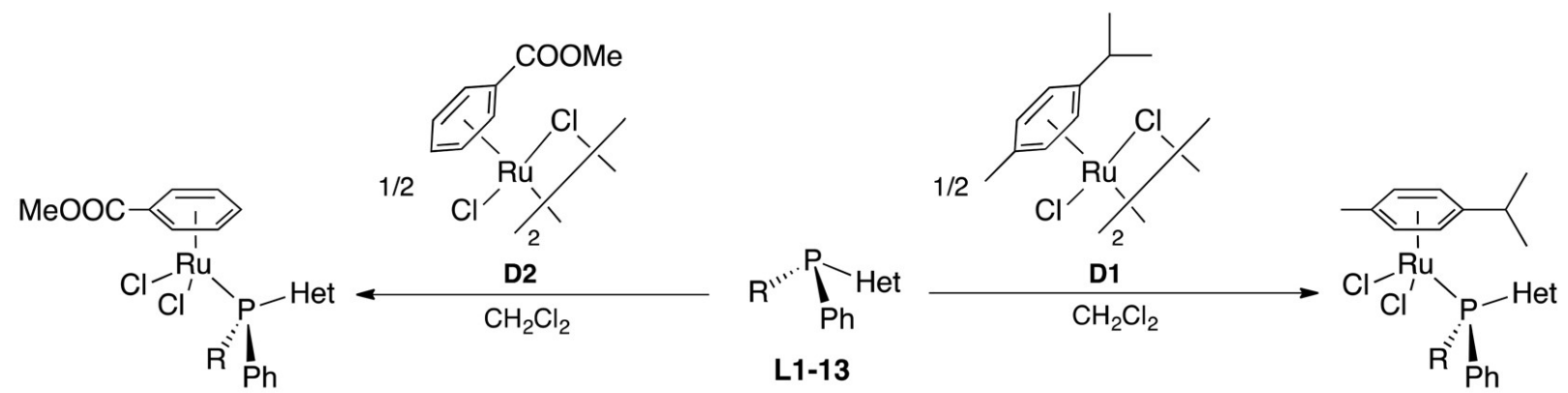

1171

Ru6*, Ru9*, Ru11*, Ru13*

Ru1-6, Ru8-13 

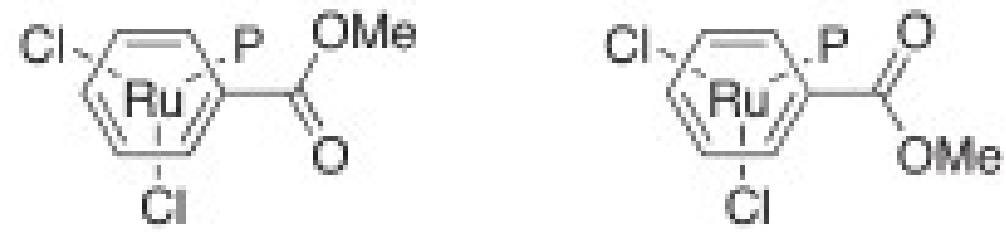

1177 
1178

1179

1180

1181

1182

1183
FIGURE 2

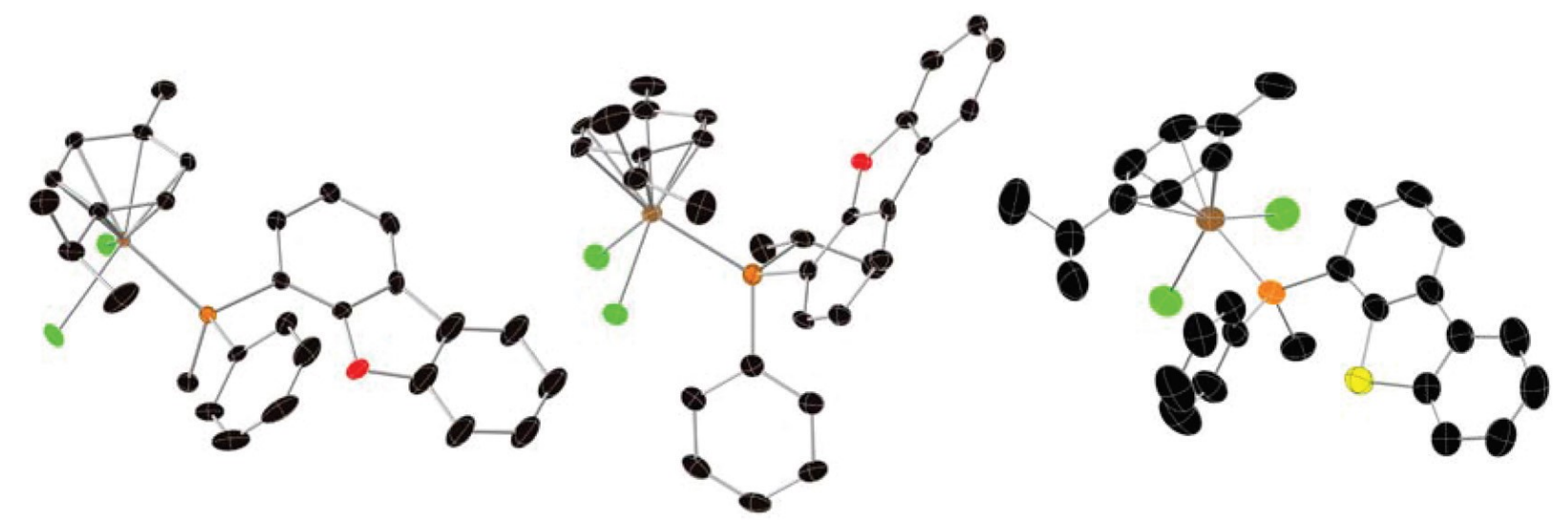




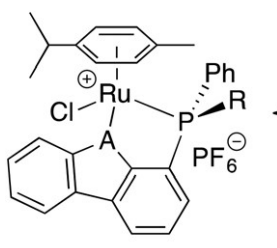

Ru1', 4'-8'

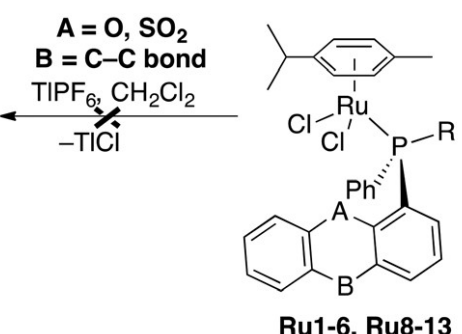

Ru1-6, Ru8-13

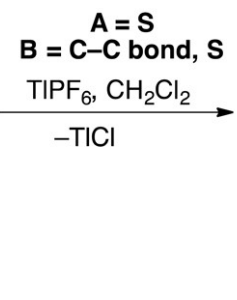

$\mathbf{B}=\mathrm{C}-\mathrm{C}$ bond, $\mathrm{S}$
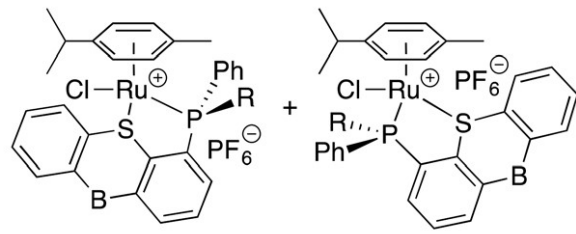

Ru2', Ru3', Ru9'-13' 


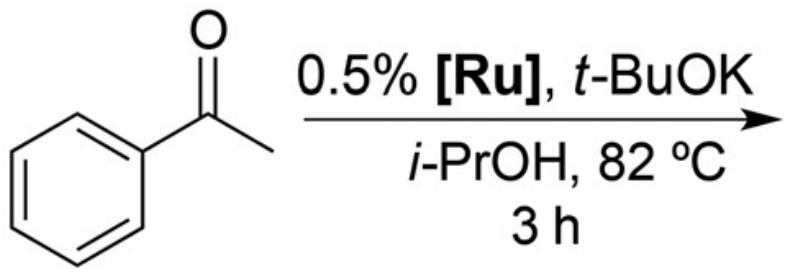

1192 acetophenone<smiles>CC(O)c1ccccc1</smiles>

1-phenylethanol

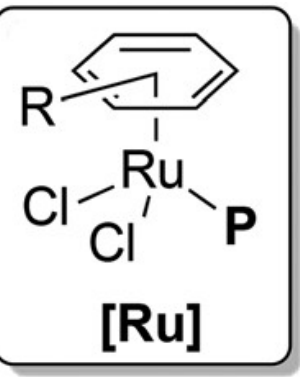


1194 Table 1 Selected distances $(\AA)$ and angles $\left(^{\circ}\right)$ for complexes Ru5, Ru6 and Ru10 1195

\begin{tabular}{|c|c|c|c|}
\hline Parameter & Rus $5^{a}$ & Rut & Ru10 \\
\hline $\mathrm{Ru}-\mathrm{Cl}$ & $\begin{array}{c}2.4093(10), \\
2.4188(11) \\
2.4146(10) \\
2.4204(10)\end{array}$ & $\begin{array}{l}2.4065(12) \\
2.4069(13)\end{array}$ & $\begin{array}{l}2.3983(11) \\
2.4242(11)\end{array}$ \\
\hline $\mathrm{Ru}-\mathrm{P}$ & $\begin{array}{l}2.3362(11) \\
2.3378(11)\end{array}$ & $2.3737(13)$ & $2.3432(11)$ \\
\hline${ }^{\mathrm{B}} \mathrm{Ru}-\mathrm{C}_{\mathrm{nn}}$ & & 2.210 & 2.220 \\
\hline $\mathrm{P}-\mathrm{C}_{\mathrm{P}}$ & $\begin{array}{l}1.807(5) \\
1.824(4)\end{array}$ & $1.833(5)$ & $1.818(4)$ \\
\hline $\mathrm{P}-\mathrm{C}_{\text {Has }}$ & $\begin{array}{l}1.822(4) \\
1.815(4)\end{array}$ & $1.825(5)$ & $1.836(4)$ \\
\hline $\mathrm{P}-\mathrm{C}_{\mathrm{R}}$ & $\begin{array}{l}1.82 \alpha^{\prime}(5) \\
1.82 \alpha^{\prime}(5)\end{array}$ & $1.865(5)$ & $1.816(4)$ \\
\hline $\mathrm{P}-\mathrm{Ru}-\mathrm{Cl}$ & $\begin{array}{l}84.32(4), 85.63(4) \\
86.65(4), 83.44(4)\end{array}$ & $91.17(5), 86.33(5)$ & $85.08(4), 83.86(4)$ \\
\hline $\mathrm{Cl}-\mathrm{Ru}-\mathrm{Cl}$ & $\begin{array}{l}88.53(4) \\
88.27(4)\end{array}$ & $87.69(5)$ & $88.14(4)$ \\
\hline
\end{tabular}

aThere are two crystallographically distinct molecules in the unit cell. "Averaged value of the six $\eta^{6}-\mathrm{Ph} \mathrm{Ru}-\mathrm{C}$ distances. 
1200 Table 2 Results of the transfer hydrogenation of acetophenone catalysed by Ru complexes

\begin{tabular}{|c|c|c|c|c|}
\hline En $\operatorname{tr} y^{\mu}$ & Frecursar & Time/h & Conmersion/ts & $\mathrm{ex} / \mathrm{s}$ \\
\hline 1 & Bul & $1 / 3 / 5$ & $31 / 79 / 24$ & -5 \\
\hline 2 & Bunz & $1 / 3 / 5$ & $28,69 / 45$ & -5 \\
\hline 3 & Fuz" & $1 / 3 / 5$ & $40 / 73 / k$ & -5 \\
\hline 4 & Bus & $1 / 3 / 5$ & $11 / 28 / 39$ & -5 \\
\hline 5 & Bus" & $1 / 3 / 5$ & $8 / 21 / 29$ & -5 \\
\hline 5 & Rut & $1 / 3 / 5$ & $15 / 32 / 46$ & $14(h)$ \\
\hline 7 & Bus & $1 / 3 / 5$ & $92 / 99 / 24 \pi$ & -5 \\
\hline 4 & Ruh & $1 / 3 / 5$ & 3574.4 & -5 \\
\hline 9 & $\mathrm{Buh}{ }^{*}$ & $1 / 3 / 5$ & BOAG/4y & $<5$ \\
\hline 10 & Bus & $1 / 3 / 5$ & 25,4B/A3 & $4(s)$ \\
\hline 11 & Buy & $1 / 3 / 5$ & $32 / 75 / 92$ & $1 \geq[R]$ \\
\hline 12 & Bus" & $1 / 3 / 5$ & $54 / 1 / 4 h$ & $\nabla(\boldsymbol{k})$ \\
\hline 13 & Bug' & $1 / 3 / 5$ & $10 / 29 / 3$ & $<5$ \\
\hline 14 & Bu10 & $1 / 3 / 5$ & $16,32 / 41$ & 45 \\
\hline 15 & Bu11 & $1 / 3 / 5$ & $19 / 49 / 75$ & $54(h)$ \\
\hline 14 & Kun11* & $1 / 3 / 5$ & $52 / 95 / 44$ & $\pi(h)$ \\
\hline 17 & Bu11' & $1 / 3 / 5$ & $4 / 9 / 17$ & $14(h)$ \\
\hline 14 & Bu1 1" & $1 / 3 / 5$ & $19 / 4 \mathrm{~B} / \mathrm{L}$ & $\pi(\boldsymbol{k})$ \\
\hline 19 & Ku12 & $1 / 3 / 5$ & $21 / 5 \mathrm{~B} / \mathrm{B}$ & $34(s)$ \\
\hline 20 & $\operatorname{Bun} 1 z^{\prime}$ & $1 / 3 / 5$ & $9 / 24 / 34$ & $14(s)$ \\
\hline 21 & Bu13 & $1 / 3 / 5$ & $64,94 / 59$ & -5 \\
\hline 22 & hul $13^{*}$ & $1 / 3 / 5$ & $50 / 83 / 95$ & -5 \\
\hline 23 & Bu13' & $1 / 3 / 5$ & $34 / 55 / 71$ & $<5$ \\
\hline
\end{tabular}

“Catalytic conditions Bu comples (0.02 mund) and $t$ EuOK (0.1 mund) diswoked in $25 \mathrm{~mL}$ of $\mathrm{i}-\mathrm{PrOH}$ and activated at $45 \mathrm{QC}$ for 15 minutes before adding scetophenone (4.0 mmol $\downarrow$ " Oonversion of acetophenone. "Enantiomeric erses at $24 \mathrm{~h}$. 